Prepared in cooperation with the City of Charlotte and Mecklenburg County

\title{
Frequency of Annual Maximum Precipitation in the City of Charlotte and Mecklenburg County, North Carolina, through 2004
}

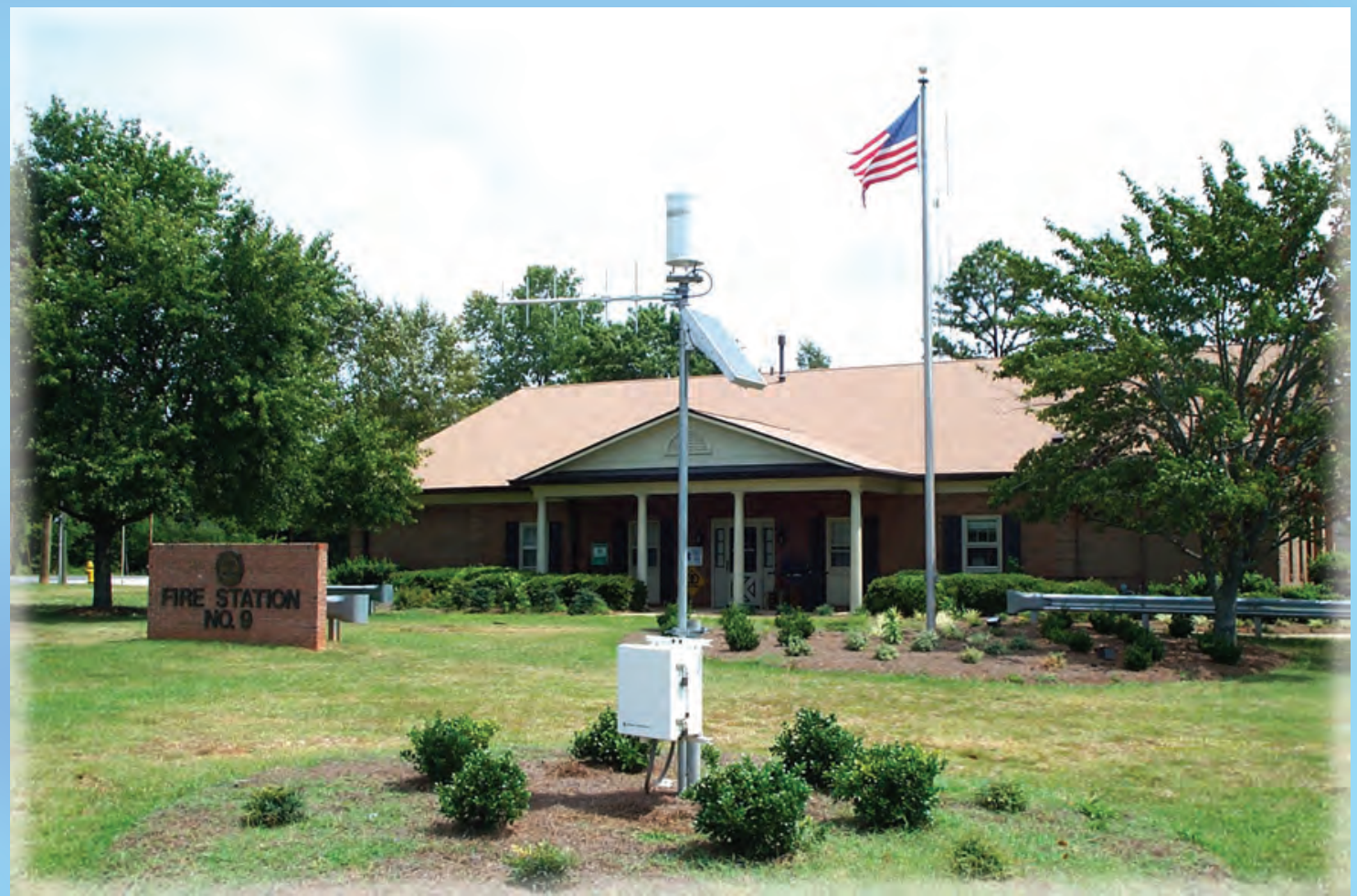

Scientific Investigations Report 2006-5017 
Cover. Precipitation data-collection site CRN07 at Fire Station 9, McKee Road, Charlotte, North Carolina. (photograph from U.S. Geological Survey files) 


\section{Frequency of Annual Maximum Precipitation in the City of Charlotte and Mecklenburg County, North Carolina, through 2004}

By J. Curtis Weaver

Prepared in cooperation with the City of Charlotte amd Mecklenburg County

Scientific Investigations Report 2006-5017 


\title{
U.S. Department of the Interior \\ P. Lynn Scarlett, Acting Secretary
}

\section{U.S. Geological Survey \\ P. Patrick Leahy, Acting Director}

\section{U.S. Geological Survey, Reston, Virginia: 2006}

For product and ordering information:

World Wide Web: http://www.usgs.gov/pubprod

Telephone: 1-888-ASK-USGS

For more information on the USGS - the Federal source for science about the Earth, its natural and living resources, natural hazards, and the environment:

World Wide Web: http://www.usgs.gov

Telephone: 1-888-ASK-USGS

\author{
Any use of trade, product, or firm names in this publication is for descriptive purposes only and does not imply \\ endorsement by the U.S. Government. \\ Although this report is in the public domain, permission must be secured from the individual copyright owners to \\ reproduce any copyrighted materials contained within this report. \\ Suggested citation: \\ Weaver, J.C., 2006, Frequency of annual maximum precipitation in the city of Charlotte and Mecklenburg County, \\ North Carolina, through 2004: U.S. Geological Survey Scientific Investigations Report 2006-5017, 53 p.
}




\section{Contents}

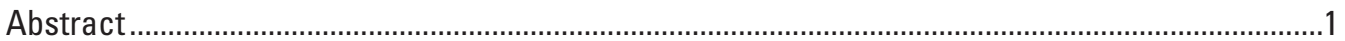

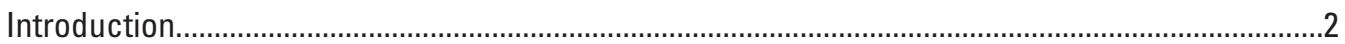

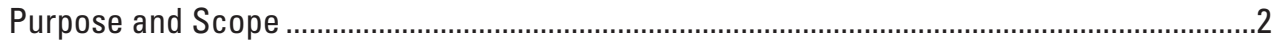

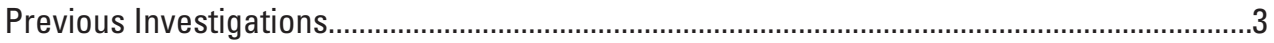

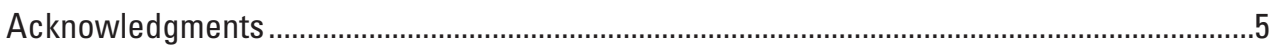

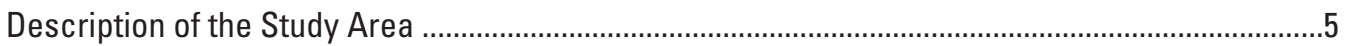

Setting and Climate ........................................................................................................

U.S. Geological Survey Precipitation Data-Collection Sites .......................................................

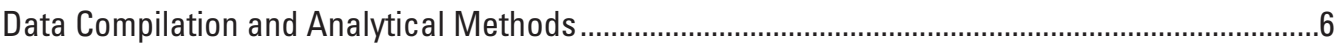

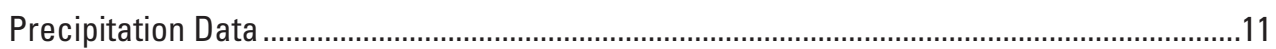

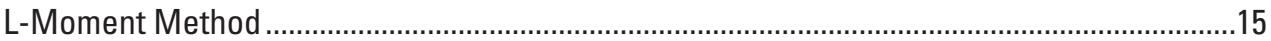

Frequency of Annual Maximum Precipitation in the City of Charlotte and Mecklenburg County................................................................................................17

L-Moment Ratio Diagrams and Goodness-of-Fit Measures...................................................17

Depth-Duration and Intensity-Duration Frequency Curves ...................................................22

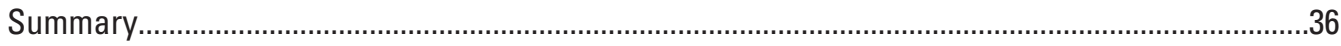

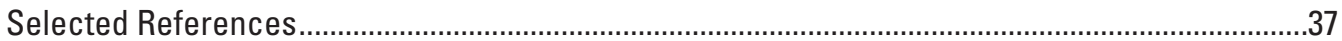

\section{Figures}

1-2. Maps showing:

1. Location of Mecklenburg County in the Catawba River and Rocky River basins in North and South Carolina..........................................................................

2. Locations of major streams and U.S. Geological Survey precipitation network sites in Charlotte and Mecklenburg County, North Carolina, October 1988 through September 2004

3. Graphs showing time series of annual maximum of 24-hour (1,440-minute) precipitation totals at selected U.S. Geological Survey precipitation sites in or near Mecklenburg County, North Carolina.

4. Map showing selected National Weather Service precipitation stations in North and South Carolina in the vicinity of Mecklenburg County,

North Carolina

5-13. Graphs showing:

5. Time series of annual maximum of 24-hour (1,440-minute) precipitation totals at selected National Weather Service precipitation stations in or near Mecklenburg County, North Carolina

6. L-moment ratios for selected durations for the CRN initial dataset analysis of precipitation data for Charlotte and Mecklenburg County, North Carolina

7. Precipitation (A) depth-duration and (B) intensity-duration frequency curves for the 2-year recurrence interval for Charlotte and Mecklenburg County, North Carolina

8. Precipitation (A) depth-duration and (B) intensity-duration frequency curves for the 5-year recurrence interval for Charlotte and Mecklenburg County, North Carolina 
9. Precipitation $(A)$ depth-duration and $(B)$ intensity-duration frequency curves for the 10-year recurrence interval for Charlotte and Mecklenburg County, North Carolina

10. Precipitation (A) depth-duration and (B) intensity-duration frequency curves for the 25-year recurrence interval for Charlotte and Mecklenburg County, North Carolina

11. Precipitation (A) depth-duration and (B) intensity-duration frequency curves for the 50-year recurrence interval for Charlotte and Mecklenburg County, North Carolina

12. Precipitation (A) depth-duration and (B) intensity-duration frequency curves for the 100-year recurrence interval for Charlotte and Mecklenburg County, North Carolina

13. Precipitation $(A)$ depth-duration and $(B)$ intensity-duration frequency curves for the 500-year recurrence interval for Charlotte and Mecklenburg County, North Carolina

14. Box plots showing annual maximum (A) 1-hour (60-minute) and (B) 24-hour

(1,440-minute) precipitation distributions at selected U.S. Geological

Survey and National Weather Service precipitation stations in or near Mecklenburg County, North Carolina.

\section{Tables}

1. U.S. Geological Survey precipitation network sites in Mecklenburg County, North Carolina, October 1988 through September 2004

2. Annual maximum precipitation totals through December 2004 for selected durations at selected U.S. Geological Survey precipitation sites in Mecklenburg County, North Carolina

3. Selected National Weather Service precipitation network stations in North and South Carolina in the vicinity of Mecklenburg County, North Carolina

4. Summary of goodness-of-fit and heterogeneity measures for precipitationfrequency analyses in Charlotte and Mecklenburg County, North Carolina

5. Summary of precipitation depth-duration and intensity-duration frequency in Charlotte and Mecklenburg County, North Carolina ..

6. Annual maximum 1- and 24-hour precipitation totals for selected U.S. Geological Survey and National Weather Service precipitation sites in or near Mecklenburg County, North Carolina. 


\section{Conversion Factors, Temperature, Datums, and Acronyms}

\begin{tabular}{lcl}
\hline \multicolumn{1}{c}{ Multiply } & By & \multicolumn{1}{c}{ To obtain } \\
\hline & Length & \\
inch (in.) & 25.4 & millimeter $(\mathrm{mm})$ \\
foot $(\mathrm{ft})$ & 0.3048 & meter $(\mathrm{m})$ \\
mile (mi) & 1.609 & kilometer $(\mathrm{km})$ \\
& Area & \\
square mile $\left(\mathrm{mi}^{2}\right)$ & 2.590 & square kilometer $\left(\mathrm{km}^{2}\right)$ \\
& Flow & \\
cubic foot per second $\left(\mathrm{ft}^{3} / \mathrm{s}\right)$ & 0.02832 & cubic meter per second $\left(\mathrm{m}^{3} / \mathrm{s}\right)$ \\
cubic foot per second per square & 0.01093 & cubic meter per second per square \\
mile $\left[\left(\mathrm{ft}^{3} / \mathrm{s}\right) / \mathrm{mi}^{2}\right]$ & & kilometer $\left[\left(\mathrm{m}^{3} / \mathrm{s}\right) / \mathrm{km}^{2}\right]$ \\
& Volume per time & \\
inch per year $(\mathrm{in} / \mathrm{yr})$ & 2.54 & centimeter per year $(\mathrm{cm} / \mathrm{yr})$ \\
\hline
\end{tabular}

Temperature: In this report, temperature is given in degrees Fahrenheit $\left({ }^{\circ} \mathrm{F}\right)$, which can be converted to degrees Celsius $\left({ }^{\circ} \mathrm{C}\right)$ by using the following equation:

$$
{ }^{\circ} \mathrm{C}=5 / 9 \times\left({ }^{\circ} \mathrm{F}-32\right)
$$

Vertical coordinates: Vertical coordinates in this report are referenced to the North American Vertical Datum of 1988 (NAVD 88).

Horizontal coordinates: Unless otherwise specified, horizontal (latitude and longitude) coordinates in this report are referenced to the North American Datum of 1983 (NAD 83).

\section{Acronyms:}

$\begin{array}{ll}\text { CRN } & \text { Charlotte Raingage Network } \\ \text { DDF } & \text { depth-duration frequency } \\ \text { GEV } & \text { generalized extreme value } \\ \text { GIS } & \text { geographic information system } \\ \text { GLO } & \text { generalized logistic } \\ \text { GN } & \text { generalized normal } \\ \text { GP } & \text { generalized Pareto } \\ \text { NAD 27 } & \text { North American Datum of 1927 } \\ \text { NCDC } & \text { National Climatic Data Center } \\ \text { NOAA } & \text { National Oceanic and Atmospheric Administration } \\ \text { NWS } & \text { National Weather Service } \\ \text { PE3 } & \text { Pearson Type III } \\ \text { PWM } & \text { probability-weighted moment } \\ \text { USGS } & \text { U.S. Geological Survey }\end{array}$





\title{
Frequency of Annual Maximum Precipitation in the City of Charlotte and Mecklenburg County, North Carolina, through 2004
}

\author{
By J. Curtis Weaver
}

\section{Abstract}

A study of annual maximum precipitation frequency in Mecklenburg County, North Carolina, was conducted to characterize the frequency of precipitation at sites having at least 10 years of precipitation record. Precipitation-frequency studies provide information about the occurrence of precipitation amounts for given durations (for example, 1 hour or 24 hours) that can be expected to occur within a specified recurrence interval (expressed in years). In this study, annual maximum precipitation totals were determined for durations of 15 and 30 minutes; 1, 2, 3, 6, 12, and 24 hours; and for recurrence intervals of $2,5,10,25,50,100$, and 500 years.

Precipitation data collected by the U.S. Geological Survey network of raingages in the city of Charlotte and Mecklenburg County were analyzed for this study. In September 2004, more than 70 precipitation sites were in operation; 27 of these sites had at least 10 years of record, which is the minimum record typically required in frequency studies. Missing record at one site, however, resulted in its removal from the dataset. Two datasets-the Charlotte Raingage Network (CRN) initial and CRN modified datasets-were developed from the U.S. Geological Survey data, which represented relatively short periods of record (10 and 11 years). The CRN initial dataset included very high precipitation totals from two storms that caused severe flooding in areas of the city and county in August 1995 and July 1997, which could significantly influence the statistical results. The CRN modified dataset excluded the highest precipitation totals from these two storms but included the second highest totals.

Two additional datasets were developed using National Oceanic and Atmospheric Administration (NOAA) records from eight selected National Weather Service precipitation stations in or near Mecklenburg County. These datasets were included in this investigation in order to analyze long-term records of precipitation data in the vicinity of Mecklenburg County and to provide an overall quality-assurance check of results of the L-moment method that was applied to all datasets. The periods of record for the quarterly data (15-, $30-$, and 60-minute durations) ranged from 24 to 33 years at the eight National Weather Service stations, and the periods of record for the hourly data (1-, 2-, 3-, 6-, 12-, and 24-hour durations) generally were about 55 years. One of the NOAA datasets consisted only of precipitation totals from the National Weather Service stations. The other NOAA dataset consisted of the eight National Weather Service stations combined with an aggregated U.S. Geological Survey site represented by using regional (county) L-moment statistics to simulate a set of statistics for one site (as though only one U.S. Geological Survey site had been in operation).

The L-moment method used in this report is the collective group of statistical techniques used in the analyses of annual maximum precipitation totals to compute the regional weighted L-moment statistics for each duration. The L-moment statistical calculations included the mean, L-scale, coefficient of L-variation, L-skew, and L-kurtosis. L-moment ratio diagrams of the site and regional L-skew and L-kurtosis statistics plotted against selected theoretical probability distributions resulted in the use of the generalized logistic and extreme-value distributions as the most appropriate for estimating precipitation frequency. Precipitation-frequency estimates were provided as depth-duration values, in inches, and intensity-duration values, in inches per hour. Values also were presented as precipitation-frequency curves to assess the differences in results from the four datasets. For comparative purposes, tabulated and graphical frequency information presented in this report include values determined from previous and similar studies completed by the National Weather Service.

Precipitation-frequency curves were examined in the order of ascending recurrence intervals, and the spread between the curves for the CRN initial and CRN modified datasets generally increased. Beginning with the 60-minute duration and 5-year recurrence interval, percentage differences between many of the corresponding depths in the two datasets exceeded 15 percent, indicating that the large annual maximum precipitation totals for 1995 and 1997 exerted a 
high degree of influence on the results. The precipitation depths for the NOAA datasets exhibited a smaller degree of spread than the CRN datasets and generally tended to straddle the midrange between the $\mathrm{CRN}$ datasets. Comparisons of precipitation depths between the combined NOAA and aggregated U.S. Geological Survey dataset and the CRN initial dataset indicate that percentage differences generally were less than 15 percent for durations less than 6 hours and for recurrence intervals less than 25 years. The estimated 24-hour, 100-year precipitation depth of 10.99 inches for the CRN initial dataset is about 51 percent higher than the corresponding value of 7.29 inches for the combined NOAA and aggregated U.S. Geological Survey dataset.

The small sample available from the U.S. Geological Survey precipitation network, which was influenced by the occurrence of two large observations (1995 and 1997), indicates that frequency characteristics may be biased higher than actual values. Resolution of this question can only be accomplished with additional data. In the absence of further analyses, results from the combined NOAA and aggregated U.S. Geological Survey dataset currently (2005) can be considered appropriate for use in deriving frequency characteristics for Mecklenburg County. This combined dataset provides consideration of the substantial amount of precipitation data, including some large rainfalls that have occurred in the county, and the NOAA precipitation data representing longer periods of record.

\section{Introduction}

The characterization of precipitation frequency is an important component in hydrologic investigations and engineering design. An understanding of the varying nature of input (precipitation) to the hydrologic system allows for the prediction of output (stream runoff) from the system. Hydrologists use precipitation-frequency information to develop models for use in predicting runoff and flood inundation. Engineers use precipitation-frequency information in making decisions concerning the size of hydraulic structures, such as culverts and bridges. Governmental entities involved in hydraulic engineering design rely on established durations and recurrence intervals (or return periods) for streamflows and(or) precipitation as standards in the design and decisionmaking processes. For example, an interstate highway bridge is designed for a specific discharge (for instance, the 100-year peak discharge) that generally is associated with precipitation having a high recurrence interval, whereas a residential street culvert is designed for a predicted streamflow with a lower recurrence interval (for instance, 25 years or less) that, likewise, is associated with precipitation having a low recurrence interval.
The effects of increased urbanization on runoff in the city of Charlotte and Mecklenburg County, North Carolina, have been the focus of water-resources data-collection and analysis investigations conducted by the U.S. Geological Survey (USGS) since the early 1990s. Streams in the county are in the Catawba and Rocky River basins, which drain to the larger Santee River basin and Yadkin-Pee Dee River basin, respectively. These combined basins drain much of central North Carolina and South Carolina (fig. 1). The earliest USGS streamflow record in Mecklenburg County dates back to 1924, and a few other streamgaging stations in the county have records dating back to 1962 .

Since 1963, the USGS has collected precipitation data at various locations in Charlotte and Mecklenburg County (Robinson and others, 1996). In October 1992, the USGS in cooperation with the city of Charlotte and Mecklenburg County began to expand areal coverage by installing additional data-collection sites, primarily within the city limits of Charlotte. By the mid- to late-1990s, precipitation data were being collected in most areas of and immediately surrounding the county; and by September 2004, data were being collected at more than 70 sites (fig. 2), 27 of which had at least 10 years of record. Because previous precipitation-frequency studies were completed 20 or more years ago and at least 10 years of more recent data were available from the USGS sites, the USGS conducted an investigation in cooperation with the city of Charlotte and Mecklenburg County to characterize the frequency of precipitation at USGS precipitation sites having at least 10 years of record.

This investigation supports USGS priority issues for the Cooperative Water Program at both the national and local levels (U.S. Geological Survey, 2005). The collection, analysis, and publication of long-term environmental and natural-resource information are part of the USGS mission (U.S. Geological Survey, 2000). Results of this investigation provide policymakers and water-resource managers in Mecklenburg County with tools and data that are essential to assessing management strategies for stormwater drainage in and around Mecklenburg County.

\section{Purpose and Scope}

This report presents the frequency of annual maximum precipitation totals for durations of 15 and 30 minutes and $1,2,3,6,12$, and 24 hours; and for recurrence intervals of $2,5,10,25,50,100$, and 500 years. Data collected in Charlotte and Mecklenburg County through December 2004 were used to compile annual maximum precipitation totals for the calendar year, the period used in previous precipitation-frequency studies. Because the sites used in the analyses are located relatively close to each other (compared 


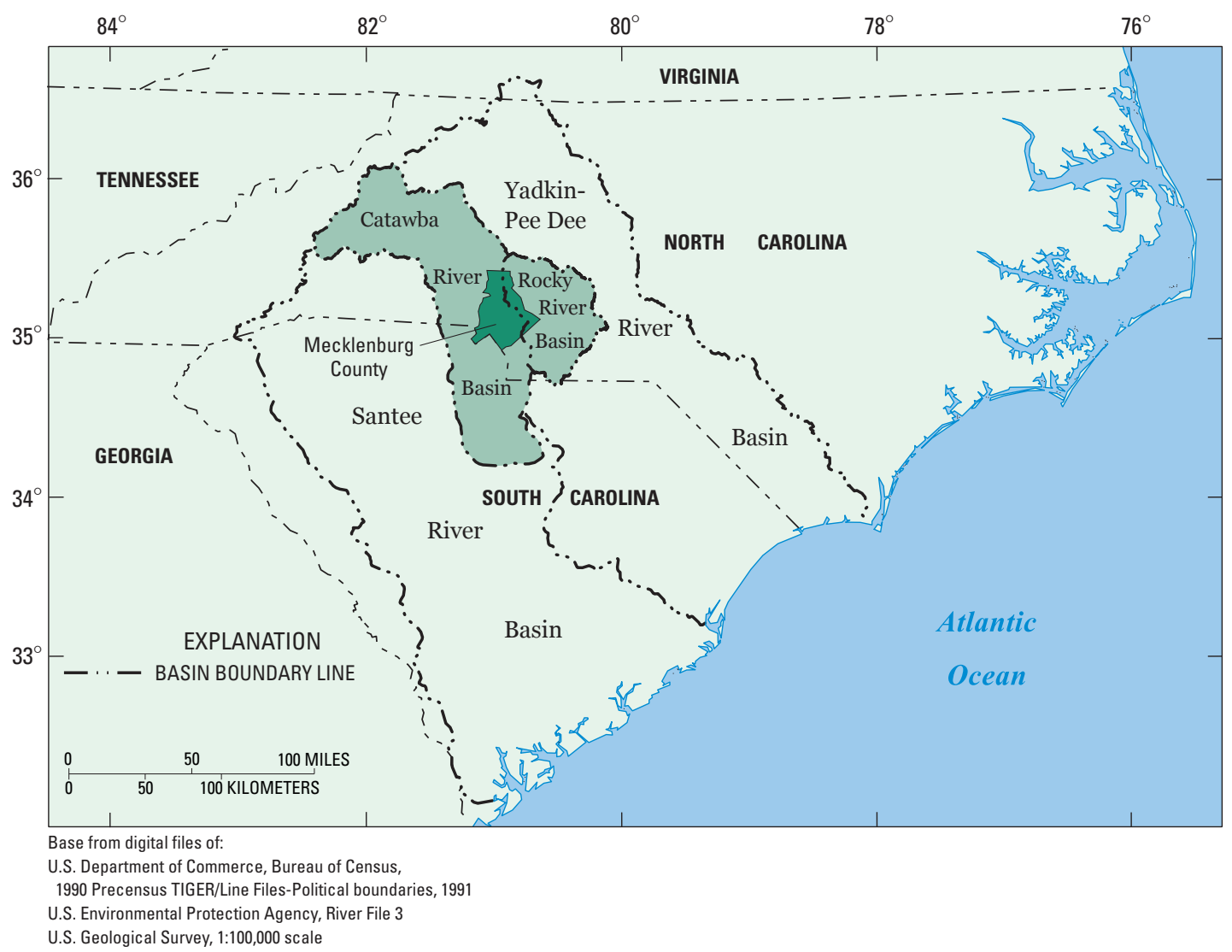

Figure 1. Location of Mecklenburg County in the Catawba River and Rocky River basins in North and South Carolina.

to those that might be used in a larger regional or statewide study), the precipitation-frequency values presented in this report are based on a regional statistical assessment of the data collected at these sites. No precipitation-frequency values are presented for individual sites, and no statistical relations are given for predicting the precipitation amounts for selected durations and recurrence intervals at ungaged locations.

\section{Previous Investigations}

Although numerous USGS investigations have focused on the quantity and quality of water resources in Charlotte and Mecklenburg County, this study represents the first investigation of precipitation frequency in the study area. Observed precipitation data collected during 1993-98 as part of an investigation to characterize urban stormwater quantity and quality are documented in several USGS publications (Robinson, Hazell, and Garrett, 1996, 1998; Sarver and others, 1999). Precipitation data collected from the USGS network were used extensively in another study to develop relations for estimating peak discharges and unit hydrographs for streams in Charlotte and Mecklenburg County (Weaver, 2003).

Previous investigations of precipitation frequency in Mecklenburg County and across North Carolina have been documented by Hershfield (1961, commonly known as Technical Paper 40 or TP-40); Miller (1964, known as Technical Paper 49); Frederick and others (1977, known as NWS (National Weather Service) HYDRO-35); and Bonnin and others (2004, known as NOAA Atlas 14). Hershfield (1961) used precipitation data for varying periods of record through 1958 from across the contiguous United States at 6,185 daily sites, 2,081 hourly sites, and 200 sites where data were collected at short intervals ( 30 minutes to 24 hours). Using these data, Hershfield developed the depth-duration frequency (DDF) of precipitation for durations of 30 minutes to 24 hours and return periods, or recurrence intervals, of 2 to 100 years. 


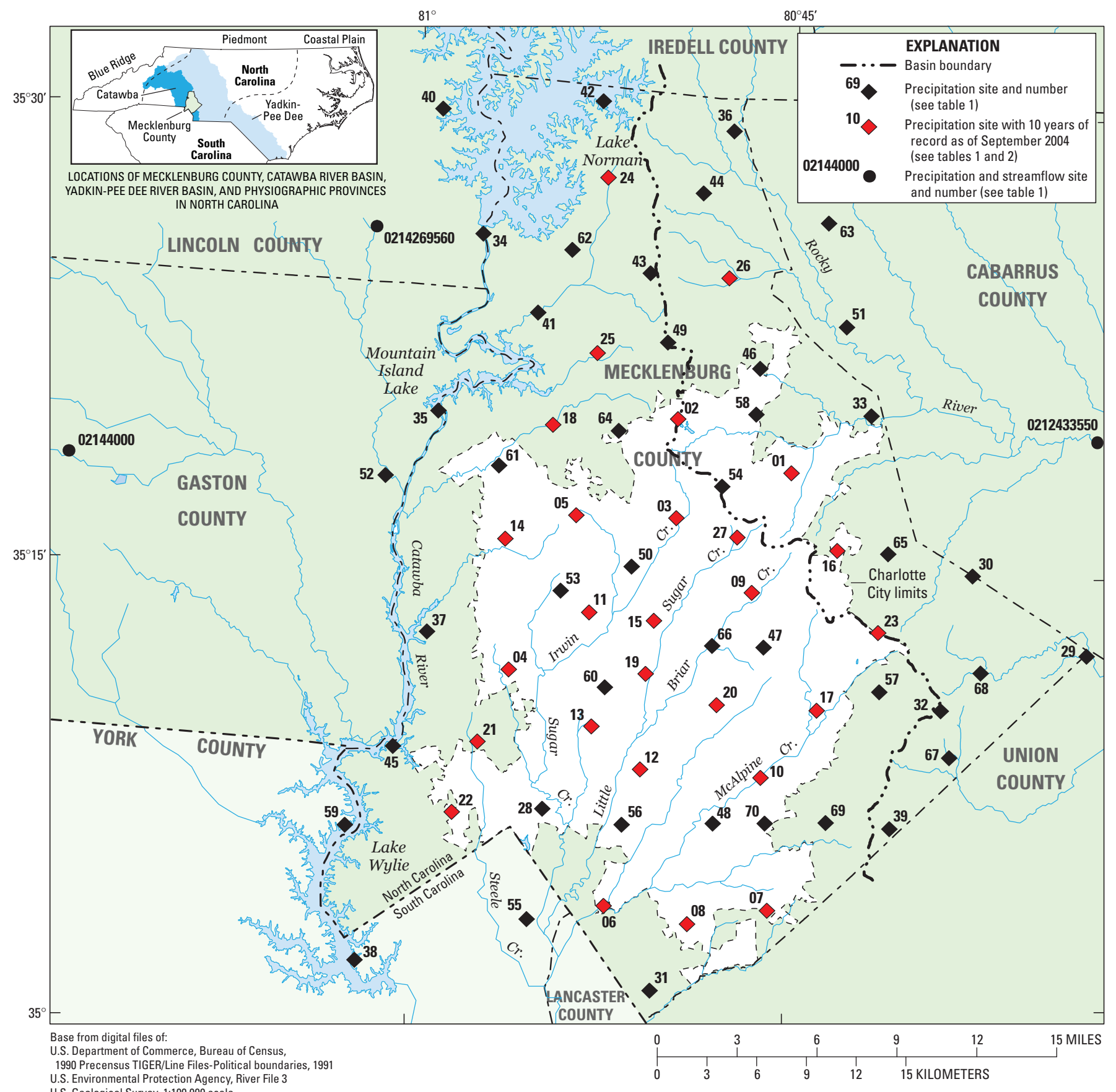

Figure 2. Locations of major streams and U.S. Geological Survey precipitation network sites in Charlotte and Mecklenburg County, North Carolina, October 1988 through September 2004. 
Miller (1964) used additional data available through 1961 as well as some of Hershfield's (1961) results to extend the DDF statistics for durations of 2 to 10 days at return periods of 2 to 100 years. Frederick and others (1977) likewise used additional data available through 1972 at 1,900 hourly sites and 200 sites where data were collected at short intervals (5 to 60 minutes) to develop the DDF of precipitation for durations of 5 to 60 minutes and return periods of 2 to 100 years.

More recently, the NWS has begun the process of updating precipitation-frequency statistics for the United States (Bonnin and others, 2004) based on available periods of record through December 2000 and replacing those provided by Hershfield (1961), Miller (1964), and Frederick and others (1977). By spring 2005, updated statistics had been released for two areas-the semiarid southwestern United States, including New Mexico, Arizona, Utah, Nevada, and portions of southern California (volume 1); and the Ohio River basin and surrounding States, including North Carolina and the District of Columbia among the 13 States (volume 2).

\section{Acknowledgments}

The foresight and leadership in initiating and conducting this investigation and previous USGS investigations in Mecklenburg County are credited to Mr. Jim Schumacher, City of Charlotte, and Mr. Dave Canaan, Mecklenburg County. Additionally, important contributions to this investigation were made by numerous other Charlotte-Mecklenburg Storm Water Services employees, including Mr. Tom Calhoun, City of Charlotte, and Mr. Bill Tingle, Mecklenburg County.

The author acknowledges Dr. William H. Asquith of the USGS Texas Water Science Center for his guidance in the precipitation-frequency methods used during this investigation. Dr. Asquith has conducted a number of investigations of the effects of precipitation frequency on the hydrologic system in Texas. In particular, his knowledge and instruction of the L-moment method proved invaluable in the completion of the study for Mecklenburg County and, subsequently, in the completion of this report. Some material from Dr. Asquith's previous reports, particularly the discussion pertaining to the L-moment method, has been reproduced in this report.

The author also acknowledges Ms. Sue Giller, Hydrosphere Data Products, Inc., who compiled annual maximum precipitation totals for NWS stations in North Carolina and South Carolina. Use of these precipitation data provided a stronger basis for assessing the data collected at the USGS sites.

Finally, the author acknowledges Mr. William F. Hazell of the USGS and Ms. Nicole Scheman, formerly of the USGS, who compiled and reviewed the extensive volume of USGS precipitation data used in this investigation.

\section{Description of the Study Area}

Mecklenburg County is in south-central North Carolina in the southern Piedmont Physiographic Province and encompasses a total area of about 567 square miles $\left(\mathrm{mi}^{2}\right)$. The county is bounded on the west by the Catawba River and its reservoirs - part of Lake Norman, Mountain Island Lake, and part of Lake Wylie (fig. 2), which compose $21.9 \mathrm{mi}^{2}$ of the county area. Charlotte is the principal municipality in Mecklenburg County and the largest city in North Carolina. The city encompasses about $237 \mathrm{mi}^{2}$, or 43.5 percent of Mecklenburg County's nearly $545-\mathrm{mi}^{2}$ land area.

The 2003 population for the incorporated area of Charlotte was nearly 585,000, and the total population of Mecklenburg County was about 752,000 (U.S. Census Bureau, 2005). These numbers are 37.0 and 47.1 percent higher than the corresponding 1990 population values. The higher percentage change for the county represents the expansion of urban development into unincorporated areas of the county.

Approximately 75 percent of Mecklenburg County is drained by the Catawba River, which is part of the Santee River basin. The remaining 25 percent of the county is drained by the Rocky River and its tributaries in the Yadkin-Pee Dee River basin (fig. 2). Most of the Charlotte metropolitan area is drained by four large creeks-Irwin, Little Sugar, Briar, and McAlpine Creeks (fig. 2).

\section{Setting and Climate}

The topography of Mecklenburg County is characterized by broad, gently rolling interstream areas and by steep slopes along the drainage ways. The elevation of the county ranges from 520 feet (ft) at the State line at the county's southern border to about $830 \mathrm{ft}$ in the extreme northern part of the county (McCachren, 1980). The area is predominately underlain by granite with some slate in the southeast (LeGrand and Mundorff, 1952). The soils in the county are described as well-drained, sandy loams with a clayey subsoil.

The climate of the county is characterized by hot, humid summers and short, mild winters with more moderate conditions during the spring and fall. The monthly mean temperature at Charlotte Douglas Airport ranges from about 42 degrees Fahrenheit $\left({ }^{\circ} \mathrm{F}\right)$ in January to about $80{ }^{\circ} \mathrm{F}$ in July (National Oceanic and Atmospheric Administration, 2004). In all areas of the county, daily maximum temperatures in the summer frequently reach levels exceeding $90^{\circ} \mathrm{F}$, sometimes for long periods of consecutive days.

Precipitation in Mecklenburg County averages about 43 inches per year (in/yr), similar to most areas of central North Carolina where average precipitation is between 40 and $50 \mathrm{in} / \mathrm{yr}$. In comparison, the lowest and highest average precipitation recorded in North Carolina are about $37 \mathrm{in} / \mathrm{yr}$ in Asheville (Buncombe County) and 92 in/yr in Lake Toxaway (Transylvania County) in the western part of the State (State Climate Office of North Carolina, 2005). 
Because the determination of precipitation frequency is based on annual maximum precipitation totals observed at data-collection sites, it is interesting to note some of the large precipitation amounts that have been recorded in the region. Though large precipitation amounts generally occur as a result of intense thunderstorms during the summer, many of the larger totals are associated with tropical storms during late summer and fall.

In North Carolina, the greatest 24-hour precipitation total on record is 22.2 inches observed July 15-16, 1916, in Altapass (Mitchell County) as a result of a tropical storm that came inland from the South Carolina coast and caused some of the most extensive and destructive flooding on record (Zembrzuski and others, 1991; State Climate Office of North Carolina, 2005). During September 6-9, 2004, rainfall totals in western North Carolina associated with Hurricane Frances exceeded 12 inches in several areas, and some isolated totals exceeded 18 inches, causing widespread, catastrophic flooding (National Weather Service, 2004a). Only 2 weeks later, rainfall from Hurricane Ivan (September 16-19, 2004) drenched areas of western North Carolina, resulting in substantial additional runoff to the already high flows occurring in the mountainous terrain. Compared to Hurricane Frances, however, rainfall totals from Hurricane Ivan generally were between 4 and 8 inches, and only a few totals exceeded 8 inches in the severely flooded basins of the higher elevations (National Weather Service, 2004b).

In Mecklenburg County, the largest daily precipitation total at the NWS climate observation station at Charlotte Douglas Airport is 6.88 inches recorded on July 23, 1997 , during the passage of Hurricane Danny (Southeast Regional Climate Center, 2005). Other notable daily rainfall totals recorded at this station include 4.51 inches on August 3, 1978, and 4.21 inches on October 4, 1992 (Southeast Regional Climate Center, 2005). Because daily totals reflect 24-hour amounts measured at fixed times (for instance, from 8:00 a.m. to 8:00 a.m.), daily totals typically are less than 24-hour precipitation totals for storms occurring for 2 or more consecutive days. Maximum 24-hour totals recorded at the USGS precipitation sites during July 22-24, 1997, were between 9 and 9.5 inches at several sites. Robinson, Hazell, and Young (1998), however, reported a maximum rainfall amount of 11.40 inches for a continuous 24-hour period during this same storm (site 30, fig. 2). Other notable 24-hour totals over 8 inches were recorded at the USGS precipitation sites (maximum 8.7 inches at site 20, fig. 2) during Tropical Storm Jerry, August 26-28, 1995.

\section{U.S. Geological Survey Precipitation Data- Collection Sites}

The precipitation data analyzed during this investigation were collected from an extensive USGS network of raingages located throughout the city of Charlotte and Mecklenburg
County (fig. 2; table 1). Near the beginning of the 1993 water year $^{1}$, the raingage network consisted of 14 data-collection sites providing coverage predominantly across the southern two-thirds of the county. By the end of the 2004 water year, a network of more than 70 precipitation data-collection sites provided coverage for the entire county and parts of adjacent counties.

Although the size of the network has varied since the 1993 water year, 27 of the USGS data-collection sites had at least 10 years of record at the end of the 2004 water year. Missing record at one site resulted in removal of the site from this investigation. Precipitation data collected at the remaining 26 sites as of December 2004 were included in the analyses to characterize the frequency of precipitation for the county. Annual maximum precipitation totals were computed by using the calendar year, which is consistent with the annual period used in previous precipitation-frequency studies. Further information on the USGS raingage network is provided by Hazell and Bales (1997) and U.S. Geological Survey (2004).

\section{Data Compilation and Analytical Methods}

Regionalization is the process of developing statistical relations and(or) mapping of spatially varying factors or other statistical parameters that can be used to estimate environmental phenomena (for example, peak discharges, rainfall totals) where observed data are not available. Regionalization techniques commonly are applied to data collected from large study areas, such as a physiographic province, a region having similar geologic or soil characteristics, a state, or even a multistate area. Such techniques generally are designed to permit the determination of estimates where site-specific data are not available (for example, the estimation of peak discharges or precipitation amounts for 100-year recurrence intervals at ungaged sites).

Because the study area for this report consists of one county (Mecklenburg), the determination of regional or countywide estimates for the selected durations and recurrence intervals was based on the use of regional L-moment statistics fitted to an appropriate probability distribution. No statistical relations or mapping of spatial factors were developed for estimating precipitation at ungaged locations where site-specific data are not available. For instance, as presented in this report, the annual 24-hour maximum precipitation estimated for a given recurrence interval is considered applicable to all areas of the county. This section describes the precipitation data compiled for the study and presents a brief description of the L-moment method.

\footnotetext{
${ }^{1}$ Water year is the 12 -month period from October 1 through September 30 and is identified by the year in which the period ends. For example, the 2004 water year is from October 1, 2003, to September 30, 2004.
} 


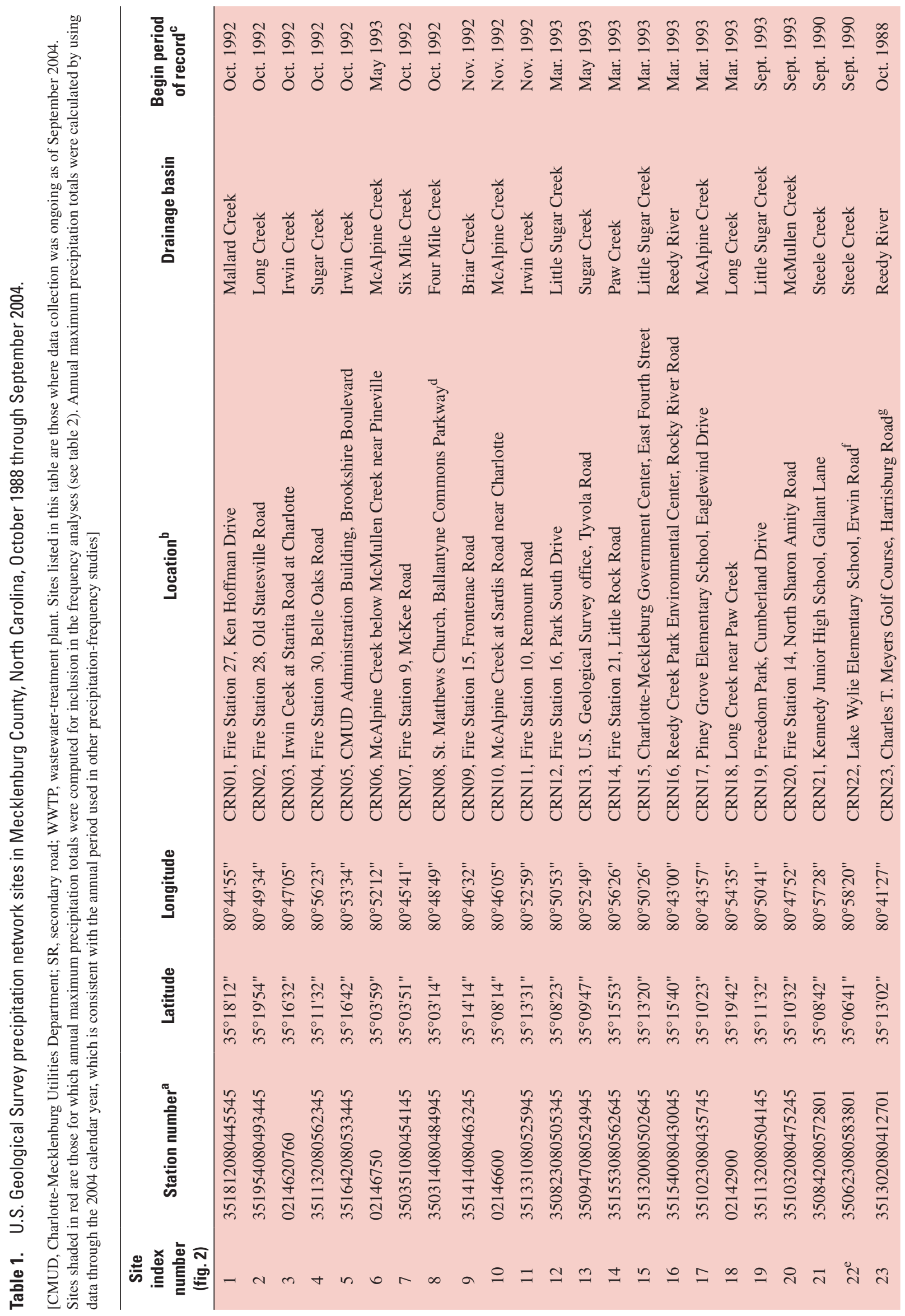




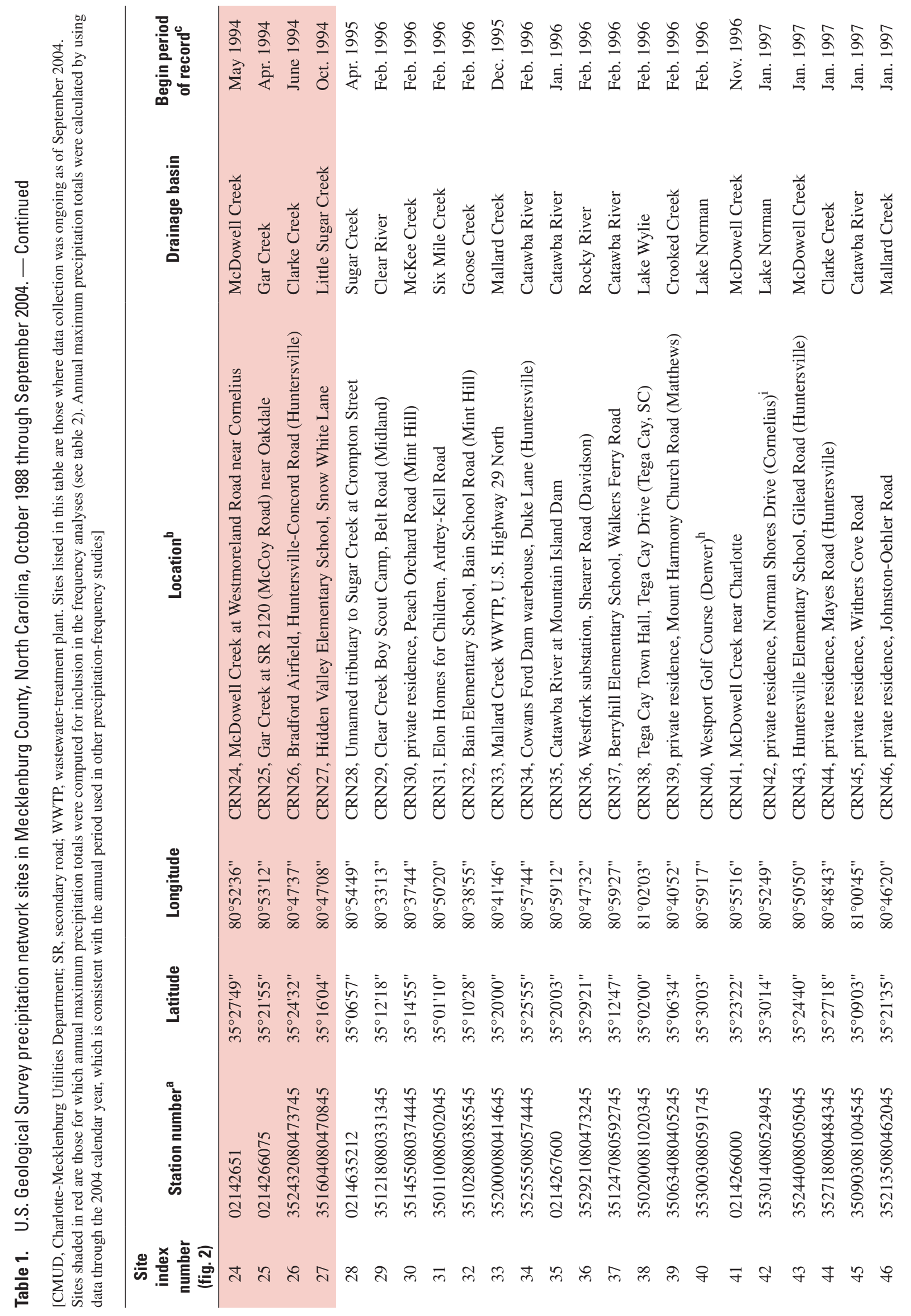




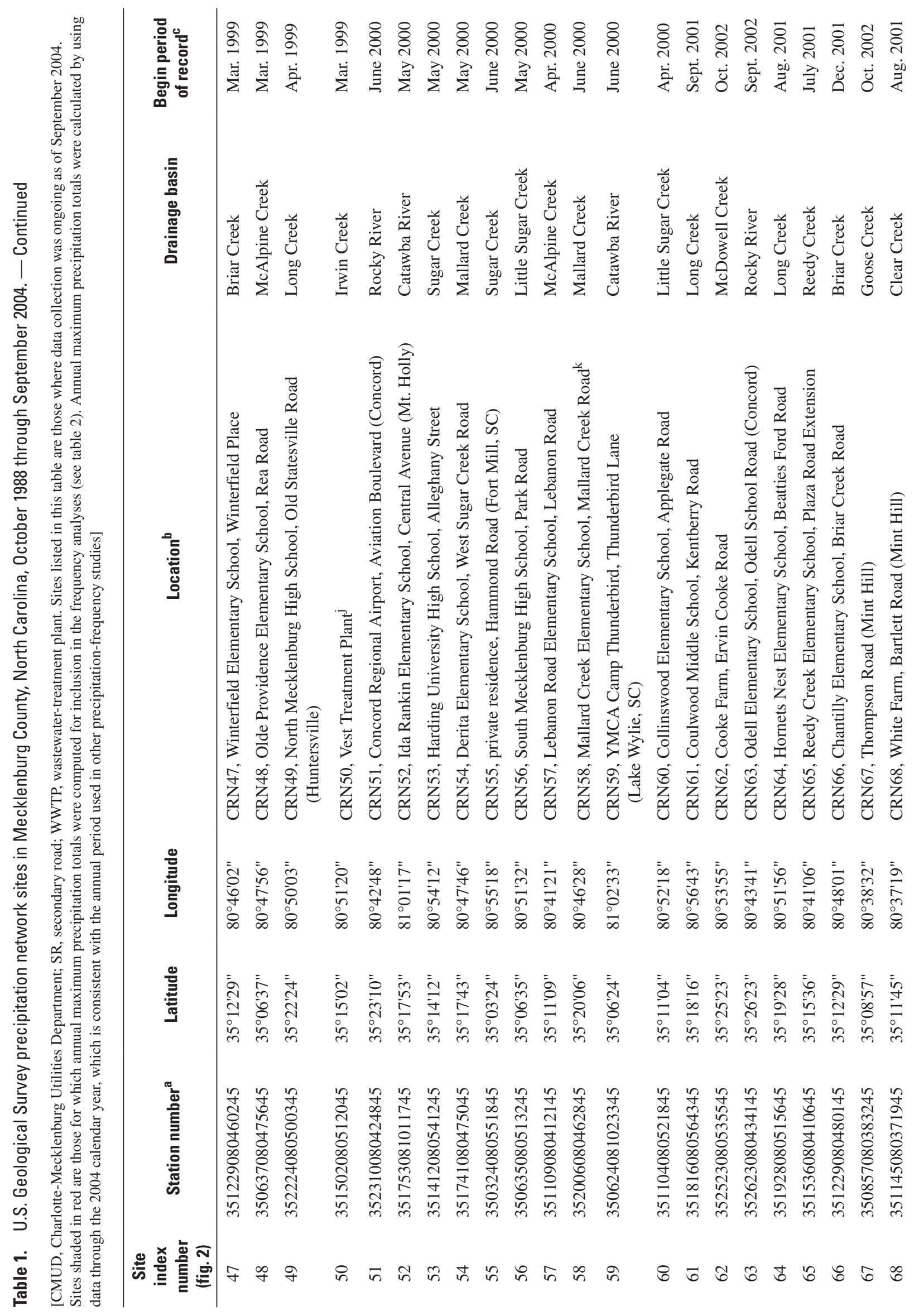




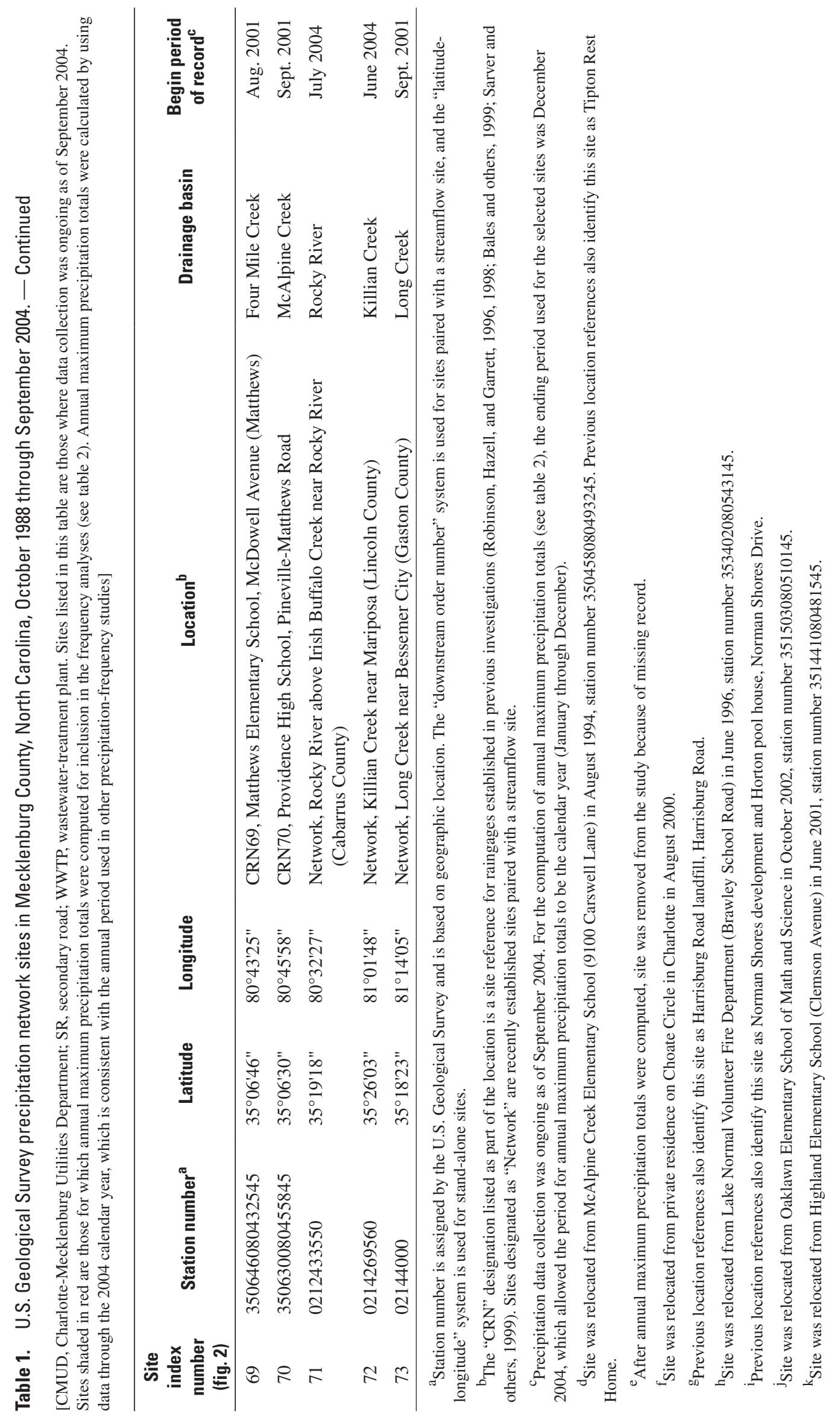




\section{Precipitation Data}

Precipitation data at USGS sites having at least 10 years of record were used in the computation of annual maximum precipitation totals. Although most of the precipitation data-collection sites are located in the southern two-thirds of Mecklenburg County (primarily within the Charlotte city limits), the spatial distribution of the sites provides a countywide coverage for assessing the frequency of annual maximum precipitation totals (fig. 2). Initially, 27 sites were selected for analysis, but 1 site had substantial missing record and was removed from the study. The availability of data recorded at 5-minute intervals permitted the compilation of annual maximum precipitation totals for selected durations (15 minutes to 24 hours) based on actual beginning and ending times of precipitation and not on an arbitrary fixed time of data collection. For example, the 1-hour maximum total for a given calendar year is likely to be for a compilation period that begins at a 5-minute interval other than at the top of the hour. Consistent with other precipitation-frequency studies, annual maximum totals were compiled using the calendar year (January through December; table 2, p. 40; fig. 3).

The available periods of record at the USGS datacollection sites are relatively short compared with the periods of record commonly used to complete frequency studies. Additionally, maximum values of precipitation in 1995 and 1997 (table 2) generally were much larger than in other years because of the extremely large rainfall amounts associated with storms that caused extensive flooding in Mecklenburg County (Robinson, Hazell, and Young, 1998). Two very large observations in the relatively small sample of precipitation totals led to concern that statistical results could be biased by the 1995 and 1997 values. Thus, annual maximum precipitation values at the USGS sites were computed for two scenarios - an initial compilation (the Charlotte Raingage Network (CRN) initial dataset) of precipitation totals included the August 1995 and July 1997 storm totals, and a modified compilation (the CRN modified dataset) replaced the large storm values for August 1995 and July 1997 with the second largest values for these years (table 2). Including the CRN modified dataset in the analysis of the USGS data served as a sensitivity test to assess the influence of the 1995 and 1997 precipitation totals on the overall statistical results.

To further investigate the effects of relatively short periods of record on precipitation frequency at the USGS sites, annual maximum precipitation totals for eight selected long-term NWS precipitation stations in the vicinity of Mecklenburg County also were compiled for durations from

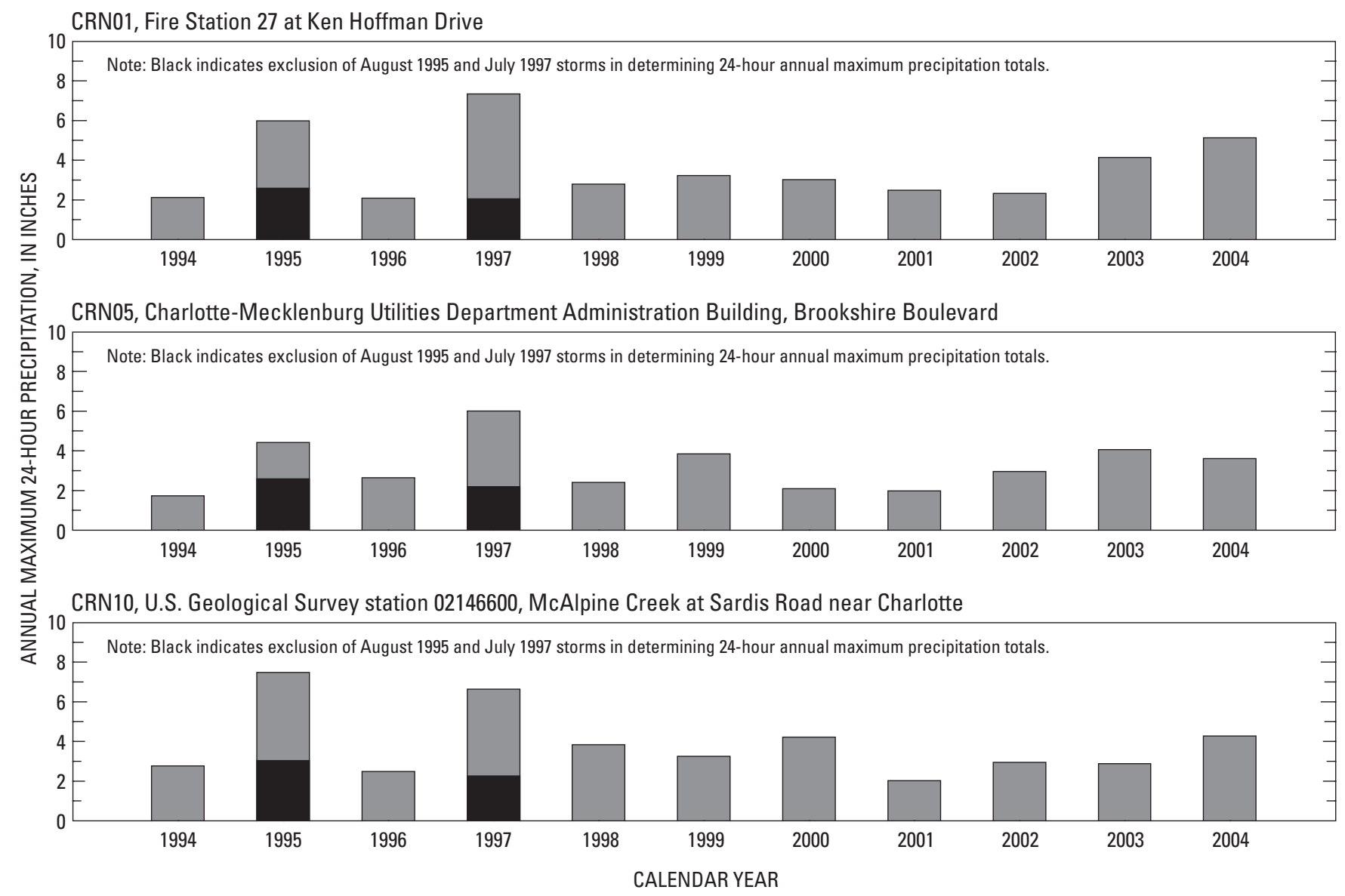

Figure 3. Time series of annual maximum of 24-hour (1,440-minute) precipitation totals at selected U.S. Geological Survey precipitation sites in or near Mecklenburg County, North Carolina. 


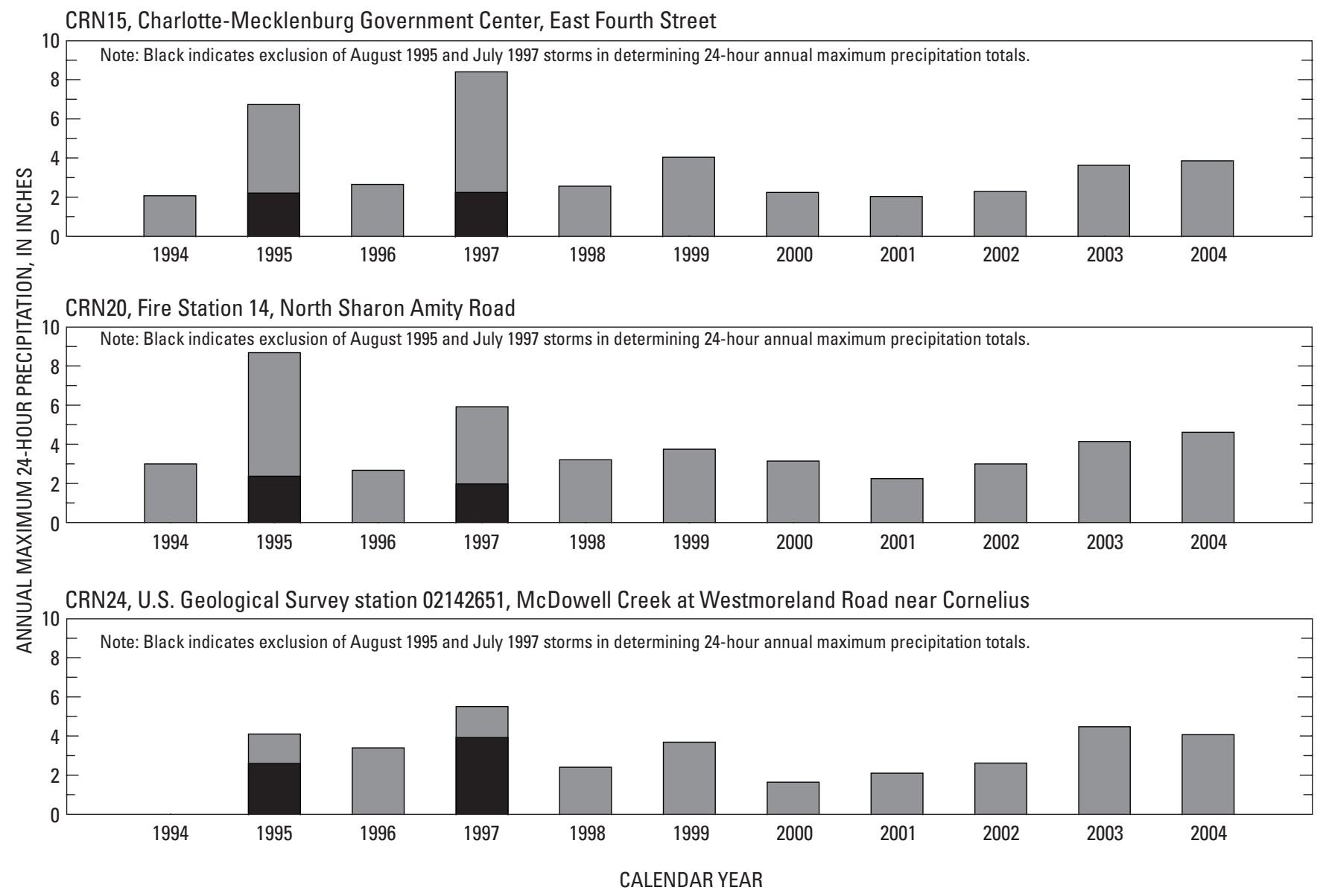

Figure 3 (Continued). Time series of annual maximum of 24-hour (1,440-minute) precipitation totals at selected U.S. Geological Survey precipitation sites in or near Mecklenburg County, North Carolina.

15 minutes (quarterly) to 24 hours (fig. 4; table 3). Within NOAA, precipitation data for NWS stations are available from several datasets maintained by the National Climatic Data Center (NCDC) in Asheville, North Carolina (National Climatic Data Center, 2004). These NOAA datasets include quarterly, hourly, and daily precipitation data collected across the United States. For this study, the annual maximum precipitation totals through December 2003 were compiled for the NWS stations in North and South Carolina (Ms. Sue Giller, Hydrosphere Data Products, Inc., written commun., November 24, 2004).

Precipitation data from the quarterly dataset for the eight NWS stations were used to compute the annual maximum totals for 15- and 30-minute and 1-hour durations. Similarly, precipitation data from the hourly dataset were used to compute the annual maximum totals for 1-, 2-, 3-, 6-, 12-, and 24-hour durations. The resulting dataset consists of seven sites for the 15- and 30-minute durations and eight sites for the 1- to 24-hour durations. (No quarterly precipitation data were available for the NWS station at Charlotte Douglas Airport; table 3, fig. 4.) The periods of record for the quarterly data ranged from 24 to 33 years at the eight selected stations (table 3), and the periods of record for the hourly and daily datasets generally were about 55 years. Annual maximum precipitation totals were compiled from the quarterly and hourly datasets at the eight selected stations to form the third analysis included in this investigation (shown for six selected stations in fig. 5).

A fourth dataset was developed to represent a combination of the NWS stations and an aggregated USGS site. This aggregated site was created by using the regional L-moment statistics to simulate one set of site statistics (as though only one USGS site had been in operation). More specifically, the fourth dataset was created by combining the regional L-moment statistics computed for each duration in the CRN initial dataset with the individual L-moment statistics from the NWS stations. Combining the aggregated USGS site with the selected NWS stations provided a means of analysis that incorporated the presence of long-term records with the USGS precipitation data while, at the same time, preventing the incorporated data from being dominated by data from 26 individual USGS sites. This resulted in a sample of eight sites for the 15- and 30-minute durations and nine sites for the 1- to 24-hour durations (table 3). 


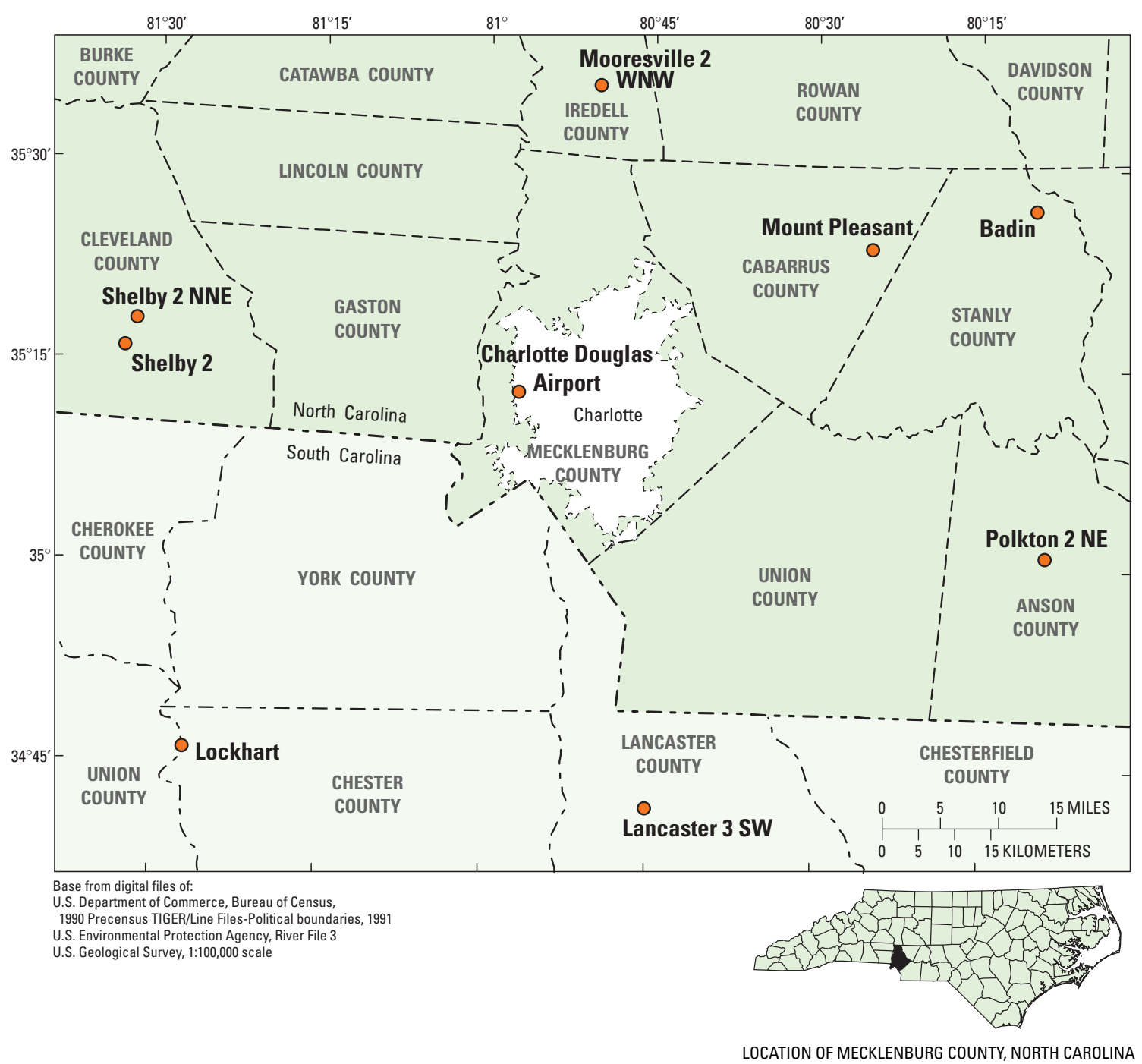

Figure 4. Selected National Weather Service precipitation stations in North and South Carolina in the vicinity of Mecklenburg County, North Carolina. (See table 3 and figure 5 for additional information on the National Weather Service precipitation stations.)

Including the NOAA (third and fourth) datasets in this investigation served two purposes - to analyze precipitation data collected at sites in the vicinity of Mecklenburg County having long-term records, and to provide quality assurance of results from the L-moment method applied to all datasets.

In order to compute the annual maximum totals at the USGS sites, an extensive analysis of missing precipitation data was conducted to identify years during which computed values may not represent the actual maximum precipitation that occurred at a site. Because most sites have periods of missing record and the overall available periods of record at the USGS sites during this investigation were relatively short, the assessment of missing data required considerable judgment. All periods of missing precipitation data for each site were compiled. A comparison of the dates of annual maximum totals between a given site and the remaining sites then was made to determine whether the annual values were maximum values for the year or were affected by the missing data.

The assessment of missing records resulted in removal of records for some years from the analyses. At sites CRN03, CRN23, and CRN26, annual totals for 1995 were removed from the CRN initial dataset because of missing data during the August 1995 storm (table 2). Extended periods of missing data at site CRN22 resulted in the removal of precipitation data for this site from the analyses. Other sites where selected annual maximum precipitation totals were removed from the analyses include CRN05 (1994), CRN07 (2002), and CRN19 (1994; table 2). 
Table 3. Selected National Weather Service precipitation network stations in North and South Carolina in the vicinity of Mecklenburg County, North Carolina.

[N/A, not available. Stations are listed alphabetically]

\begin{tabular}{llccc}
\hline \multirow{2}{*}{$\begin{array}{c}\text { National Weather Service station name } \\
\text { (site identification) }\end{array}$} & & \multicolumn{2}{c}{ County } & \multicolumn{2}{c}{ Begin precipitation record, year } \\
\cline { 3 - 5 } & & Quarterly & Hourly & Daily $^{\text {a }}$ \\
\hline Badin (31-438) & Stanly & 1972 & 1948 & 1948 \\
Charlotte Douglas Airport (31-1690) & Mecklenburg & N/A & 1948 & 1948 \\
Lancaster 3 SW (38-4918) & Lancaster (South Carolina) & 1980 & 1948 & 1948 \\
Lockhart (38-5232) & Union (South Carolina) & 1976 & 1948 & 1948 \\
Mooresville 2 WNW (31-5814) & Iredell & 1978 & 1949 & 1949 \\
Mount Pleasant (31-5945) & Cabarrus & 1971 & 1948 & 1948 \\
Polkton 2 NE (31-6867) & Anson & 1971 & 1948 & 1948 \\
Shelby 2 (31-7850) & Cleveland & 1971 & 1948 & 1949 \\
Shelby 2 NNE (31-7845) & Cleveland & 1994 & 1994 & 1893 \\
\hline
\end{tabular}

${ }^{\mathrm{a}}$ Quarterly precipitation record represents data available at 15-minute increments, and daily precipitation record represents totals for the calendar day (midnight to midnight).

${ }^{b}$ Limited quarterly precipitation record (1973-79) was available for this site until July 1998 when collection of climate data at 5-minute intervals began as part of the National Weather Service's Automated Surface Observing System program. Because the available quarterly record does not include data for 1995 and 1997 when two major storms resulted in catastrophic flooding in Mecklenburg County, data for this site were not included in frequency analyses for durations less than 1 hour.

${ }^{\mathrm{C}}$ Quarterly and hourly precipitation record ended at the Shelby 2 (31-7850) site in 1993 and began at Shelby 2 NNE (31-7845) in 1994. Annual maximum precipitation totals for these two stations were combined for the analyses.

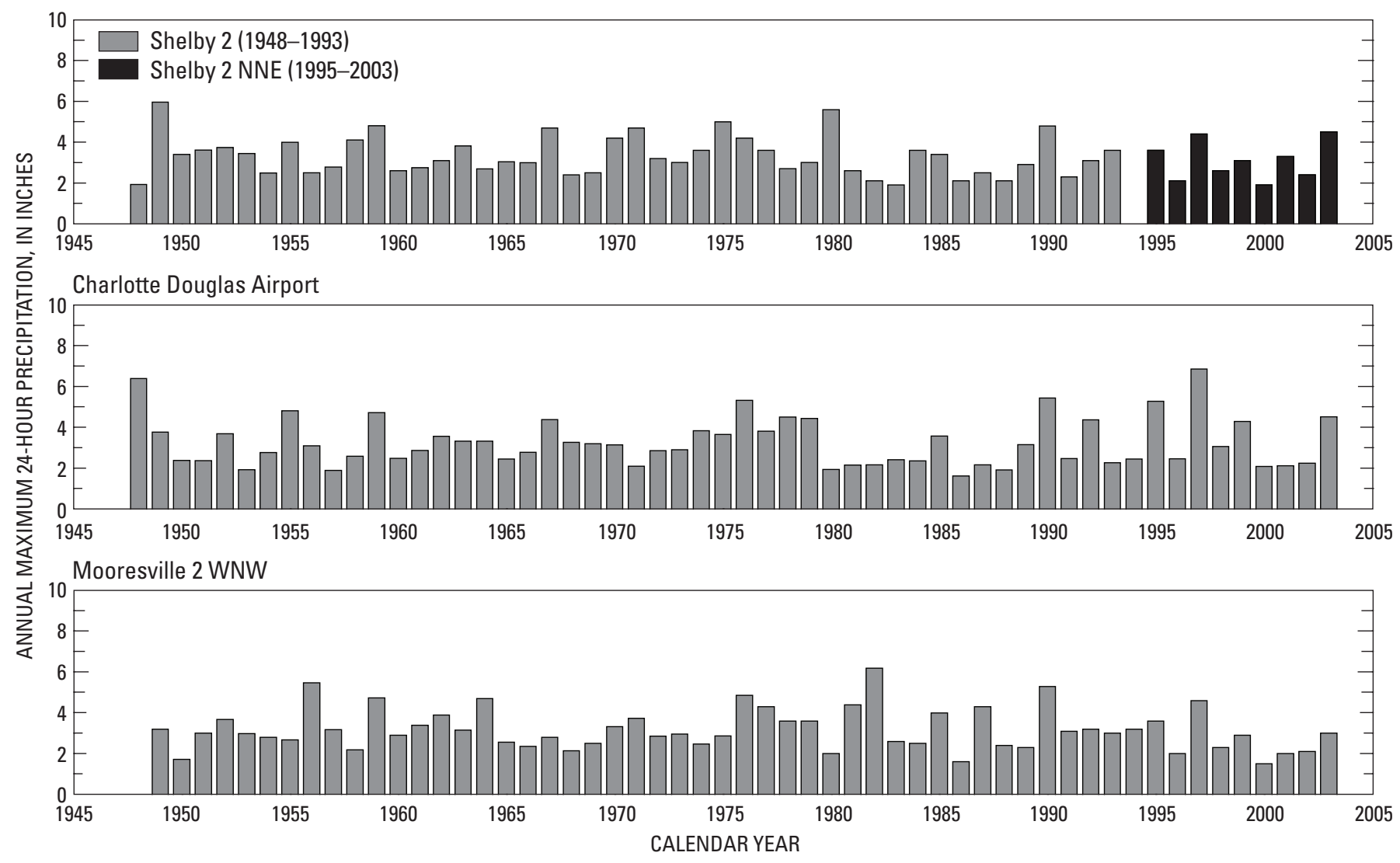

Figure 5. Time series of annual maximum of 24-hour (1,440-minute) precipitation totals at selected National Weather Service precipitation stations in or near Mecklenburg County, North Carolina (locations shown in fig. 4). 


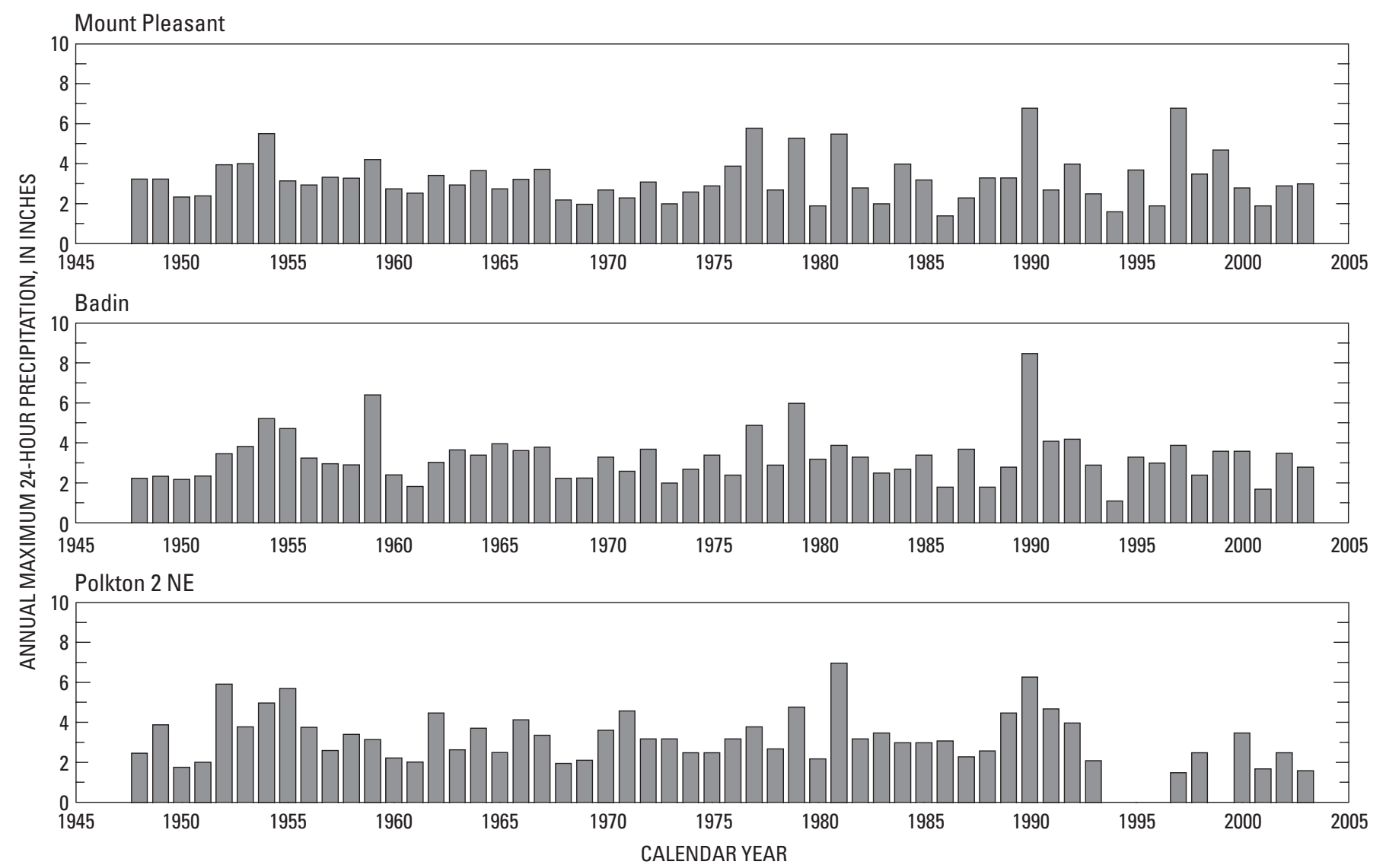

Figure 5 (Continued). Time series of annual maximum of 24-hour (1,440-minute) precipitation totals at selected National Weather Service precipitation stations in or near Mecklenburg County, North Carolina (locations shown in fig. 4).

\section{L-Moment Method}

The L-moment method is the collective group of statistical techniques used in the analyses of annual maximum precipitation totals to compute the regional weighted L-moment statistics for each duration. The method includes the computation of site and regional L-moment statistics, the use of L-moment diagrams to select appropriate probability distributions, and other statistical measures used to screen and assess the data used in the analyses. The discussion presented here (and in the subsequent section, L-Moment Ratio Diagrams and Goodness-of-Fit Measures) is reproduced in part from several previously published studies on precipitation frequency (Parrett, 1997; Tortorelli and others, 1999; Asquith, 2003; Bonnin and others, 2004).

The L-moment method was fully formulated by the mid-1990s and is the standard technique used in recent precipitation studies (Bonnin and others, 2004). Prior to the availability of the L-moment method, characterization of precipitation frequency (Hershfield, 1961; Miller, 1964; Frederick and others, 1977) was based on the use of conventional product moments. Product moments, however, are not regarded as suitable for use with many datasets, particularly those with large ranges in values, non-normal distributions, or outliers, because the biases and sampling variances are so large that statistics generated from analyses of these data tend to be unusable (Kirby, 1974; Wallis and others, 1974; Asquith, 2003). For instance, higher-order third and fourth moments that describe sample skewness and kurtosis can be biased strongly by short periods of record (Bonnin and others, 2004).

The L-moment method allows for the computation of statistics that are more useful than the conventional-moments method in selecting the most appropriate probability distribution to describe precipitation frequency. Asquith (2003, p. 92) summarized the benefits of using the L-moment method:

The L-moments provide an attractive theoretical framework because of some statistical considerations and their applicability to quantile functions.

The L-moments have many well documented statistical advantages over the product moments. Specifically, L-moments are less sensitive to the presence of outliers in the data, exhibit less bias, are more accurate in small samples, and do not require logarithmic or other power transformations of the data. Transformations are traditionally used to reduce the skewness of the data and compensate for the shortcomings of the product moments by reducing the influence of large data values. Transformations, particularly logarithmic, are not always possible with data possessing zero or negative values. Furthermore, logarithmic transformations generally inflate 
the influence of small values, especially positive values considerably less than one. The L-moments also provide more secure inferences of distributional form than do the product moments. The L-moments specify a distribution even if some of the product moments do not exist (Hosking, 1990, p. 108), and Hosking also reports that an L-moment specification of a distribution is unique, which is not true of a product moment specification.

The L-moment method provides the means of estimating the shape of the distribution along with the uncertainty of the estimates (Bonnin and others, 2004). The method also provides a heterogeneity check for groups of sites; in other words, whether a group of sites within a study area needs to be subdivided into smaller groups or possibly combined with other sites to form a larger, regional group.

The general procedure for developing estimates of precipitation frequency is as follows:

- Annual maximum totals for the selected durations were computed for each calendar year,

- Individual (for each site) L-moment statistics were computed,

- The L-moment statistics from each site were used to check for discordancy,

- Regional weighted L-moment statistics were computed for each duration using the individual L-moment statistics; heterogeneity and goodness-of-fit measures were computed for assessing possible probability distributions, and

- Quantile (or recurrence interval) estimates from the selected probability distribution were used to compute the precipitation-frequency values.

A more theoretical discussion of the L-moment method, reproduced from Asquith (1998) and Tortorelli and others (1999), follows. A more comprehensive discussion, including presentation of theoretical equations for the L-moment method, can be found in Hosking (1986, 1990), Hosking and Wallis (1993, 1997), and Vogel and Fennessey (1993).

Consider a random variable $\mathrm{X}$ (precipitation depth in this report) with a cumulative probability distribution function $\mathrm{F}$ (non-exceedance probability). The quantities,

$$
M_{i j k}=E\left[X^{i} F^{j}(1-F)^{k}\right]=\int_{0}^{1} X^{i} F^{j}(1-F)^{k} d F
$$

where $E=$ the expectation operator, are known as probability-weighted moments (PWM) as defined by Greenwood and others (1979). By letting $M_{i j k}=M_{1 r 0}$, the PWM for moment $r$ can be expressed as

$$
\beta_{r}=E\left[X F^{r}\right]
$$

An unbiased sample estimate of $\beta_{r}$ (PWM) for any distribution is computed from the following (Landwehr and others, 1979):

$$
b_{r}=\frac{1}{n} \sum_{j=1}^{n-r}\left[\frac{\left(\begin{array}{c}
n-j \\
r
\end{array}\right)}{\left(\begin{array}{c}
n-1 \\
r
\end{array}\right)}\right] x_{j}
$$

where

$$
\begin{aligned}
b_{r}= & \text { unbiased sample estimate of } \beta_{r} \text { for moment } \\
& \text { number } r=0,1,2, \ldots \text { and } \\
x_{(j)}= & \text { ordered values of } X \text { where } x_{(1)} \text { is the largest } \\
& \text { observation and } x_{(n)} \text { is the smallest. }
\end{aligned}
$$

In a sense, the PWM are somewhat analogous to the more widely known product moments (mean, standard deviation, coefficient of variation, skew, kurtosis). For example, $b_{0}$ is equal to the mean; however, interpretation of the higher-order PWM is difficult. To facilitate PWM interpretation, Hosking (1986, 1990) developed L-moments as specific linear combinations of the PWM. Unbiased L-moment sample estimates are obtained by substituting the sample estimates of $\beta_{r}$ in the following equation:

$$
\lambda_{r+1}=\sum_{k=0}^{r} \beta_{k}(-1)^{r-k}\left(\begin{array}{l}
r \\
k
\end{array}\right)\left(\begin{array}{c}
r+k \\
k
\end{array}\right) .
$$

The L-moments can be formulated into values that are analogous, though not equal, to the product moments (Hosking, 1990). The mean, scale, coefficient of variation, skewness, and kurtosis of a distribution estimated by using equation 4 are expressed by the following L-moments $\left(\lambda_{r}\right)$ and L-moment ratios $\left(\tau_{r}\right)$ :

$$
\begin{gathered}
\lambda_{1} \equiv \text { mean } \\
\lambda_{2} \equiv \text { L-scale; }
\end{gathered}
$$

$$
\tau_{2}=\frac{\lambda_{2}}{\lambda_{1}} \equiv \text { L-coefficient of variation }(L-C V)
$$

$$
\tau_{3}=\frac{\lambda_{3}}{\lambda_{2}} \equiv \text { L-skew; and }
$$

$$
\tau_{4}=\frac{\lambda_{4}}{\lambda_{2}} \equiv \text { L-kurtosis }
$$


For this report, the L-moments and the L-moment ratios were calculated for each duration and each station by using unbiased estimators. The use of the unbiased estimators for L-moment computation decreases the chance of selecting an inappropriate distribution to fit a given dataset (Hosking and Wallis, 1995, p. 2024). The L-moment method includes computations that can be used to screen data, subdivide the sites into smaller groups, and select the most appropriate probability distribution.

The discordancy test provides a means of screening the data to identify sites that have very unusual or possibly erroneous data, such as values incorrectly recorded or transcribed into a database. Values considered unusual may be the result of changes in site location or environmental factors affecting a site or the collection of data (Hosking and Wallis, 1997). Based on the background and theory provided by Hosking and Wallis (1997), a site is considered discordant if the discordancy measure is greater than 3 . The occurrence of a discordancy measure that exceeds this threshold does not mean that data from the affected site should be removed from the sample. Rather, data from such sites are re-examined to ensure the data were entered correctly. If the data values are verified to be correct, further checks include determining whether other factors, such as site location or surroundings, may have caused the data to misrepresent true conditions.

In this study, discordancy measures greater than 3 were noted at two sites among three durations in the CRN initial analysis - site 17 at the 3-hour duration and site 6 at the 6- and 12-hour durations (fig. 2). Likewise, discordancy measures greater than 3 were noted at two sites among three durations in the CRN modified analysis-site 25 at the 30-minute duration and site 4 at the 6- and 24-hour durations (fig. 2). No discordancy measures greater than 3 were observed in the analyses using the NOAA datasets. Where measures were greater than 3 , the data were checked to ensure that no errors were made in the data values or that no values were outliers. No such instances were found; thus, no data were removed. Hosking and Wallis (1997) state that a discordant site may be the result of an extreme, localized meteorological event affecting one or more sites in a region. Because storms during the summer can produce a wide range of precipitation amounts over a small region, it is possible for a site to appear discordant even when the data are valid.

Regional frequency analysis generally involves subdividing sites across a broad region into smaller groups having similar climatic characteristics or hydrologic factors, such as sites located in mountainous regions and sites located in coastal regions. A group of sites having similarity in frequency distribution characteristics is said to form a homogeneous region (Hosking and Wallis, 1997). Homogeneous is interpreted to mean that, except for a location-specific scaling factor, (1) the form of the distribution for the homogeneous region is known, and (2) the distribution is exactly defined (by specification of its parameters). A quantifiable means of determining whether a group of sites forms a homogeneous region is available through the heterogeneity measure or H-statistic (Hosking and Wallis, 1997).

A group of sites is considered acceptably homogeneous if the heterogeneity measure is less than 1 , possibly heterogeneous if between 1 and 2, and definitely heterogeneous if greater than 2 (Hosking and Wallis, 1997). Negative heterogeneity measures can occur and likely are caused by a positive correlation among data values at different sites (Hosking and Wallis, 1997). Because the geographical extent of Mecklenburg County is small relative to the size of regions commonly assessed in regionalization studies, the sites in this study were not subdivided into smaller groups. Nevertheless, use of a heterogeneity measure provided a means of assessing the region based on the sites used in the analyses.

After regional L-moment statistics were computed for each of the durations, a goodness-of-fit (Z-statistic) test was used to assess whether a particular probability distribution was applicable to the regional data. Consistent with previous USGS precipitation-frequency studies, five 3-parameter distributions were evaluated in this study using the regional weighted L-moment statistics. The distributions included in the evaluations are generalized extreme value (GEV), generalized logistic (GLO), generalized normal (GN), Pearson Type III (PE3), and generalized Pareto (GP). A 5-parameter Wakeby distribution is evaluated if none of the 3-parameter distributions satisfy the goodness-of-fit test. A distribution is considered to have a good fit if the absolute value of the goodness-of-fit measure is less than 1.64 (Hosking and Wallis, 1997). More discussion on the $\mathrm{H}$ - and $\mathrm{Z}$-statistic values computed for this report is provided in the section, L-Moment Ratio Diagrams and Goodness-of-Fit Measures.

\section{Frequency of Annual Maximum Precipitation in the City of Charlotte and Mecklenburg County}

Application of the L-moment method to the four datasets used in this investigation resulted in a wide range of annual maximum precipitation-frequency characteristics for Charlotte and Mecklenburg County. Selection of the appropriate probability distributions and the development of precipitation depth- and intensity-duration frequency curves are discussed in this section.

\section{L-Moment Ratio Diagrams and Goodness-of-Fit Measures}

L-moment ratio diagrams allow simple comparisons between the sample estimates of L-skew $\left(\tau_{3}\right)$ and L-kurtosis $\left(\tau_{4}\right)$ and their theoretical counterparts from selected probability distributions (Asquith, 1998; Tortorelli and others, 1999; fig. 6). The diagrams provide a means of choosing the 

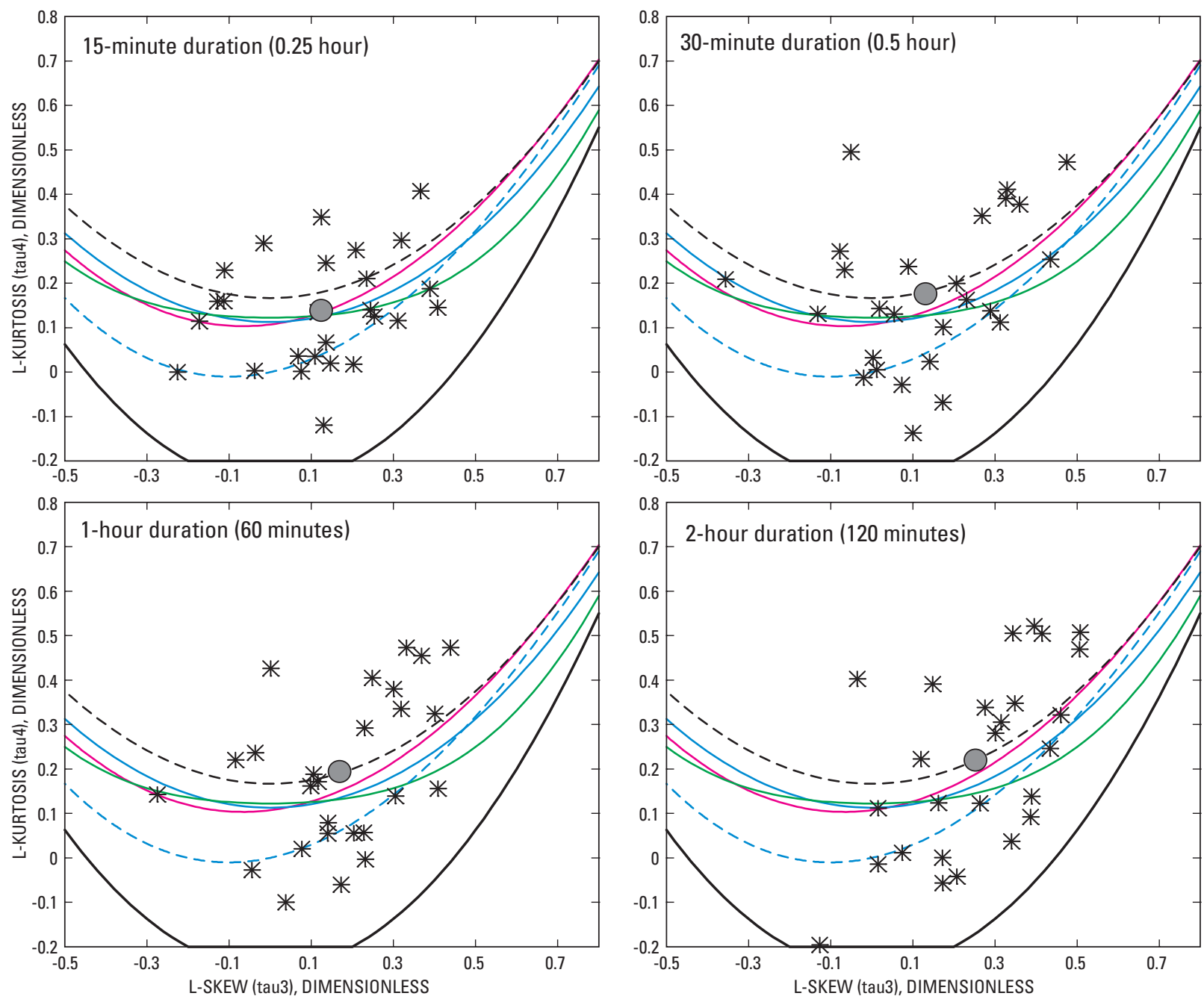

\section{EXPLANATION}

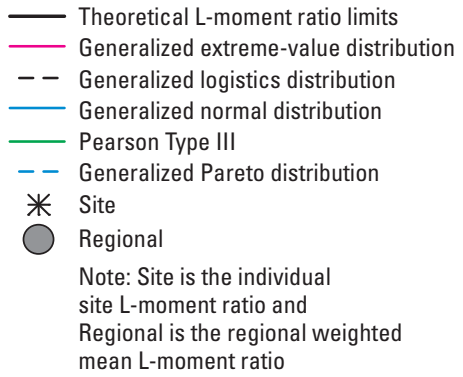

Figure 6. L-moment ratios for selected durations for the CRN initial dataset analysis of precipitation data for Charlotte and Mecklenburg County, North Carolina. 

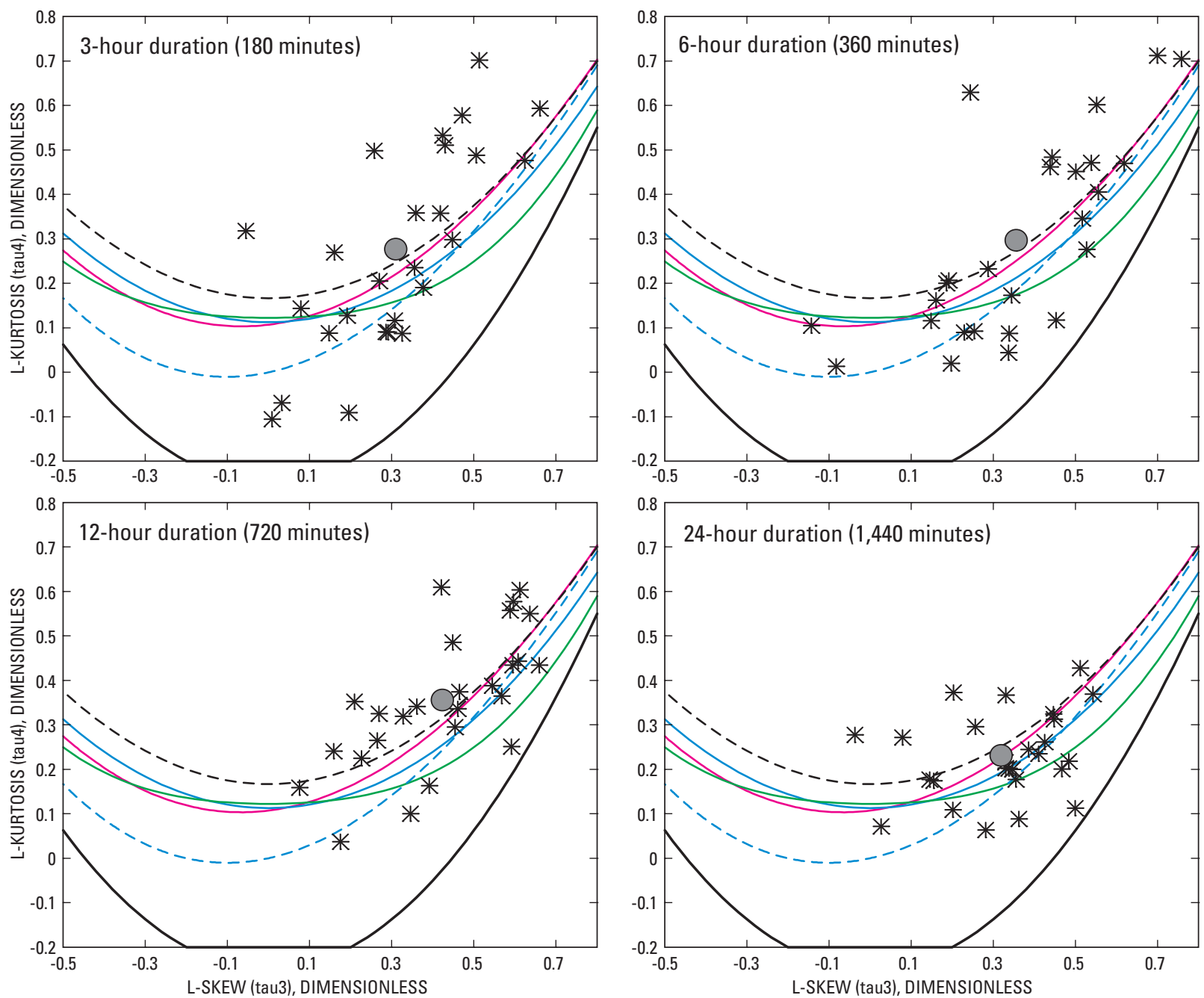

EXPLANATION

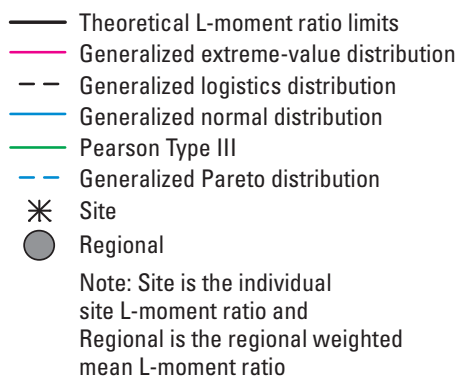

Figure 6 (Continued). L-moment ratios for selected durations for the CRN initial dataset analysis of precipitation data for Charlotte and Mecklenburg County, North Carolina. 
appropriate probability distribution to represent a sample dataset. Vogel and Fennessey (1993) demonstrated the significant differences between product-moment ratio diagrams (skew and kurtosis) and L-moment ratio diagrams; furthermore, they concluded that L-moment ratio diagrams are preferred over product-moment ratio diagrams for distribution selection.

To aide in the understanding of L-moment ratio diagrams, a brief discussion of the concepts of statistical skew and kurtosis may be in order. Skew is a measure of the symmetry, or lack thereof, in a sample distribution (National Institute for Standards and Technology, 2005). Samples defined by a normal distribution are symmetrical about a center and have a skewness of zero (where the mean and median are practically equal or identical). A sample with a positive skewness has a distribution tail that extends to the right, and the mean is larger than the median. Conversely, a sample with a negative skewness has a distribution tail that extends to the left, and the mean is less than the median.

Kurtosis is a measure of the "peakedness" of a sample; that is, whether data are sharply peaked or flat relative to a normal distribution (National Institute for Standards and Technology, 2005). Samples defined by a standard normal distribution have a kurtosis value of 3 . Thus, to quantify excess kurtosis, a value of 3 is subtracted from the initial kurtosis measure, resulting in either a positive measure indicative of a sharp peak in a sample distribution or a negative measure indicative of a flat or broad peak in a sample distribution.

For each duration, the relation between values of $\tau_{3}$ (L-skew) and $\tau_{4}$ (L-kurtosis) for each site, the weighted-mean values of $\tau_{3}$ and $\tau_{4}$ for the CRN initial dataset, and the theoretical $\tau_{3}$ and $\tau_{4}$ relations (Hosking, 1991) from the GEV, GLO, GN, PE3, and GP probability distributions are shown in figure 6 . The asterisk points represent the $\tau_{3}$ and $\tau_{4}$ for each station, and the filled circle represents the weighted-mean value of $\tau_{3}$ and $\tau_{4}$.

The scatter around the weighted-mean (regional) values of $\tau_{3}$ and $\tau_{4}$ in figure 6 , in general, represents sampling variability - in other words, sites having longer periods of record are more likely to have $\tau_{3}$ and $\tau_{4}$ that plot closer to the regional mean (Asquith, 1998; Tortorelli and others, 1999). Data for the corresponding weighted mean of $\tau_{3}$ and $\tau_{4}$ computed from the CRN initial dataset generally plotted between the GLO and GEV distributions (fig. 6). Specifically, the weighted mean for the 15-minute and 24-hour durations plotted closer to the GEV distribution, and the weighted means for the remaining durations plotted closer to the GLO distribution. Although not shown, this trend is supported in similar L-moment ratio diagrams for the other three datasets analyzed in this investigation. In general, the GEV and GLO distributions provided the most satisfactory fits based on the L-moment statistics computed from the datasets. The GN, PE3, and GP distributions were dismissed on the basis of their general relation to the data points. Final determinations of the GEV or GLO distributions for specific durations in the four datasets were then made by examining goodness-of-fit and heterogeneity measures computed in the analyses.

A goodness-of-fit measure (Z-statistic) of the GLO and GEV distributions was computed for each duration by following the methods of Hosking and Wallis (1993) and considering the entire county as a single region (see weighted means in fig. 6). The Z-statistics of the GLO and GEV distributions of each duration are listed in table 4. For the shorter durations (up to 1 hour) in the CRN initial and modified datasets, the GEV distribution tended to have the lower absolute Z-statistic values while the GLO values generally were lower for higher durations (table 4). In the NOAA datasets, absolute values of the Z-statistic from the GLO distribution were lower for the 15- and 30-minute durations, and those from the GEV distribution were lower for durations of 1 hour and longer.

The goodness-of-fit measure can be interpreted in two ways. The first interpretation (Hosking and Wallis, 1993) is that a distribution is considered appropriate if the absolute value of the Z-statistic is less than 1.64. This interpretation, however, has validity only if the region represented by the data is considered acceptably close to homogeneous (Hosking and Wallis, 1993, 1997). Among the Z-statistic values computed (table 4), all but six pairs of values for the GLO and GEV distributions had at least one value less than the absolute value of 1.64. The instances in which both values exceeded this threshold were the 15-minute duration in both NOAA datasets; the 3-, 6-, and 12-hour durations in the CRN initial datasets; and the 24-hour duration in the CRN modified datasets (table 4).

The heterogeneity measures (H-statistic) for the county were computed for each duration following the methods of Hosking and Wallis (1993). Among the 32 computed values of the H-statistics (table 4), 29 values were less than positive 2, which Hosking and Wallis $(1993,1997)$ conclude as being indicative of a homogeneous region. As previously discussed, Hosking and Wallis also conclude that negative heterogeneity values (15 of 29 values in table 4) likely are caused by a positive correlation between the data values among the different sites. The range of H-statistic values (generally less than 2 and/or negative (-) values) seen for most durations in these datasets, therefore, seem to echo their conclusions (table 4). Given the close spatial locations of the precipitation sites in Mecklenburg County, it would be expected that a grouping of sites in this relatively small study area would form a homogeneous group. The close spatial locations of the sites, however, also would likely result in positive correlation among the data collected at the individual sites. Because approximately half of the heterogeneity values are negative, it appears that caution should be applied in accepting the grouping of sites as a true homogeneous region. Therefore, strict interpretation of the goodness-of-fit measure is questionable.

A second interpretation of the goodness-of-fit measure is that the form of the distribution with the smallest absolute value of Z-statistic is considered appropriate, but the distribution parameters may require additional specification (Hosking 
Table 4. Summary of goodness-of-fit and heterogeneity measures for precipitation-frequency analyses in Charlotte and Mecklenburg County, North Carolina.

[GLO, generalized logistic distribution; GEV, generalized extreme-value distribution; min, minute; hr, hour; CRN, designation for U.S. Geological Survey raingage network in Charlotte and Mecklenburg County; NOAA, National Oceanic and Atmospheric Administration; NWS, National Weather Service; USGS, U.S. Geological Survey]

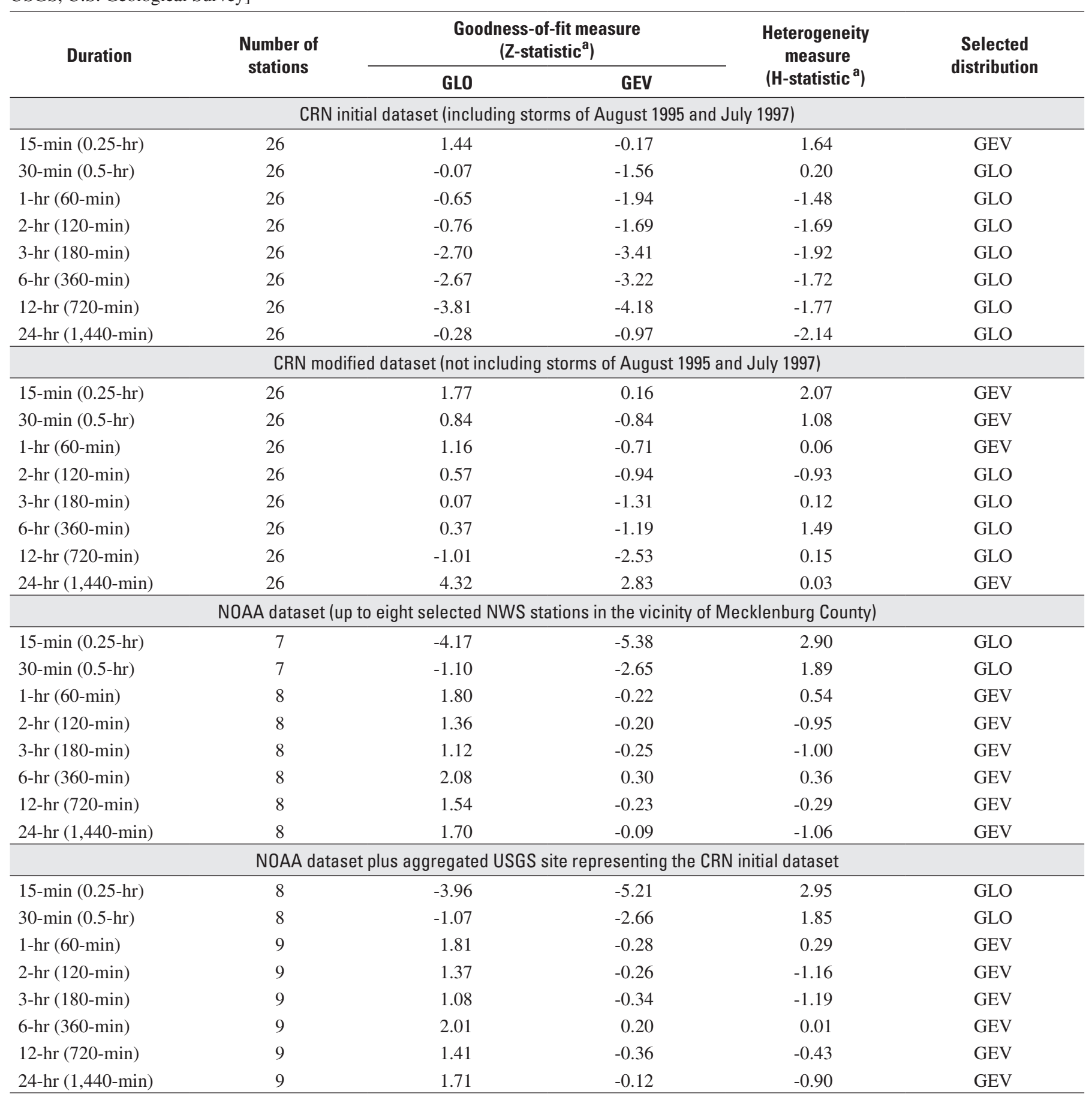

${ }^{\mathrm{a}}$ Hosking and Wallis (1993, 1997). 
and Wallis, 1993, 1997). Applying the second interpretation to the Z-statistic values (table 4) for the CRN initial dataset, the GEV distribution is judged appropriate for the 15-minute duration and the GLO distribution is judged appropriate for the remaining durations. The selected distributions for the durations in the three other datasets analyzed in this investigation are listed in table 4.

The selection of the GEV and GLO distributions is consistent with those selected in previous studies for storm durations up to 24 hours. In Texas, the GLO distribution was chosen as the most appropriate for 15-minute to 24-hour durations (Asquith, 1998). In Oklahoma, Tortorelli and others (1999) identified the GLO distribution as appropriate for the 15- and 30-minute and 1-hour durations, but the GEV distribution was selected for larger durations. Parrett (1997) selected the GEV distribution as the most satisfactory fit for the 2-, 6-, and 24-hour distributions studied in Montana. In Bonnin and others (2004, p. 36), the GEV distribution was chosen for Region 2, which includes Mecklenburg County, by using hourly data.

\section{Depth-Duration and Intensity-Duration Frequency Curves}

Using the selected distribution (table 4) for each duration (15 minutes to 24 hours) in each dataset, estimated precipitation depths (in inches) were computed for the 2-, 5-, 10-, 25-, 50-, 100-, and 500-year recurrence intervals (table 5). The precipitation depths then were expressed as precipitation intensity (in inches per hour) by using the corresponding value for duration. For comparison purposes, precipitation depths and intensity values derived by Hershfield (1961) and Bonnin and others (2004) for the NWS station at Charlotte Douglas Airport were tabulated (table 5). A visual comparison of the precipitation depths and intensity values also is provided for each of the recurrence intervals through a series of depthduration and intensity-duration frequency curves completed for each dataset and the NOAA data (figs. 7-13).
Visual examination of the precipitation-frequency curves for all recurrence intervals reveals that the largest range among computed precipitation values occurs between the CRN initial and CRN modified datasets (figs. 7-13), and the spread between these two curves generally increases in ascending order of recurrence intervals. For the 2-year recurrence interval, the percentage difference between corresponding precipitation depths in the two datasets for all durations is less than 15 percent. The percentage differences in the values for the 15- and 30-minute durations likewise are less than 15 percent at most all recurrence intervals (exception being about 29 percent for the 30-minute duration, 500-year recurrence interval). Beginning with the 1-hour duration and 5-year recurrence interval, however, percentage differences between many of the corresponding depths in the two datasets generally exceeded 15 percent, indicating that the presence of large annual maximum precipitation totals for 2 years (1995 and 1997) influenced the results. The 24-hour, 100-year precipitation depths estimated for the CRN initial and CRN modified datasets are 10.99 and 5.74 inches, respectively (table 5), which correspond to the $\mathrm{CRN}$ initial value being about 91 percent higher than the CRN modified value.

Although the frequency curves for the CRN initial and CRN modified datasets exhibit greater differences in increasing durations and recurrence intervals, the precipitation depths for the NOAA datasets (third and fourth) analyzed for this report exhibit a smaller degree of spread (figs. 7-13) and generally tended to straddle the midrange between the CRN datasets. As previously stated, the inclusion of the long-term, NOAA datasets for the vicinity of Mecklenburg County provided overall quality assurance of the results from the L-moment method applied to all datasets.

Percentage differences between precipitation frequencies computed for Charlotte Douglas Airport (Bonnin and others, 2004) and for the eight selected NWS stations (fig. 4; the third dataset) mostly are less than 15 percent. Although results among all datasets indicate varying levels of differences, comparable precipitation depths among most values computed for selected NWS stations and the estimates for Charlotte Douglas Airport (Bonnin and others, 2004) provide a general confirmation of results determined from each analysis. 


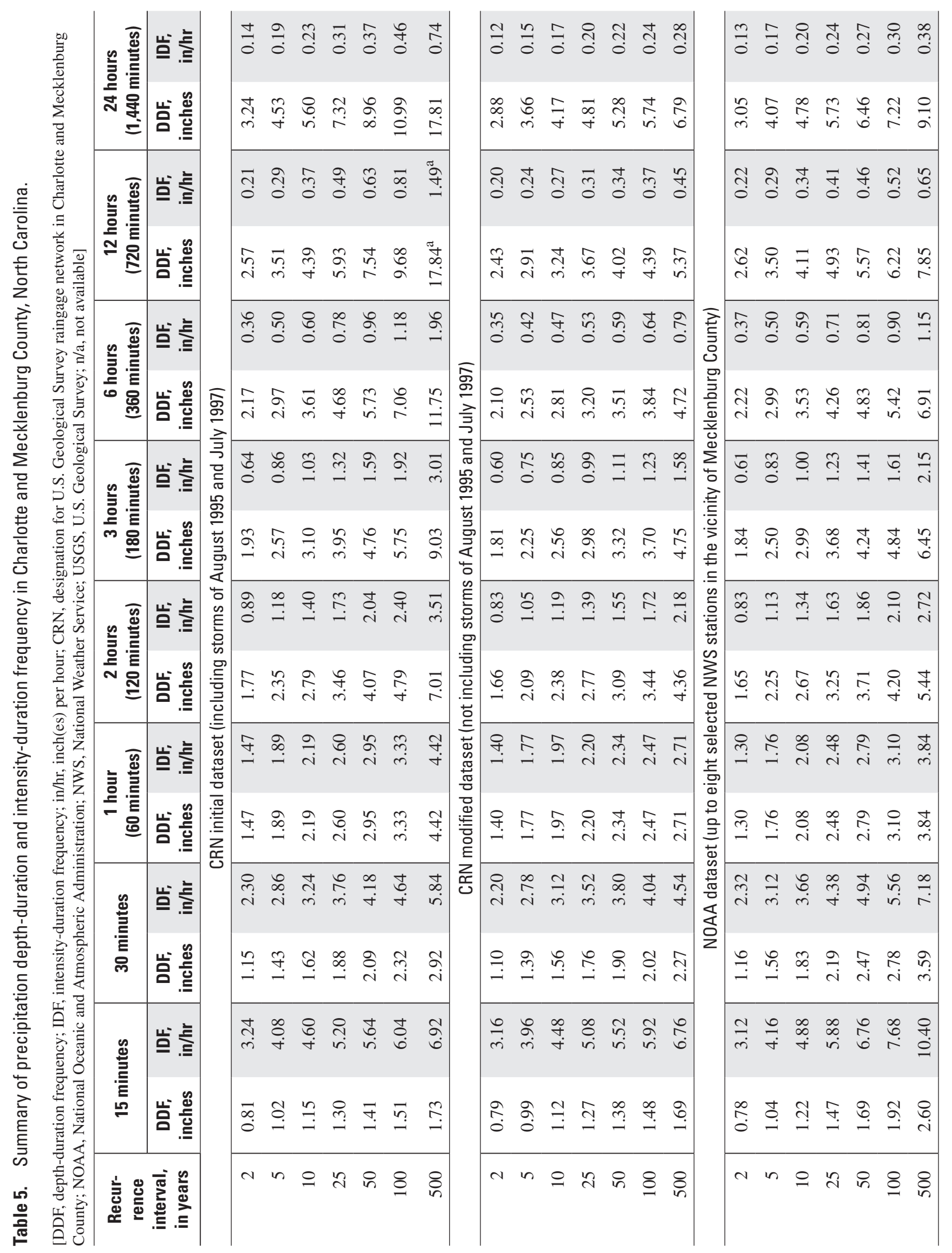




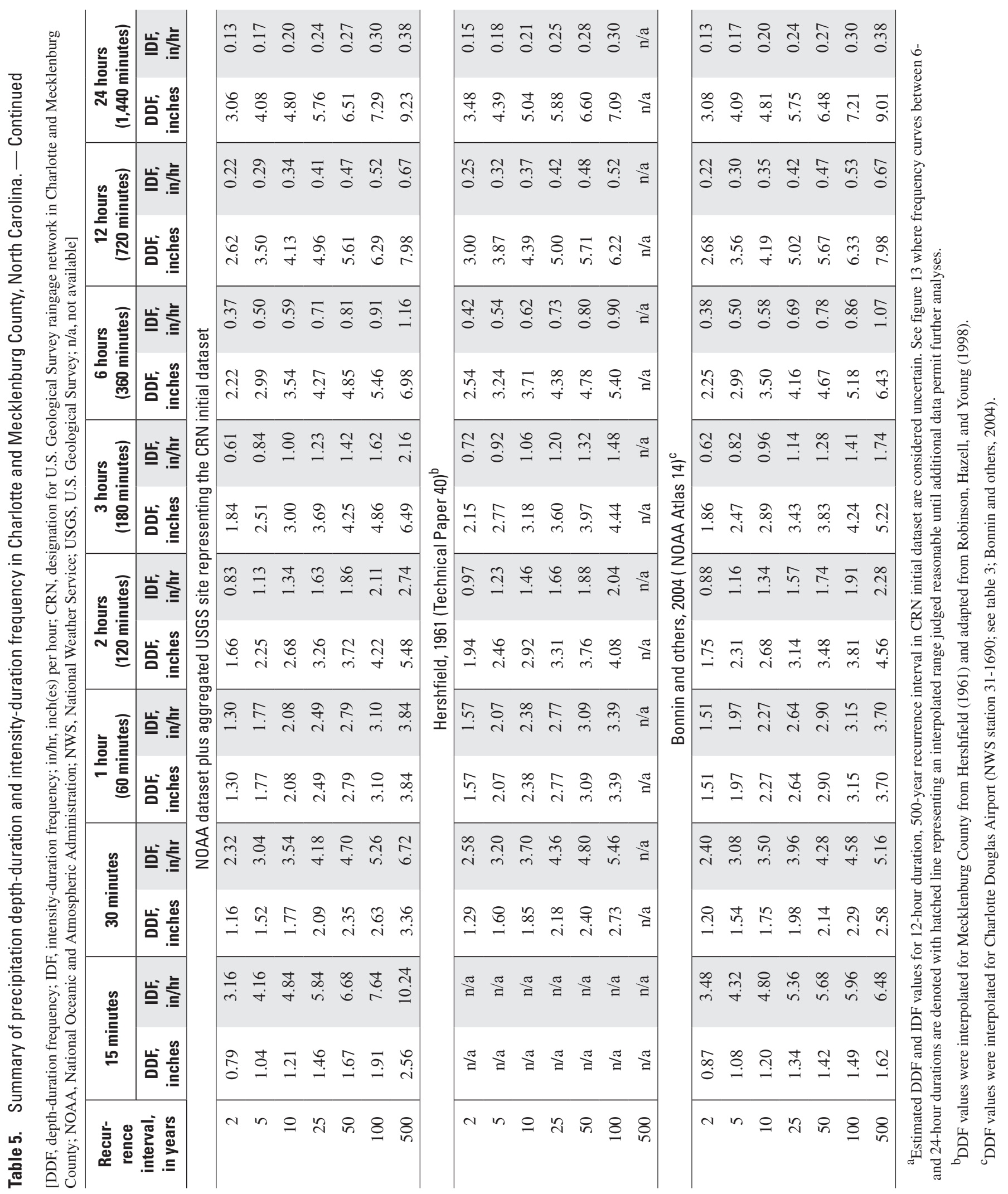



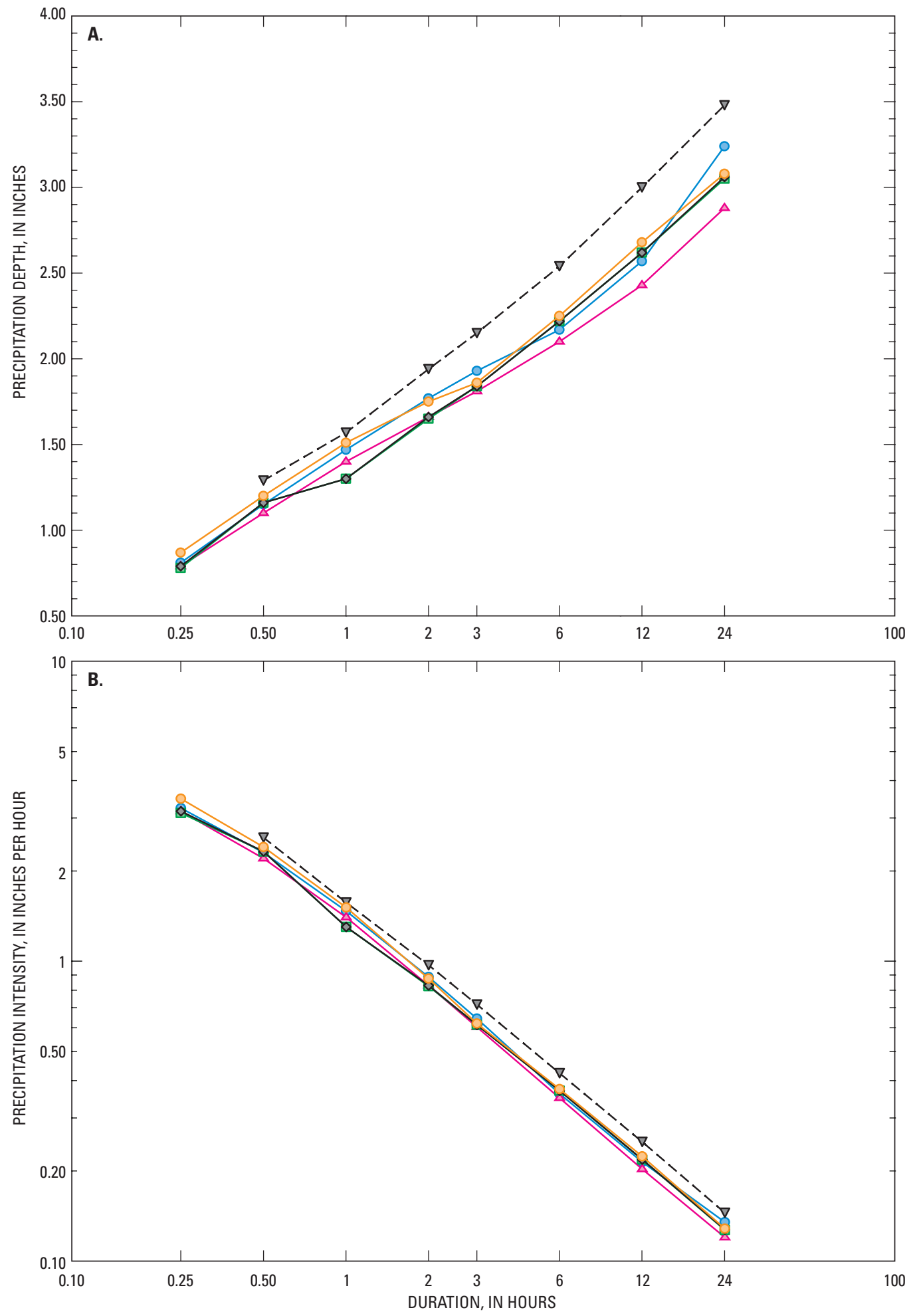

EXPLANATION

-O- CRN initial dataset (includes August 1995 and July 1997 storms)

$\triangle \smile$ CRN modified dataset (excludes August 1995 and July 1997 storms)

$-\square-$ Selected National Weather Service stations (up to eight selected sites)

$\neg$ Selected National Weather Service stations plus aggregated U.S. Geological Survey site

$-\nabla$ - Technical Paper 40 (Hershfield, 1961)

-O- Charlotte Douglas Airport, National Oceanic Atmospheric Administration Atlas 14 (Bonnin and others, 2004)

Figure 7. Precipitation (A) depth-duration and (B) intensity-duration frequency curves for the 2-year recurrence interval for Charlotte and Mecklenburg County, North Carolina. 

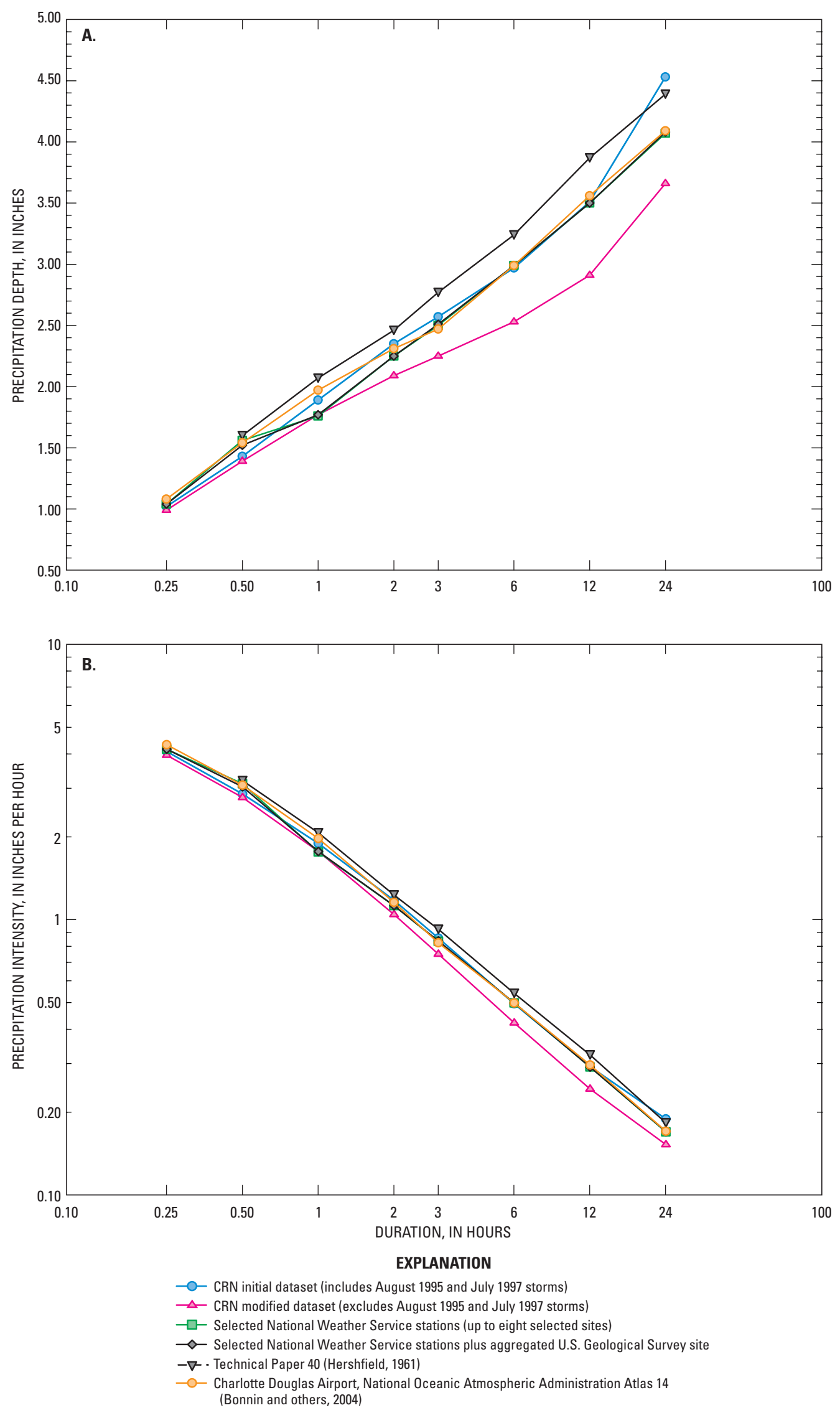

Figure 8. Precipitation $(A)$ depth-duration and $(B)$ intensity-duration frequency curves for the 5-year recurrence interval for Charlotte and Mecklenburg County, North Carolina. 

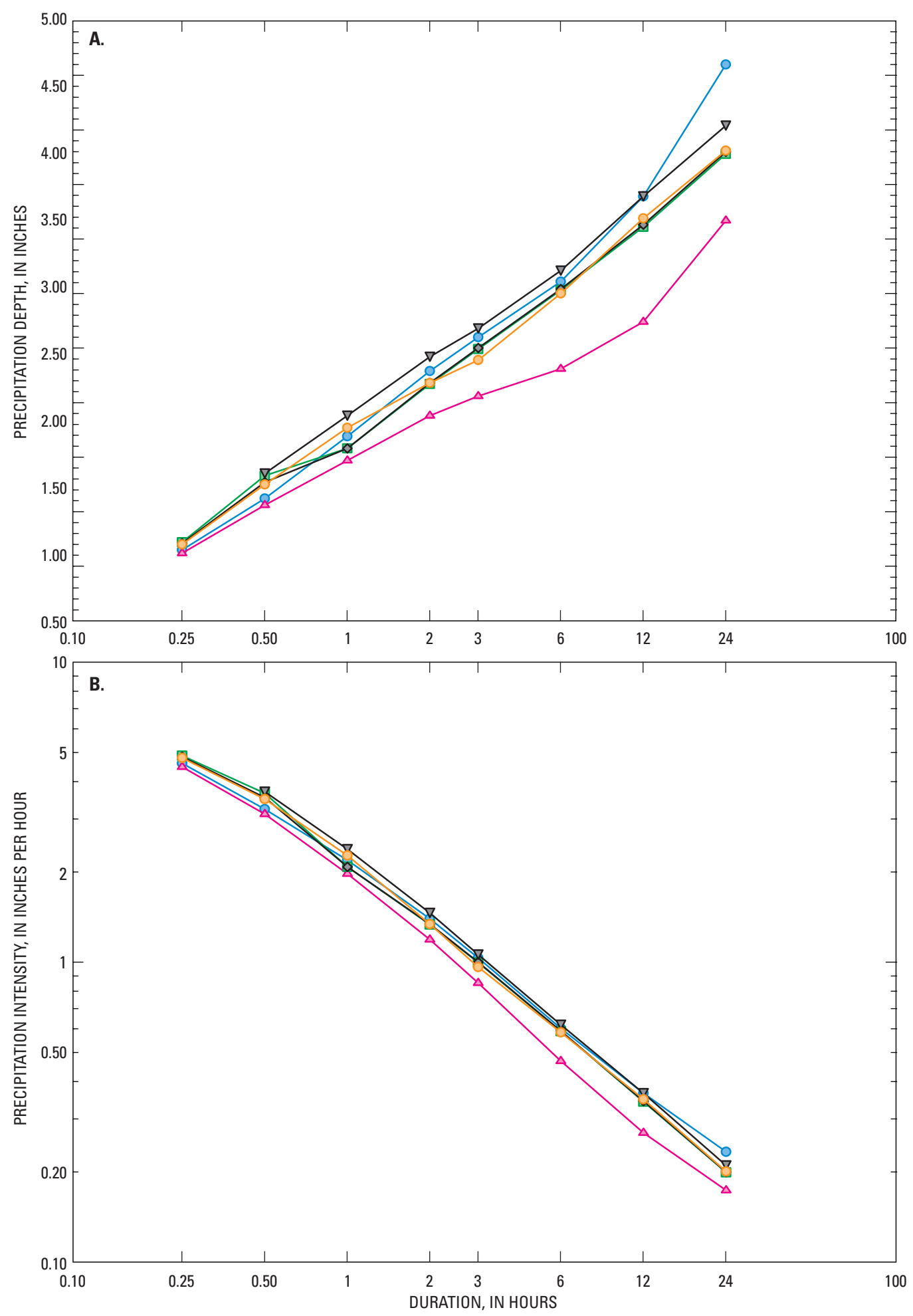

EXPLANATION

- - CRN initial dataset (includes August 1995 and July 1997 storms)

$\triangle$ CRN modified dataset (excludes August 1995 and July 1997 storms)

$-\square-$ Selected National Weather Service stations (up to eight selected sites)

$\prec$ Selected National Weather Service stations plus aggregated U.S. Geological Survey site

$-\nabla-$ - Technical Paper 40 (Hershfield, 1961)

- - Charlotte Douglas Airport, National Oceanic Atmospheric Administration Atlas 14 (Bonnin and others, 2004)

Figure 9. Precipitation (A) depth-duration and (B) intensity-duration frequency curves for the 10-year recurrence interval for Charlotte and Mecklenburg County, North Carolina. 

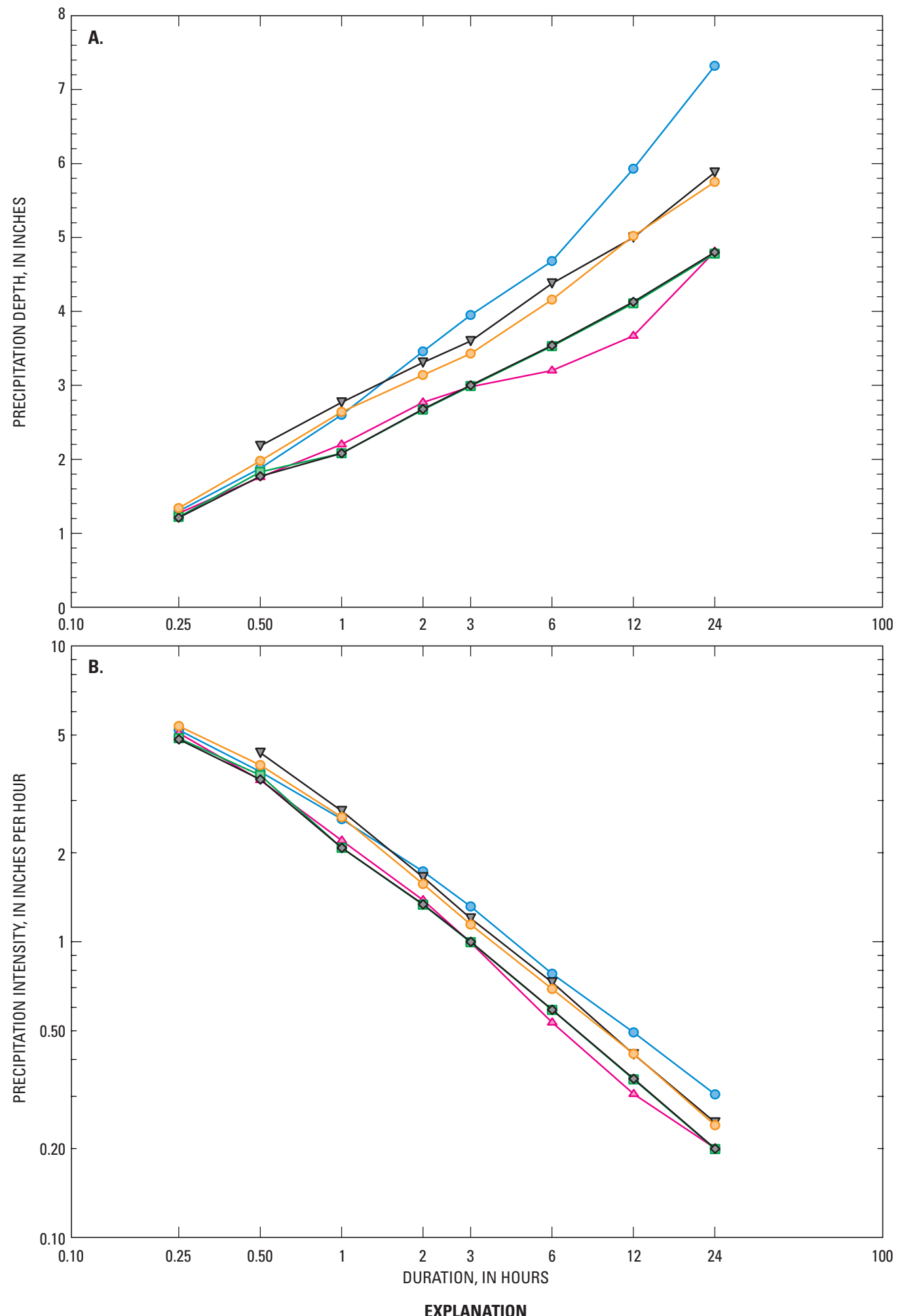

\footnotetext{
- - CRN initial dataset (includes August 1995 and July 1997 storms)

$\triangle \backsim$ CRN modified dataset (excludes August 1995 and July 1997 storms)

$-\square-$ Selected National Weather Service stations (up to eight selected sites)

$\multimap$ Selected National Weather Service stations plus aggregated U.S. Geological Survey site

$-\nabla$ - Technical Paper 40 (Hershfield, 1961)

-0 - Charlotte Douglas Airport, National Oceanic Atmospheric Administration Atlas 14

(Bonnin and others, 2004)
}

Figure 10. Precipitation $(A)$ depth-duration and $(B)$ intensity-duration frequency curves for the 25-year recurrence interval for Charlotte and Mecklenburg County, North Carolina. 

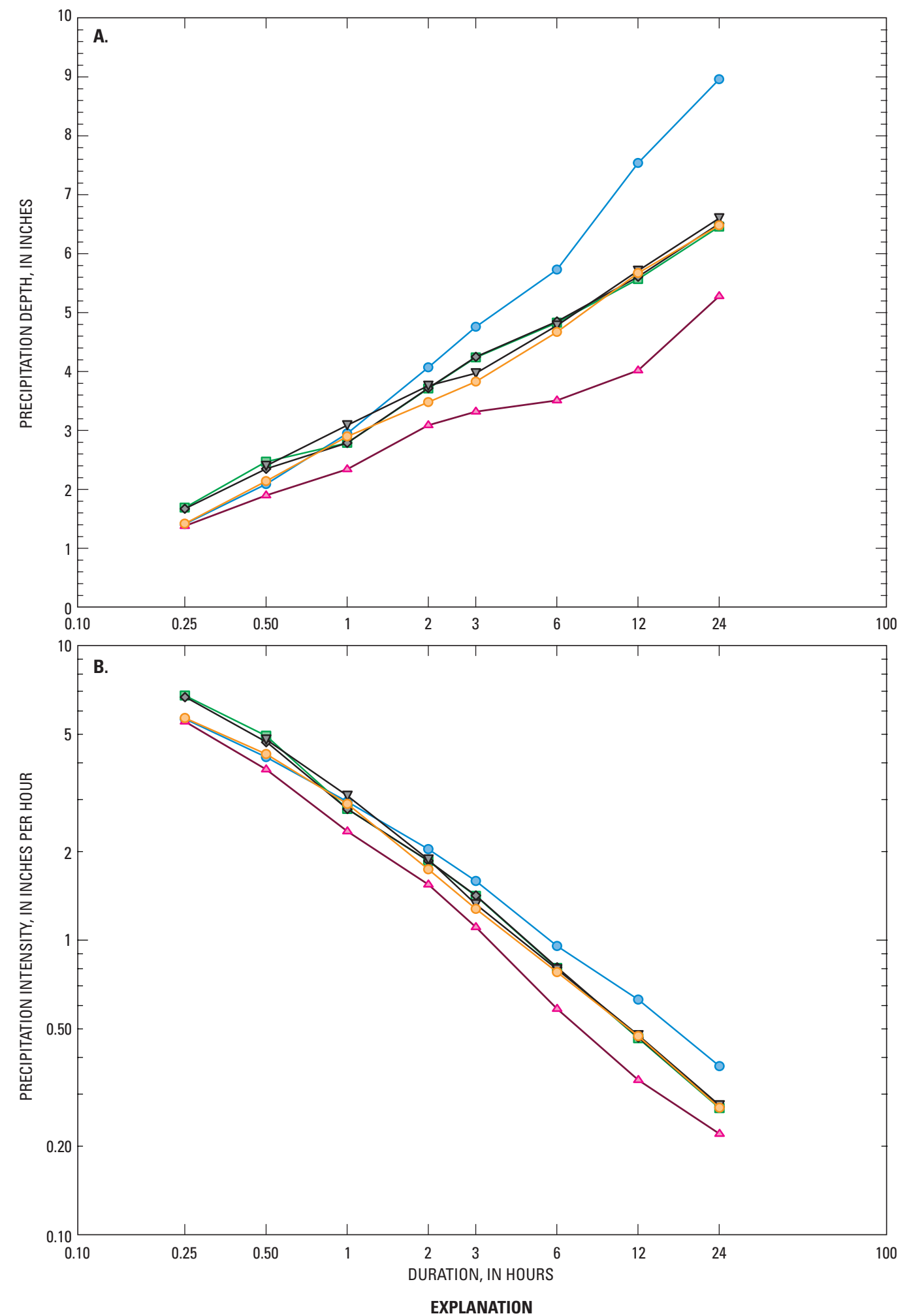

\footnotetext{
- - CRN initial dataset (includes August 1995 and July 1997 storms)

$\triangle$ CRN modified dataset (excludes August 1995 and July 1997 storms)

$\square-$ Selected National Weather Service stations (up to eight selected sites)

$\multimap$ Selected National Weather Service stations plus aggregated U.S. Geological Survey site

$-\nabla-$ Technical Paper 40 (Hershfield, 1961)

-O- Charlotte Douglas Airport, National Oceanic Atmospheric Administration Atlas 14

(Bonnin and others, 2004)
}

Figure 11. Precipitation (A) depth-duration and (B) intensity-duration frequency curves for the 50-year recurrence interval for Charlotte and Mecklenburg County, North Carolina. 

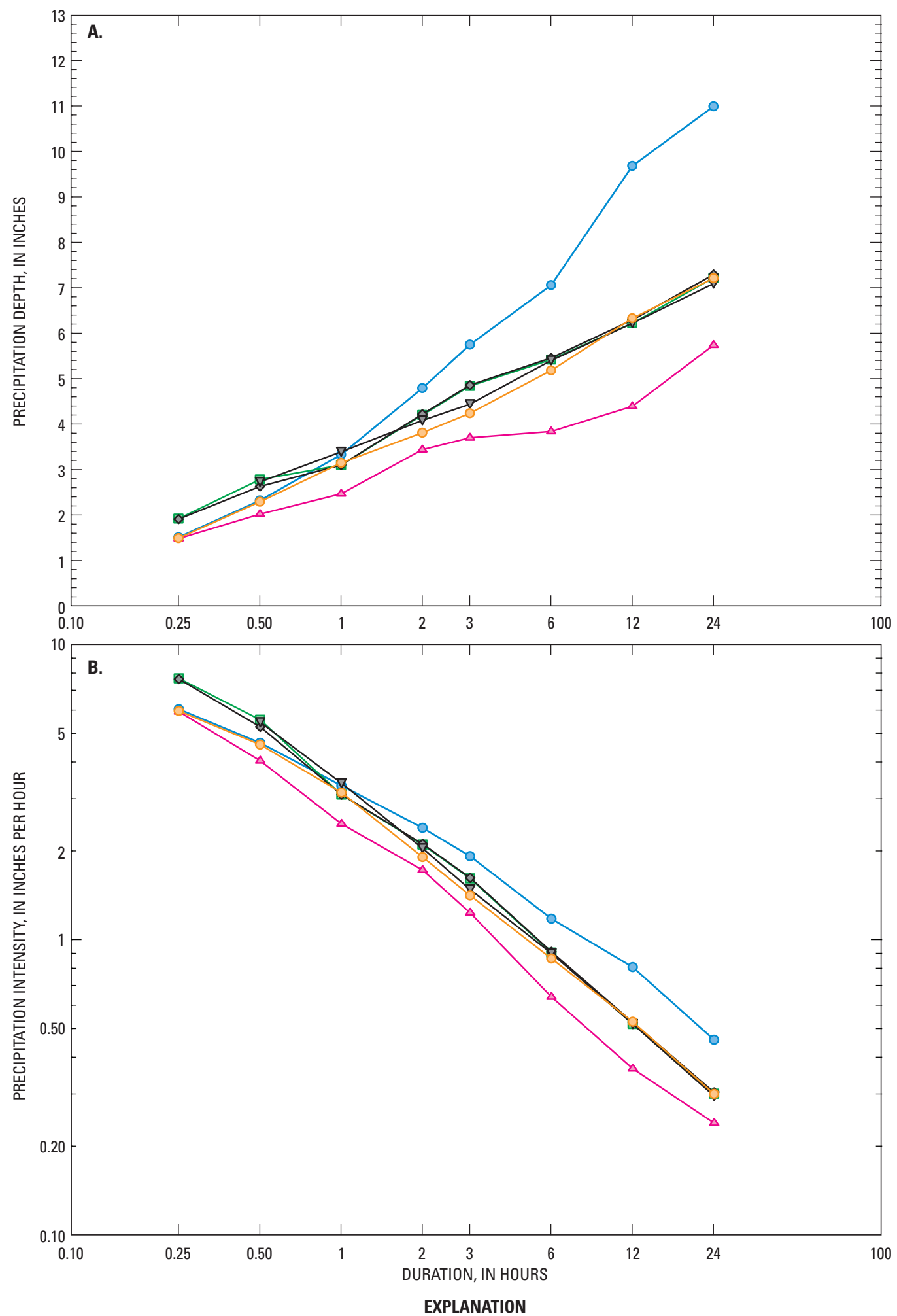

\footnotetext{
- - CRN initial dataset (includes August 1995 and July 1997 storms) $\triangle \sim$ CRN modified dataset (excludes August 1995 and July 1997 storms)

$-\square-$ Selected National Weather Service stations (up to eight selected sites)

$\multimap$ Selected National Weather Service stations plus aggregated U.S. Geological Survey site

$-\nabla$ - Technical Paper 40 (Hershfield, 1961)

-O- Charlotte Douglas Airport, National Oceanic Atmospheric Administration Atlas 14 (Bonnin and others, 2004)
}

Figure 12. Precipitation (A) depth-duration and $(B)$ intensity-duration frequency curves for the 100-year recurrence interval for Charlotte and Mecklenburg County, North Carolina. 


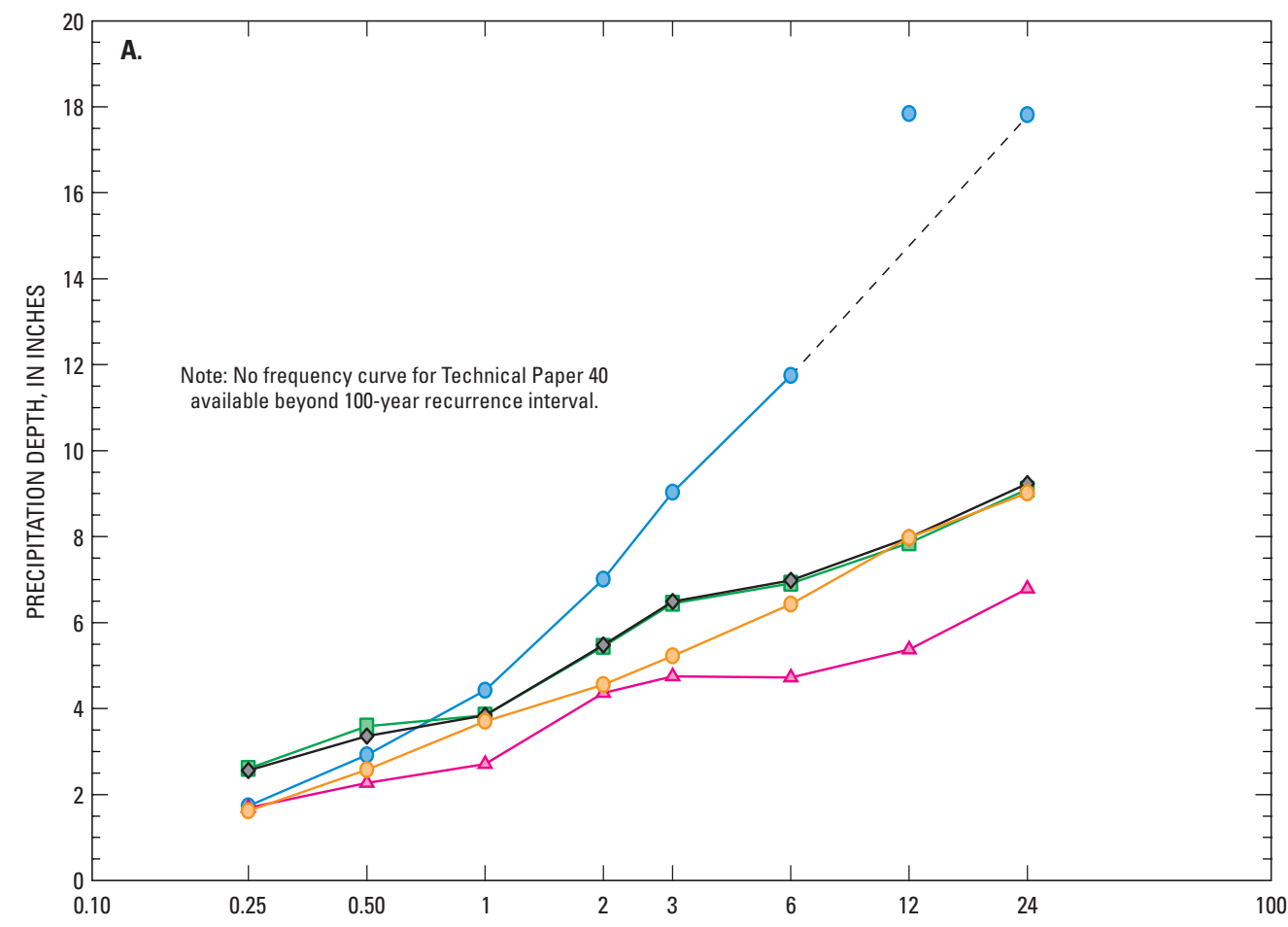

B.

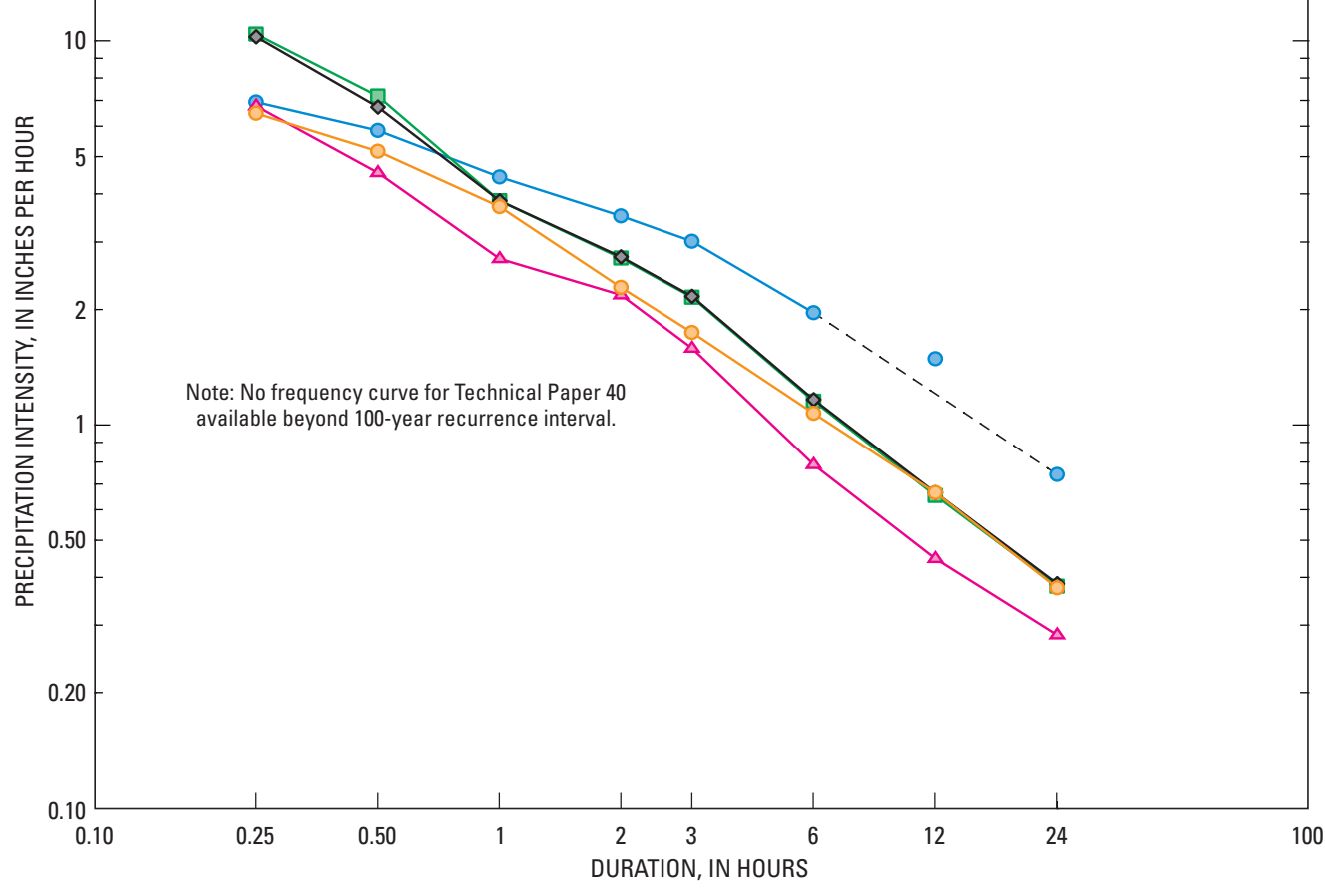

EXPLANATION

-O- CRN initial dataset (includes August 1995 and July 1997 storms

$\triangle$ CRN modified dataset (excludes August 1995 and July 1997 storms)

$-\square-$ Selected National Weather Service stations (up to eight selected sites)

$\multimap$ Selected National Weather Service stations plus aggregated U.S. Geological Survey site

$-\nabla \cdot$ - Technical Paper 40 (Hershfield, 1961)

- Charlotte Douglas Airport, National Oceanic Atmospheric Administration Atlas 14 (Bonnin and others, 2004)

- - - Interpolated curve for CRN initial dataset. Estimated 12-hour rainfall amount deemed uncertain (see table 5).

Figure 13. Precipitation $(A)$ depth-duration and $(B)$ intensity-duration frequency curves for the 500 year recurrence interval for Charlotte and Mecklenburg County, North Carolina. 
As previously discussed, the fourth dataset was developed to combine selected NWS stations in the vicinity of Mecklenburg County with an aggregated USGS site. Comparisons of precipitation depths between the fourth dataset and the CRN initial dataset indicate that percentage differences generally are less than 15 percent for durations less than 6 hours and for recurrence intervals less than 25 years. The estimated 24-hour, 100-year precipitation depth of 10.99 inches for the CRN initial dataset is about 51 percent higher than the corresponding value of 7.29 inches for the fourth dataset (table 5).

Some insight into the percentage differences can be obtained by examining box plots of the annual maximum 1- and 24-hour precipitation totals computed at selected USGS sites (CRN15 and CRN25) and NWS sites (Charlotte Douglas Airport (31-1690) and Mooresville 2 WNW (31-5814; tables 3, 6; fig. 14). For the selected USGS sites, the range in precipitation totals used in the CRN initial and CRN modified datasets are shown.

For the 1-hour duration, initial precipitation totals at USGS site CRN15 ranged from 0.98 (2002) to 3.55 (1997) inches with a median of 1.48 inches (table 6; fig. 14A) during the period of record (11 years). When modified to remove the rainfall totals associated with the August 1995 and July 1997 storms, totals ranged from 0.98 (2002) to 1.61 (2003) inches with a median of 1.33 inches. In comparison, 1-hour totals at the Charlotte Douglas Airport (NWS station 31-1690) ranged from 0.52 (2001) to 2.32 (1972) inches with a median of 1.14 inches during the 56-year period of record (table 6; fig. 14). Similar patterns occurred at USGS site CRN25 and at Mooresville (NWS station 31-5814), although the maximum 1-hour total at the Mooresville station is substantially higher (5.4 inches, measured on July 30, 1982; table 6; fig. 14). Thus, the interquartile ranges for the USGS sites, which have shorter periods of record, generally are higher than those for the NWS stations, which have much longer periods of record.

Similarly, 24-hour precipitation totals (table 6; fig. 14B) used in the CRN initial database analysis for USGS sites CRN15 and CRN25 are relatively higher than totals for the
NWS stations at Charlotte Douglas Airport and Mooresville. These patterns further confirm the analytical results of larger precipitation-frequency values for the USGS sites having short-term records when compared with those for the NWS stations with long-term records.

The wide range in results of the analyses completed on the four datasets presents an opportunity or challenge depending on how the frequency analyses are understood. With the availability of precipitation information in NOAA Atlas 14 (Bonnin and others, 2004), which is based on a larger sample of stations having long-term records, a determination of the precipitation-frequency values to use must be made by the user(s). The USGS raingage network in and surrounding Mecklenburg County is unique in terms of the density of precipitation data for a relatively small area.

Because a comparatively small sample from the USGS precipitation network may have been influenced by the occurrence of two large observations (1995 and 1997), the higher precipitation-frequency values from the $\mathrm{CRN}$ initial dataset may be considered biased. The occurrence of large or extreme events within short periods of time, however, raises the question of whether a shift in frequency characteristics may be occurring. Any dismissal of results from the analyses completed on the USGS networks because the results "seem too high" could lead to an underestimation of true frequency characteristics.

In the absence of further analyses, the use of the selected NWS stations with the aggregated USGS site (third dataset) can currently (2005) be considered appropriate for use in deriving frequency characteristics for Mecklenburg County. This dataset provides consideration of (1) the significant amount of precipitation data available through the USGS network, (2) some large rainfalls that have occurred in the county, and (3) NOAA precipitation data based on longer periods of record. Nevertheless, users of the results of this analysis must recognize that actual frequency characteristics could be somewhat higher, although quantification of any such differences will require additional data. 
Table 6. Annual maximum 1- and 24-hour precipitation totals for selected U.S. Geological Survey and National Weather Service precipitation sites in or near Mecklenburg County, North Carolina.

[USGS, U.S. Geological Survey; SR, secondary road; NWS, National Weather Service. Precipitation totals determined for each calendar year. For each site and each duration, precipitation totals are listed from minimum to maximum]

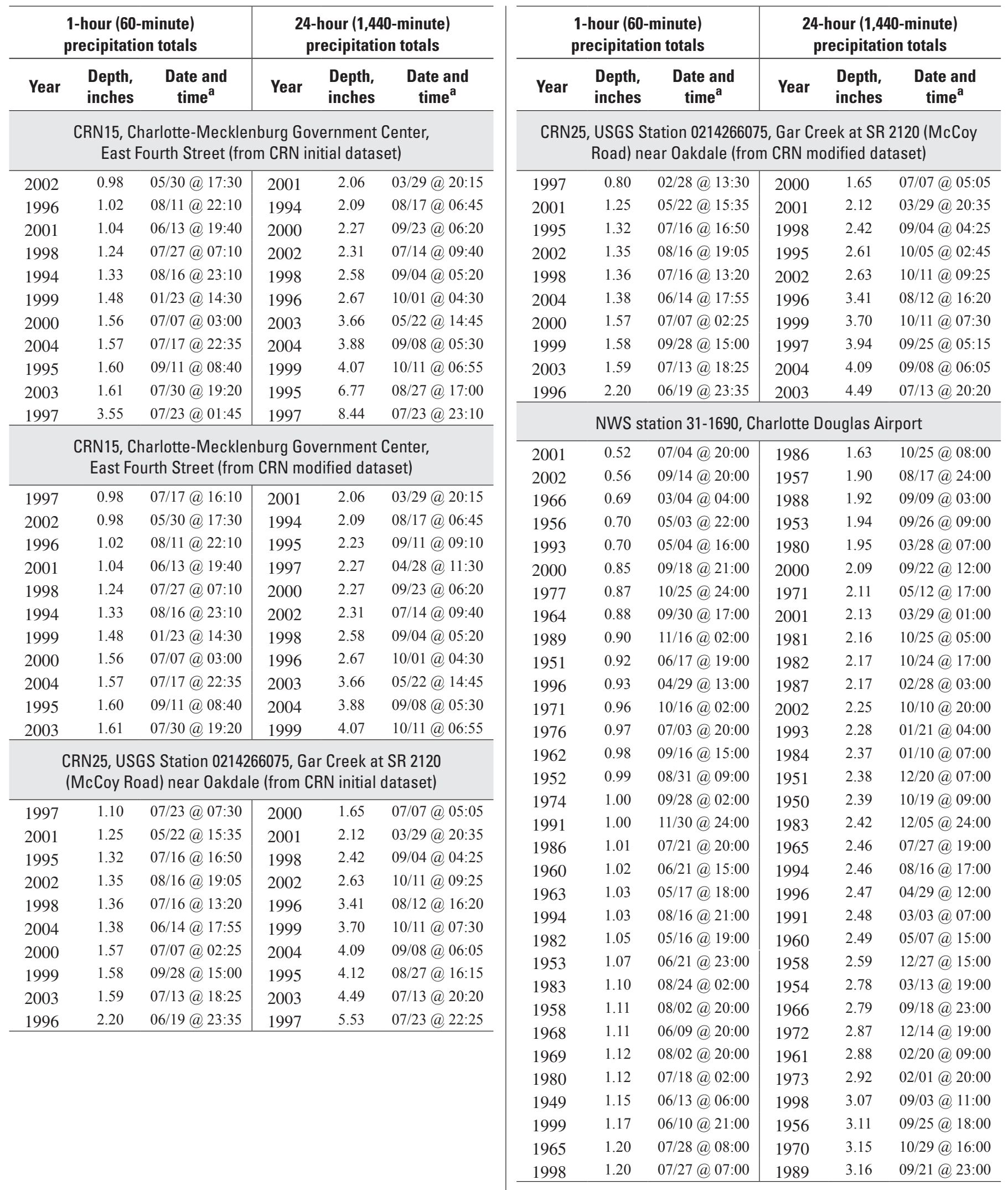


Table 6. Annual maximum 1- and 24-hour precipitation totals for selected U.S. Geological Survey and National Weather Service precipitation sites in or near Mecklenburg County, North Carolina. — Continued

[USGS, U.S. Geological Survey; SR, secondary road; NWS, National Weather Service. Precipitation totals determined for each calendar year. For each site and each duration, precipitation totals are listed from minimum to maximum]

\begin{tabular}{|c|c|c|c|c|c|}
\hline \multicolumn{3}{|c|}{$\begin{array}{l}\text { 1-hour (60-minute) } \\
\text { precipitation totals }\end{array}$} & \multicolumn{3}{|c|}{$\begin{array}{c}\text { 24-hour (1,440-minute) } \\
\text { precipitation totals }\end{array}$} \\
\hline Year & $\begin{array}{l}\text { Depth, } \\
\text { inches }\end{array}$ & $\begin{array}{c}\text { Date and } \\
\text { time }^{a}\end{array}$ & Year & $\begin{array}{l}\text { Depth, } \\
\text { inches }\end{array}$ & $\begin{array}{l}\text { Date and } \\
\text { time }^{a}\end{array}$ \\
\hline \multicolumn{6}{|c|}{ NWS station 31-1690, Charlotte Douglas Airport (continued) } \\
\hline 1988 & 1.22 & 07/21@ 20:00 & 1969 & 3.21 & 08/02@19:00 \\
\hline 1950 & 1.27 & 06/30@23:00 & 1968 & 3.28 & 06/08@24:00 \\
\hline 1984 & 1.28 & 08/12@ 24:00 & 1963 & 3.34 & 09/28@11:00 \\
\hline 1995 & 1.28 & 05/01@ 22:00 & 1964 & 3.34 & 10/15@13:00 \\
\hline 1981 & 1.33 & 07/16@19:00 & 1962 & 3.57 & 01/05@22:00 \\
\hline 1990 & 1.33 & 10/22@19:00 & 1985 & 3.59 & 08/16@17:00 \\
\hline 1957 & 1.35 & 08/17@24:00 & 1975 & 3.67 & 05/03@02:00 \\
\hline 1961 & 1.38 & 06/05@13:00 & 1952 & 3.70 & 08/30@20:00 \\
\hline 1973 & 1.41 & 07/03@18:00 & 1949 & 3.78 & 06/13@02:00 \\
\hline 2003 & 1.43 & 08/04@19:00 & 1977 & 3.83 & 03/29@13:00 \\
\hline 1959 & 1.49 & 08/26@21:00 & 1974 & 3.85 & 09/05@23:00 \\
\hline 1954 & 1.51 & 04/25@19:00 & 1999 & 4.30 & 10/10@09:00 \\
\hline 1970 & 1.57 & 07/21@18:00 & 1992 & 4.38 & 09/27@07:00 \\
\hline 1985 & 1.60 & 06/07@ 18:00 & 1967 & 4.40 & 08/22@13:00 \\
\hline 1992 & 1.63 & 09/28@ 04:00 & 1979 & 4.45 & 09/29@14:00 \\
\hline 1955 & 1.65 & 10/01@01:00 & 1978 & 4.52 & 08/03@16:00 \\
\hline 1967 & 1.66 & 08/22@13:00 & 2003 & 4.53 & 05/21@15:00 \\
\hline 1987 & 1.72 & 08/02@18:00 & 1959 & 4.74 & 09/29@09:00 \\
\hline 1975 & 1.77 & 08/27@20:00 & 1955 & 4.83 & 09/30@08:00 \\
\hline 1997 & 1.78 & 07/23@02:00 & 1995 & 5.30 & 08/26@18:00 \\
\hline 1979 & 1.81 & 09/30@03:00 & 1976 & 5.34 & 10/08@10:00 \\
\hline 1978 & 2.07 & 08/03@16:00 & 1990 & 5.46 & 10/10@15:00 \\
\hline 1948 & 2.32 & 08/03@18:00 & 1948 & 6.41 & 08/03@12:00 \\
\hline 1972 & 2.32 & 07/26@18:00 & 1997 & 6.88 & 07/23@01:00 \\
\hline \multicolumn{6}{|c|}{ NWS station 31-5814, Mooresville 2 WNW (Iredell County) } \\
\hline 1976 & 0.69 & 07/23@ 20:00 & 2000 & 1.5 & 09/19@05:00 \\
\hline 2000 & 0.70 & 09/25@06:00 & 1986 & 1.6 & 12/23@14:00 \\
\hline 1992 & 0.80 & 08/13@15:00 & 1950 & 1.72 & 05/14@07:00 \\
\hline 1999 & 0.80 & 08/25@04:00 & 1980 & 2.00 & 09/24@20:00 \\
\hline 2002 & 0.80 & 07/26@ 09:00 & 1996 & 2.00 & 08/11@20:00 \\
\hline 1964 & 0.83 & 01/01@12:00 & 2001 & 2.00 & 03/29@05:00 \\
\hline 1968 & 0.85 & 07/18@17:00 & 2002 & 2.10 & 07/25@21:00 \\
\hline 1970 & 0.85 & 08/01@ 01:00 & 1968 & 2.14 & 03/11@20:00 \\
\hline 1966 & 0.90 & 07/16@ 05:00 & 1958 & 2.19 & 12/27@15:00 \\
\hline 1998 & 0.90 & 06/10@ 04:00 & 1989 & 2.30 & 08/01@12:00 \\
\hline 1950 & 0.91 & 04/30@23:00 & 1998 & 2.30 & 06/09@12:00 \\
\hline 1977 & 0.91 & 09/08@ 04:00 & 1966 & 2.36 & 08/13@13:00 \\
\hline 1958 & 1.00 & 08/03@19:00 & 1988 & 2.40 & 11/27@08:00 \\
\hline 1961 & 1.00 & 06/12@18:00 & 1974 & 2.47 & 01/20@18:00 \\
\hline 1983 & 1.00 & 06/22@02:00 & 1969 & 2.50 & 06/13@20:00 \\
\hline 1988 & 1.00 & 09/23@ 01:00 & 1984 & 2.50 & 08/13@03:00 \\
\hline 1990 & 1.00 & 08/05@ 21:00 & 1965 & 2.56 & 03/17@07:00 \\
\hline 1993 & 1.00 & 09/16@22:00 & 1983 & 2.60 & 11/24@04:00 \\
\hline 1953 & 1.02 & 03/23@19:00 & 1955 & 2.67 & 08/14@08:00 \\
\hline
\end{tabular}

\begin{tabular}{|c|c|c|c|c|c|}
\hline \multicolumn{3}{|c|}{$\begin{array}{l}\text { 1-hour (60-minute) } \\
\text { precipitation totals }\end{array}$} & \multicolumn{3}{|c|}{$\begin{array}{c}\text { 24-hour }(1,440 \text {-minute }) \\
\text { precipitation totals }\end{array}$} \\
\hline Year & $\begin{array}{l}\text { Depth, } \\
\text { inches }\end{array}$ & $\begin{array}{l}\text { Date and } \\
\text { time }^{a}\end{array}$ & Year & $\begin{array}{l}\text { Depth, } \\
\text { inches }\end{array}$ & $\begin{array}{l}\text { Date and } \\
\text { time }^{a}\end{array}$ \\
\hline \multicolumn{6}{|c|}{ NWS station 31-5814, Mooresville 2 WNW (Iredell County) (continued } \\
\hline 1965 & 1.05 & 08/18@16:00 & 1954 & 2.80 & 10/15@01:00 \\
\hline 1954 & 1.07 & 02/21@04:00 & 1967 & 2.80 & 07/07@07:00 \\
\hline 1962 & 1.08 & 06/02@18:00 & 1972 & 2.86 & 06/20@12:00 \\
\hline 1986 & 1.10 & 07/01@18:00 & 1975 & 2.87 & 09/01@21:00 \\
\hline 1996 & 1.10 & 07/25@19:00 & 1960 & 2.90 & 08/31@20:00 \\
\hline 2001 & 1.10 & 06/22@15:00 & 1999 & 2.90 & 10/10@09:00 \\
\hline 1957 & 1.16 & 11/19@06:00 & 1973 & 2.96 & 08/02@21:00 \\
\hline 1978 & 1.20 & 07/02@19:00 & 1953 & 2.98 & 03/23@06:00 \\
\hline 1994 & 1.20 & 05/15@19:00 & 1993 & 3.00 & 03/23@15:00 \\
\hline 1995 & 1.20 & 07/06@20:00 & 2003 & 3.00 & 03/20@02:00 \\
\hline 1974 & 1.21 & 08/03@17:00 & 1951 & 3.01 & 12/20@12:00 \\
\hline 1973 & 1.28 & 05/28@01:00 & 1991 & 3.10 & 03/29@02:00 \\
\hline 1972 & 1.33 & 07/29@17:00 & 1963 & 3.15 & 07/28@20:00 \\
\hline 1987 & 1.40 & 04/15@08:00 & 1957 & 3.18 & 09/16@15:00 \\
\hline 1989 & 1.40 & 07/31@19:00 & 1949 & 3.20 & 10/30@06:00 \\
\hline 1960 & 1.46 & 07/23@19:00 & 1992 & 3.20 & 10/04@06:00 \\
\hline 1979 & 1.50 & 05/12@20:00 & 1994 & 3.20 & 08/16@22:00 \\
\hline 1951 & 1.56 & 07/04@21:00 & 1970 & 3.32 & 08/09@18:00 \\
\hline 1975 & 1.60 & 06/18@17:00 & 1961 & 3.39 & 06/21@04:00 \\
\hline 1952 & 1.66 & 08/01@21:00 & 1978 & 3.60 & 05/04@04:00 \\
\hline 1949 & 1.68 & 08/15@24:00 & 1979 & 3.60 & 09/04@21:00 \\
\hline 1980 & 1.70 & 07/18@01:00 & 1995 & 3.60 & 08/26@18:00 \\
\hline 1956 & 1.71 & 07/28@21:00 & 1952 & 3.68 & 03/03@08:00 \\
\hline 1955 & 1.75 & 07/19@22:00 & 1971 & 3.74 & 08/22@13:00 \\
\hline 1969 & 1.77 & 06/13@22:00 & 1962 & 3.89 & 11/09@01:00 \\
\hline 1967 & 2.00 & 08/04@15:00 & 1985 & 4.00 & 08/16@17:00 \\
\hline 1981 & 2.00 & 09/05@14:00 & 1977 & 4.30 & 09/07@17:00 \\
\hline 1959 & 2.08 & 08/26@19:00 & 1987 & 4.30 & 04/15@03:00 \\
\hline 1985 & 2.10 & 08/24@18:00 & 1981 & 4.40 & 09/05@03:00 \\
\hline 1991 & 2.10 & 06/16@18:00 & 1997 & 4.60 & 07/23@10:00 \\
\hline 2003 & 2.10 & 08/10@20:00 & 1964 & 4.70 & 10/04@04:00 \\
\hline 1997 & 2.20 & 06/12@18:00 & 1959 & 4.74 & 09/29@12:00 \\
\hline 1971 & 2.30 & 10/05@16:00 & 1976 & 4.86 & 10/08@07:00 \\
\hline 1984 & 2.30 & 08/13@14:00 & 1990 & 5.30 & 10/10@16:00 \\
\hline 1963 & 2.66 & 07/28@21:00 & 1956 & 5.48 & 09/25@21:00 \\
\hline 1982 & 5.40 & 07/30@10:00 & 1982 & 6.20 & 07/30@10:00 \\
\hline
\end{tabular}

${ }^{\mathrm{a}}$ For USGS precipitation sites, the time is the ending time (for example, the 60-minute period ending at 12:00). For NWS precipitation stations, the time is the beginning of the time period (for example, the 24-hour period beginning at 12:00). The difference in how the time periods are reported reflects the manner in which the maximum totals were compiled during this investigation. Such differences, however, do not influence the outcome of the frequency analyses. 

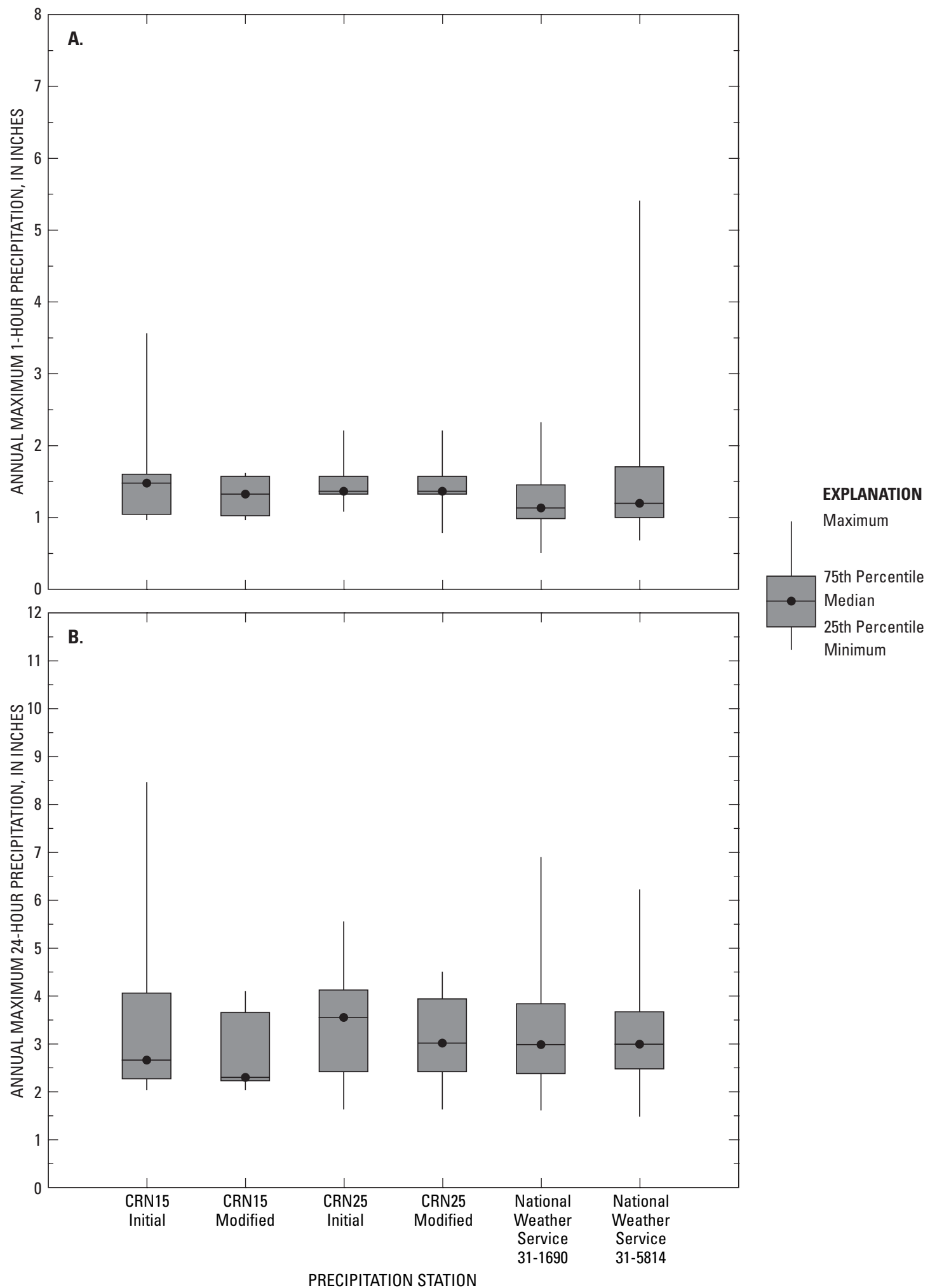

Minimum

EXPLANATION

CRN15 - Charlotte-Mecklenburg Government Center (11 observations)

CRN25 - U.S. Geological Survey station 0214266075 Gar Creek at SR 2120 (McCoy Road) near Oakdale (10 observations)

National Weather Service 31-1690 - Charlotte Douglas Airport (56 observations)

National Weather Service 31-5814 - Mooresville 2 WNW (55 observations)

Figure 14. Annual maximum (A) 1-hour (60-minute) and (B) 24-hour (1,440-minute) precipitation distributions at selected U.S. Geological Survey and National Weather Service precipitation stations in or near Mecklenburg County, North Carolina. 


\section{Summary}

The characterization of precipitation frequency is an important component in hydrologic investigations and engineering design. Hydrologists use precipitation-frequency information to develop models that help in the prediction of runoff and flood inundation, and engineers use the information to make decisions concerning the size of hydraulic structures, such as culverts and bridges.

Since 1963, the U.S. Geological Survey (USGS) has collected precipitation data at various locations in Charlotte and Mecklenburg County. In October 1992, the USGS, in cooperation with the city of Charlotte and Mecklenburg County, began to provide wider areal coverage of the county by installing additional precipitation sites primarily within the city limits of Charlotte. By the mid- and late-1990s, the network of sites provided data from most areas of the county and immediate surrounding areas. By the end of 2004, data were being collected at more than 70 sites, 27 of which had at least 10 years of record. While most of these sites are located within the Charlotte city limits, the spatial distribution of the sites provides countywide coverage for assessing the frequency of annual maximum precipitation totals. After examining periods of missing record, 1 of the 27 sites was eliminated, leaving a total of 26 USGS precipitation sites in the county for use in the analyses to determine frequency of annual maximum precipitation totals for durations of 15 and 30 minutes; $1,2,3,6,12$, and 24 hours; and for recurrence intervals of $2,5,10,25,50,100$, and 500 years.

The data compiled for this study indicate that maximum precipitation values for 2 particular years generally were much greater than those for the other years because of extremely large rainfall amounts associated with storms in August 1995 and July 1997 that caused major flooding in Mecklenburg County. The presence of two unusually large values in the relatively small sample of precipitation totals led to concern that statistical results may be influenced significantly by extremely large values in the sample. To determine the effects of large precipitation totals during 1995 and 1997, annual maximum precipitation values at the USGS sites were computed for two datasets - the CRN initial dataset, which included the August 1995 and July 1997 storm totals, and the CRN modified dataset, which excluded the largest precipitation values for these two storms.

To further investigate the effects of relatively short periods of record at the USGS sites, annual maximum precipitation totals (available through December 2003) for eight selected long-term National Weather Service (NWS) precipitation stations in the vicinity of Mecklenburg County were compiled into a third dataset for durations from 15 minutes to 24 hours. The resulting dataset consists of seven stations for the 15- and 30-minute durations and eight stations for the 1- to 24-hour durations (no quarterly precipitation data were available for the NWS station at Charlotte Douglas Airport). The periods of record for the quarterly (15-minute) data ranged from 24 to 33 years at the eight selected stations, and the period of record for the hourly data generally was about 55 years.

A fourth dataset was developed to combine the selected NWS stations in the vicinity of Mecklenburg County with an aggregated USGS site. This aggregated site was created by using the regional L-moment method to simulate one set of site statistics. Regional L-moment statistics computed for each duration in the CRN initial dataset were combined with the individual L-moment statistics for the NWS stations. This resulted in a sample of eight stations for the 15- and 30-minute durations (again, no quarterly precipitation data were available for the NWS station at Charlotte Douglas Airport) and nine stations for the 1- to 24-hour durations. Including the National Oceanic and Atmospheric Administration (NOAA) datasets in this investigation allowed the analysis of long-term precipitation record in the vicinity of Mecklenburg County and provided an overall quality-assurance check of the L-moment method applied to all datasets.

The L-moment method used in this report is the collective group of statistical techniques used in the analyses of annual maximum precipitation totals to compute the regional weighted L-moment statistics for each duration. The L-moment method allows for the computation of statistics that are more useful than the conventional-moments method in selecting the most appropriate probability distribution to describe precipitation frequency. The L-moment method provides the means of estimating the shape of the distribution along with the uncertainty of the estimates and also provides the ability to check for homogeneity among subsets of data within a broad study area or a smaller homogeneous region.

Regional frequency analysis generally involves subdividing sites spread across a broad region into smaller groups having similar frequency distributions as a result of common climatic characteristics or hydrologic factors, such as sites in mountainous regions or coastal regions. Because the geographical extent of Mecklenburg County is small relative to the size of regions commonly used in regionalization studies, however, the sites in this study were not subdivided into smaller groups.

In the L-moment ratio diagrams constructed for this investigation, the data for the corresponding weighted mean of L-skew $\left(\tau_{3}\right)$ and L-Kurtosis $\left(\tau_{4}\right)$ computed from the CRN initial dataset generally plotted between the generalized logistic and generalized extreme-value distributions. This trend was supported in similar L-moment ratio diagrams for the other three datasets analyzed in this investigation.

Using the generalized logistic or generalized extremevalue distribution for each duration (15 minutes to 24 hours) in each dataset, estimated precipitation depths (in inches) were computed for the 2-, 5-, 10-, 25-, 50-, 100-, and 500-year recurrence intervals. The precipitation depths were then expressed as precipitation intensity (in inches per hour) using the corresponding value for duration. Examination of the precipitation-frequency curves in ascending order of recurrence intervals resulted in a generally increasing spread 
between the curves for the CRN initial and CRN modified datasets. Beginning with the 60-minute duration and 5-year recurrence interval, percentage differences between many of the corresponding depths in the two datasets exceeded 15 percent, indicating that the presence of large annual maximum precipitation totals for 1995 and 1997 influenced the results in the CRN initial dataset. The 24-hour, 100-year precipitation depths estimated for the CRN initial and CRN modified datasets are 10.99 and 5.74 inches, respectively, which corresponds to the rainfall values in the CRN initial dataset being about 91 percent higher than in the CRN modified dataset.

The precipitation depths for the NOAA datasets had a smaller degree of spread than the frequency curves for the CRN initial and CRN modified datasets and generally tended to straddle the midrange between the CRN datasets. Comparisons between precipitation frequencies computed for the Charlotte Douglas Airport station and the eight selected NWS stations (third dataset) were favorable, and percentage differences between most corresponding depths were less than 15 percent.

Comparisons of precipitation depths between the fourth dataset (selected NWS stations plus an aggregated USGS site) and the CRN initial dataset indicate that percentage differences were generally less than 15 percent for durations less than 6 hours and recurrence intervals less than 25 years. The estimated 24-hour, 100-year precipitation depth of 10.99 inches for the $\mathrm{CRN}$ initial dataset is about 51 percent higher than the corresponding value of 7.29 inches for the fourth dataset.

Insight into the percentage differences of the annual maximum 1- and 24-hour precipitation totals computed for selected USGS (CRN15 and CRN25) and NWS (Charlotte Douglas Airport and Mooresville 2 WNW) stations was obtained by examining box plots of the data. The overall ranges in precipitation totals for the USGS sites during the short periods of record were relatively higher than those for the NWS stations, which have much longer periods of record. This confirmed the larger precipitation-frequency values for the USGS sites having short-term records compared with those for the NWS stations with long-term records.

Because of the small sample size available from the USGS precipitation network, which was influenced by the occurrence of two rainfalls in 1995 and 1997, it can be interpreted that frequency characteristics derived from the CRN initial dataset were influenced by the presence of the 1995 and 1997 storms. Resolution of this issue can best be addressed with additional data. In the absence of further analyses, it can be concluded that use of the third dataset-selected NWS stations with the aggregated USGS site-can currently (2005) be considered appropriate for use in deriving frequency characteristics for Mecklenburg County. This dataset provides consideration of (1) the significant amount of precipitation data, including some large rainfalls that have occurred in the county, and (2) NOAA precipitation data based on longer periods of record.

\section{Selected References}

Asquith, W.H., 1998, Depth-duration frequency of precipitation for Texas: U.S. Geological Survey Water-Resources Investigations Report 98-4044, 67 p., 1 app., 1 pl.

Asquith, W.H., 2003, Modeling of runoff-producing rainfall hyetographs in Texas using L-moment statistics: Austin, Texas, University of Texas at Austin, Ph.D. dissertation, $386 \mathrm{p}$.

Bales, J.D., Weaver, J.C., and Robinson, J.B., 1999, Relation of land use to streamflow and water quality at selected sites in the city of Charlotte and Mecklenburg County, North Carolina, 1993-98: U.S. Geological Survey WaterResources Investigations Report 99-4180, 95 p.

Bonnin, G.M., Lin, B., Parzybok, T., Yekta, M., and Riley, D., 2004, Precipitation-frequency atlas of the United States: Silver Spring, MD, National Oceanic and Atmospheric Administration Atlas 14, v. 2, version 2, National Weather Service; accessed February 1, 2005, at http://www.nws. noaa.gov/ohd/hdsc/

Frederick, R.H., Meyers, V.A., and Auciello, E.P., 1977, Fiveto 60-minute precipitation frequency for the eastern and central United States: Washington, DC, National Oceanic and Atmospheric Administration Technical Memorandum NWS HYDRO-35, 36 p.

Greenwood, J.A., Landwehr, J.M., Matalas, N.C., and Wallis, J.R., 1979, Probability weighted moments-Definition and relation to parameters of several distributions expressible in inverse form: Water Resources Research, v. 15, no. 5, p. 1049-1054.

Hazell, W.F., and Bales, J.D., 1997, Real-time rainfall measurement in the city of Charlotte and Mecklenburg County, North Carolina: U.S. Geological Survey Fact Sheet FS052-97, 4 p.

Hershfield, D.M., 1961, Rainfall frequency atlas of the United States for durations from 30 minutes to 24 hours and return periods from 1 to 100 years: Washington, DC, U.S. Weather Bureau, Technical Paper 40, 115 p.

Hosking, J.R.M., 1986, The theory of probability weighted moments: Yorktown Heights, NY, IBM Research Division, T.J. Watson Research Center, Research Report RC-12210, $160 \mathrm{p}$.

Hosking, J.R.M., 1990, L-moments-Analysis and estimation of distributions using linear combinations of order statistics: Journal Royal Statistical Society B, v. 52, no. 1, p. 105-124. 
Hosking, J.R.M., 1991, FORTRAN routines for use with the method of L-moments, Version 2: Yorktown Heights, NY, IBM Research Division, T.J. Watson Research Center, Research Report RC-17097, 117 p.

Hosking, J.R.M., 1992, Moments or L-moments?-An example comparing two measures of distributional shape: The American Statistician, v. 46, no. 3 (August 1992), p. 186-189.

Hosking, J.R.M., and Wallis, J.R., 1993, Some statistics useful in regional frequency analysis: Water Resources Research, v. 29 , no. 2 , p. 271-281.

Hosking, J.R.M., and Wallis, J.R., 1995, A comparison of unbiased and plotting-position estimators of L-moments: Water Resources Research, v. 31, no. 8, p. 2019-2025.

Hosking, J.R.M., and Wallis, J.R., 1997, Regional frequency analysis-An approach based on L-moments: Cambridge, United Kingdom, Cambridge University Press, 224 p.

Imhoff, M.W., and Davis, J.M., 1983, Precipitation probabilities based on the gamma distribution at 76 North Carolina locations: Raleigh, North Carolina Climate Program Office, North Carolina State University, 259 p.

Kirby, W., 1974, Algebraic boundedness of sample statistics: Water Resources Research, v. 10, p. 220-222.

Landwehr, J.M., Matalas, N.C., and Wallis, J.R., 1979, Probability weighted moments compared with some traditional techniques in estimating Gumbel parameters and quantiles: Water Resources Research, v. 15, no. 5, p. 1055-1064.

LeGrand, H.E., and Mundorff, M.J., 1952, Geology and groundwater in the Charlotte area, North Carolina: Raleigh, North Carolina Department of Conservation and Development, Bulletin 63, 88 p.

McCachren, C.M., 1980, Soil survey of Mecklenburg County, North Carolina: U.S. Department of Agriculture, Soil Conservation Service, $97 \mathrm{p}$.

Miller, D.R., Warner, G.S., Ogden, F.L., and DeGaetano, A.T., 2003, Precipitation in Connecticut: Storrs, CT, Connecticut Institute of Water Resources, University of Connecticut, Report No. 38, 66 p.

Miller, J.F., 1964, Two- to ten-day precipitation for return periods of 2 to 100 years in the contiguous United States: Washington, DC, U.S. Weather Bureau, Technical Paper 49, $29 \mathrm{p}$.

National Climatic Data Center, 2004, NOAA satellite and information service; accessed October 11, 2005, at http:// www.ncdc.noaa.gov/ncdc.html
National Institute for Standards and Technology, 2005, Measures of skewness and kurtosis: Information Technology Laboratory's e-Handbook of Statistical Methods (Engineering Statistics Handbook); accessed August 9, 2005, at http://www.itl.nist.gov/div898/handbook/eda/section3/ eda35b.htm

National Oceanic and Atmospheric Administration, 2004, Climatological data annual summary-North Carolina: National Oceanic and Atmospheric Administration [issued annually].

National Oceanic and Atmospheric Administration, 2005, History of the National Weather Service-Evolution of the NOAA's National Weather Service (time line): Public Affairs Office, Silver Spring, MD; accessed July 7, 2005, at http://www.weather.gov/pa/history/index.php

National Weather Service, 2004a, Event summary-Hurricane Frances, September 2004: Raleigh, NC, National Weather Service; accessed April 20, 2005, at http://www4.ncsu. edu/ nwsfo/storage/cases/20040908/

National Weather Service, 2004b, Event summary-Hurricane Ivan, September 2004: Raleigh, NC, National Weather Service; accessed April 20, 2005, at http://www4.ncsu. edu/ nwsfo/storage/cases/20040917/

Parrett, Charles, 1997, Regional analysis of annual precipitation maxima in Montana: U.S. Geological Survey WaterResources Investigations Report 97-4004, 51 p.

Robinson, J.B., Hazell, W.F., and Garrett, R.G., 1996, Precipitation, streamflow, and water-quality data from selected sites in the city of Charlotte and Mecklenburg County, 1993-95: U.S. Geological Survey Open-File Report 96-150, $136 \mathrm{p}$.

Robinson, J.B., Hazell, W.F., and Garrett, R.G., 1998, Precipitation, streamflow, and water-quality data from selected sites in the city of Charlotte and Mecklenburg County, 1995-97: U.S. Geological Survey Open-File Report 98-67, 220 p.

Robinson, J.B., Hazell, W.F., and Young, W.S., 1998, Effects of August 1995 and July 1997 storms in the city of Charlotte and Mecklenburg County, North Carolina: U.S. Geological Survey Fact Sheet FS-036-98, 4 p.

Sarver, K.M., Hazell, W.F., and Robinson, J.B., 1999, Precipitation, atmospheric deposition, streamflow, and waterquality data from selected sites in the city of Charlotte and Mecklenburg County, 1997-98: U.S. Geological Survey Open-File Report 99-273, 144 p.

Saucier, W.J., Weber, A.H., and Bayne, C.K., 1973, Precipitation variability over North Carolina: Raleigh, Water Resources Research Institute of The University of North Carolina, Report No. 84, 185 p. 
Smith, D.G., 1993, Surface- and ground-water quality data at selected landfill sites in Mecklenburg County, North Carolina, 1979-92: U.S. Geological Survey Open-File Report 93-437, $971 \mathrm{p}$.

Southeast Regional Climate Center, 2005, Historical climate summaries and normals for the southeast; accessed April 20, 2005, at http://www.dnr.state.sc.us/climate/sercc/ climateinfo/historical/historical.html

State Climate Office of North Carolina, 2005, Aspects of NC climate-Extreme weather records; accessed April 20, 2005, at http://www.nc-climate.ncsu.edu/climatelextremes. html

Tortorelli, R.L., Rea, A., and Asquith, W.H., 1999, Depthduration frequency of precipitation for Oklahoma: U.S. Geological Survey Water-Resources Investigations Report 99-4232, 113 p.

U.S. Census Bureau, 2005, State \& County QuickFacts; accessed February 16, 2005, at http://quickfacts.census. gov/qfdl

U.S. Geological Survey, 2000, U.S. Geological Survey strategic plan 2000-2005; accessed August 13, 2003, at http:// www.usgs.gov/stratplan/stratplan_rev.pdf
U.S. Geological Survey, 2004, Rainfall network in and around Mecklenburg County; accessed February 7, 2005, at http:// nc.water.usgs.gov/char/rainfall.html

U.S. Geological Survey, 2005, Program priorities for 2005: U.S. Geological Survey Water Resources Discipline Informational Memorandum No. 2005.01, accessed in July 2005 at http://water.usgs.gov/coop/priorities.html

Vogel, R.M., and Fennessey, N.M., 1993, L-moment diagrams should replace product moment diagrams: Water Resources Research, v. 29, no. 6, p. 1745-1752.

Wallis, J.R., Matalas, N.C., and Slack, J.R., 1974, Just a moment!: Water Resources Research, v. 10, no. 2, p. 211219 .

Weaver, J.C., 2003, Methods for estimating peak discharges and unit hydrographs for streams in the city of Charlotte and Mecklenburg County, North Carolina: U.S. Geological Survey Water-Resources Investigations Report 03-4108, 50 p.

Zembrzuski, T.J., Jr., Hill, C.L., Weaver, J.C., Coble, R.W., and Gunter, H.C., 1991, North Carolina floods and droughts, in National Water Summary 1988-89Hydrologic events and floods and droughts: U.S. Geological Survey Water-Supply Paper 2375, p. 425-434. 


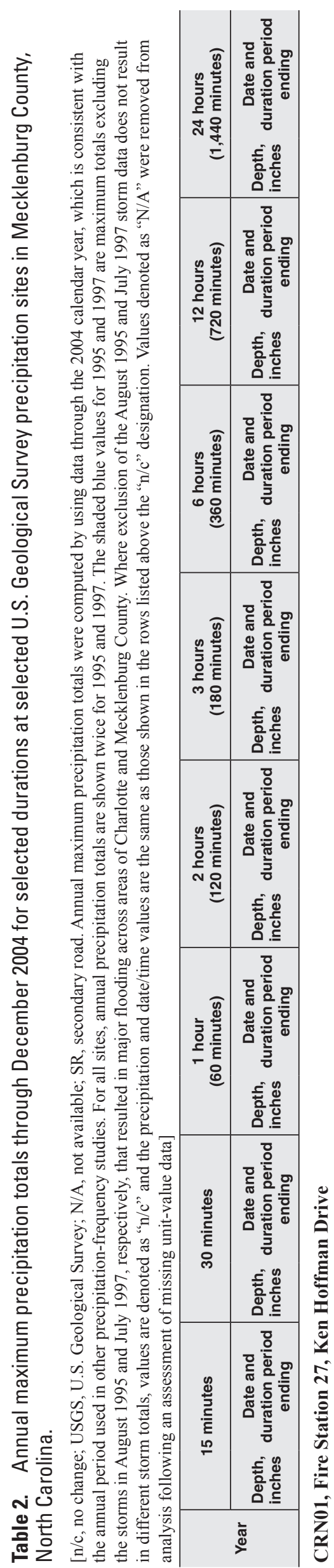

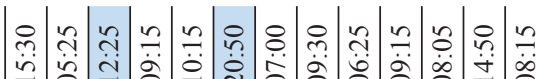

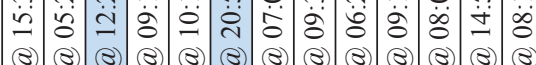

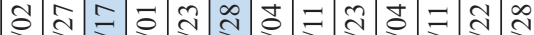
त्र

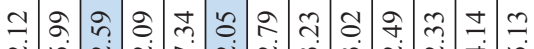

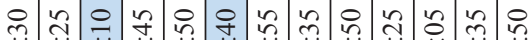

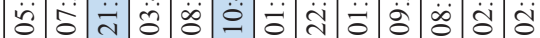

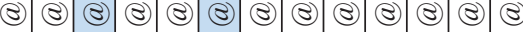

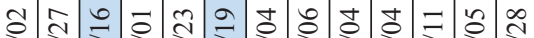

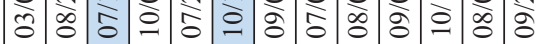

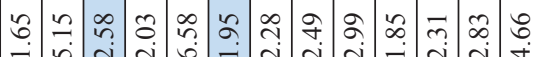

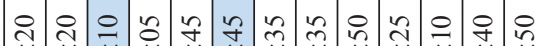

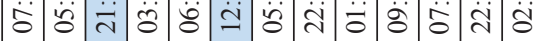

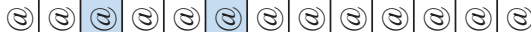

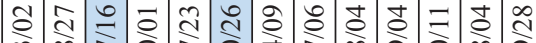

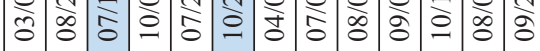
đิ

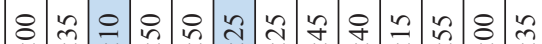

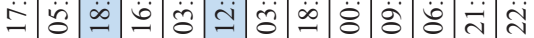

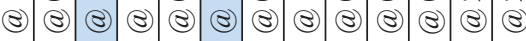

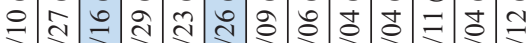
‘े

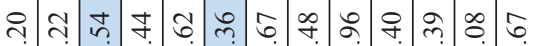

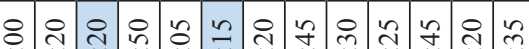

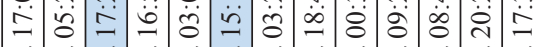

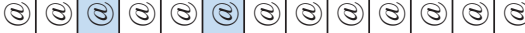

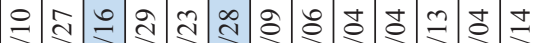
ड)

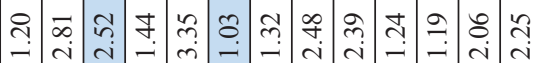
잉 ㅇำ

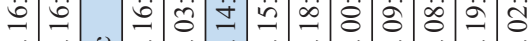
(ㅇ) (일

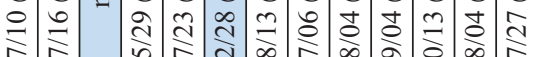
ปे

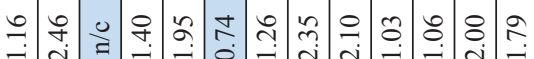

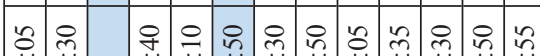

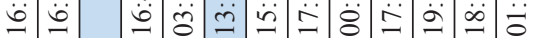
(8) (8)

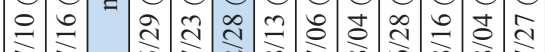

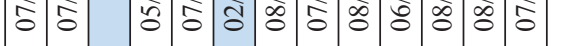
วิ)

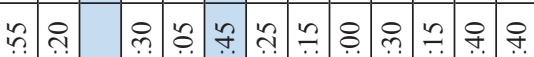

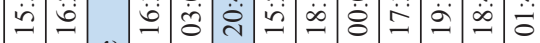

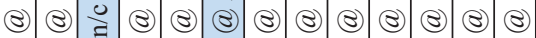

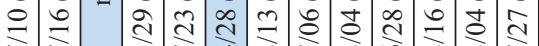

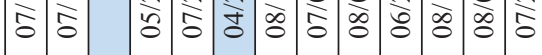
กิ:

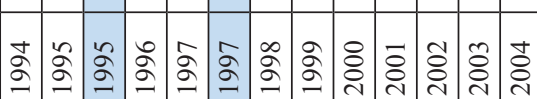

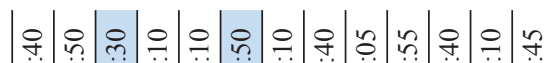

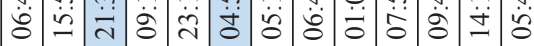

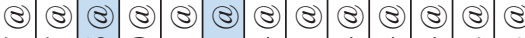

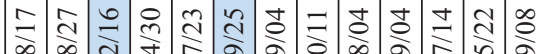
कू⿻

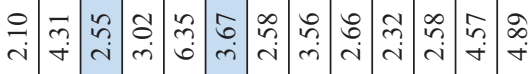

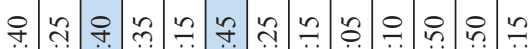

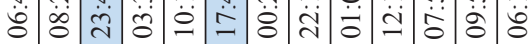

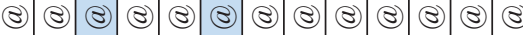

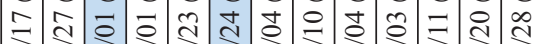

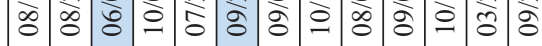

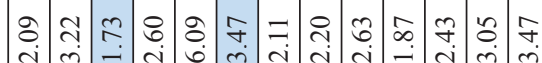

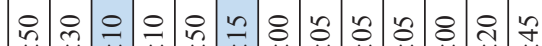

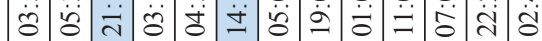

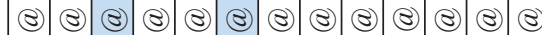

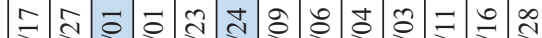
क人 茫

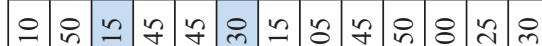

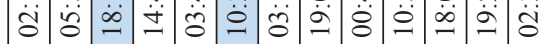

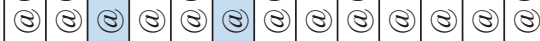

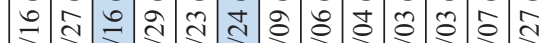

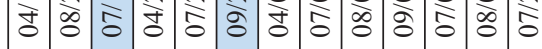

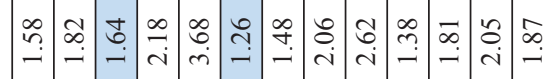

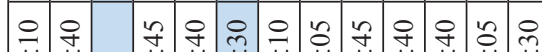

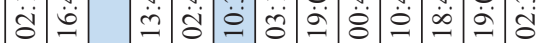

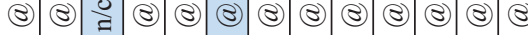

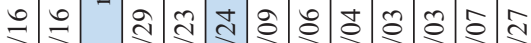

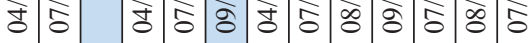

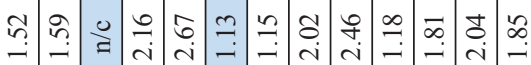

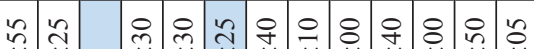

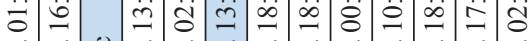

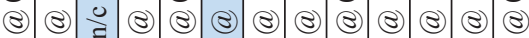
$\circ \frac{1}{4}$ )

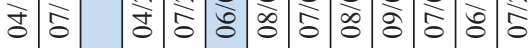

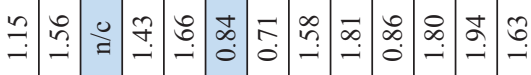

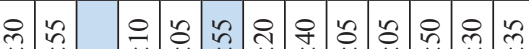

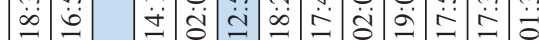
() \& ㄱำ ㄴำ 它客 ప.

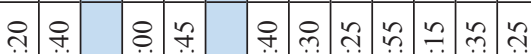

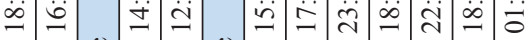
() ()

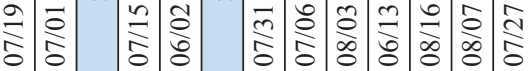

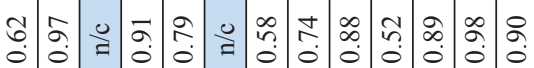

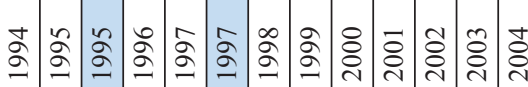


Table 2

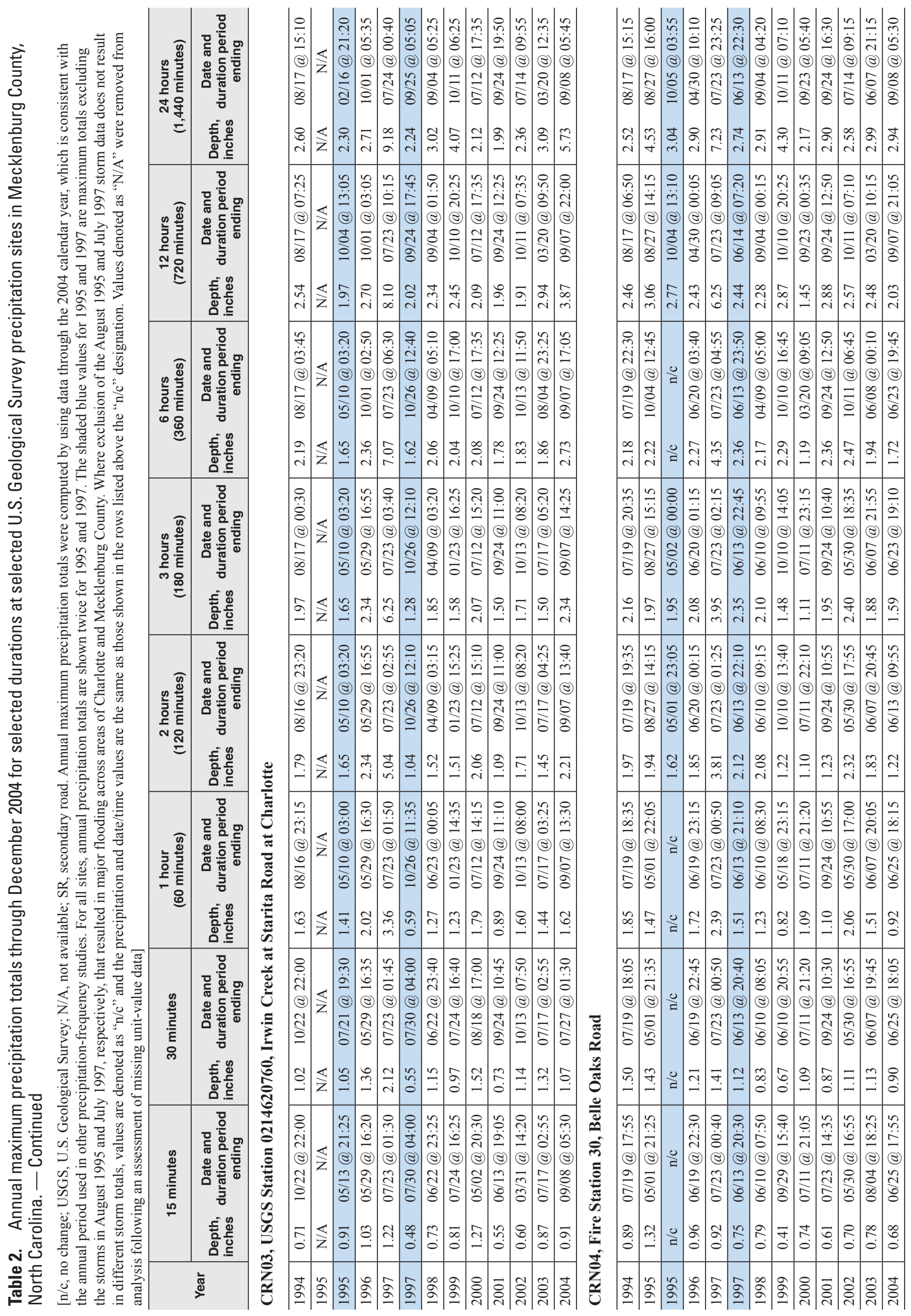




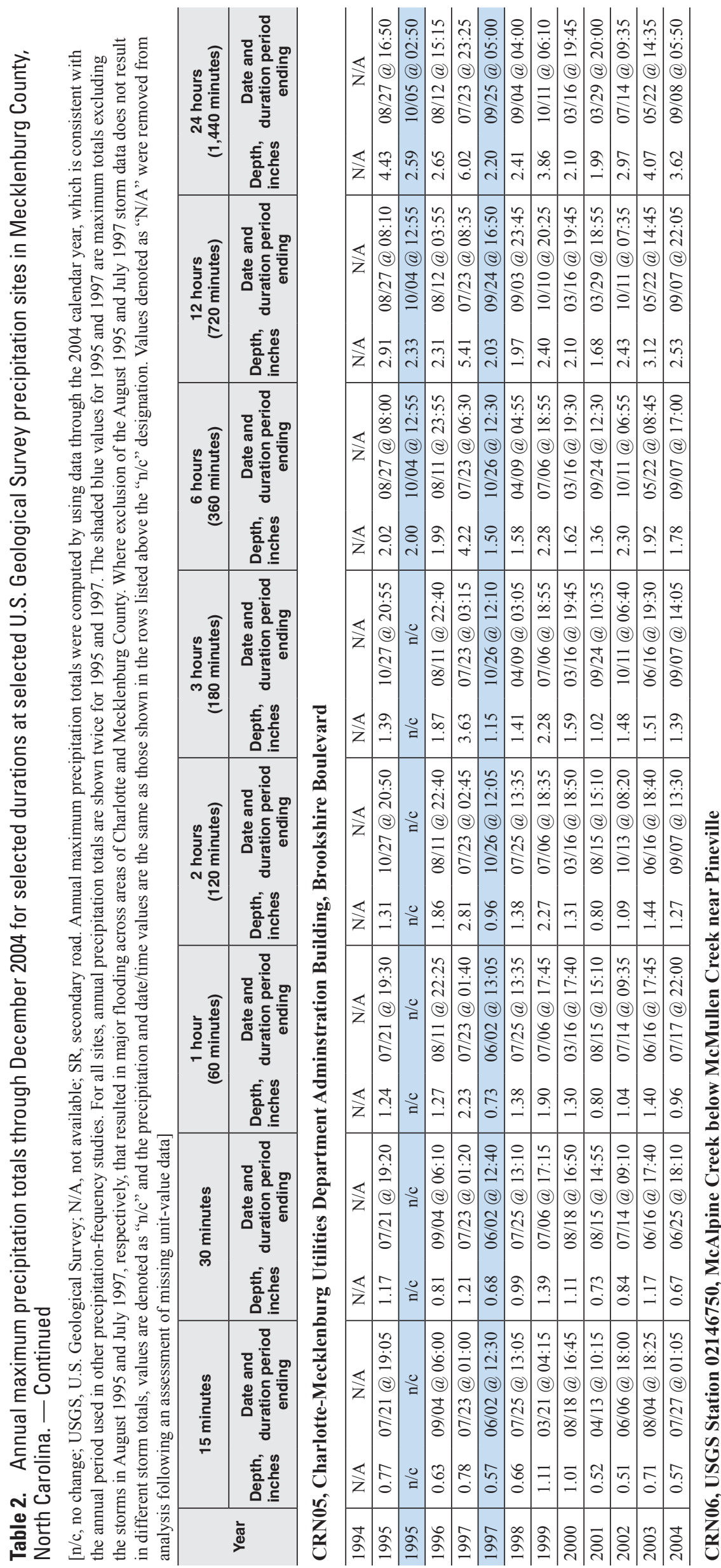

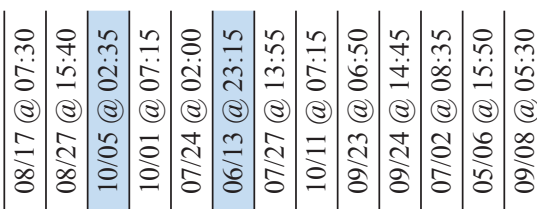

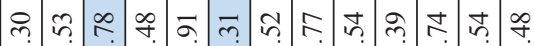

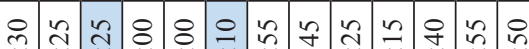

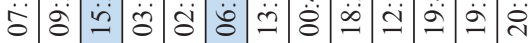

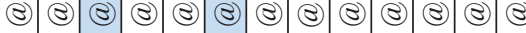

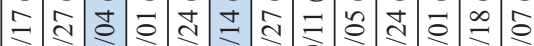

要

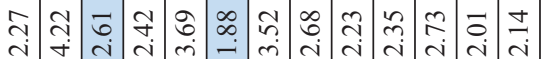

b)

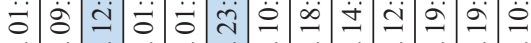

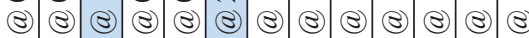

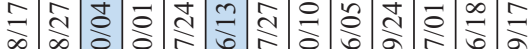

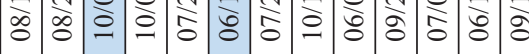

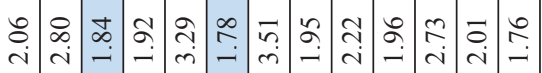

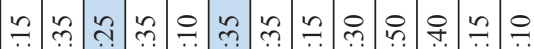

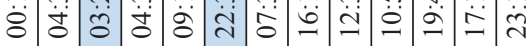

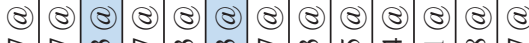

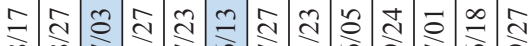

œ

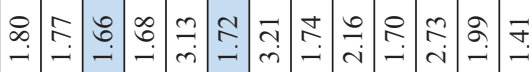

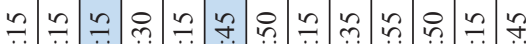

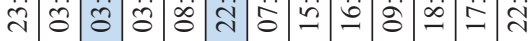

() (8) (8) (8) (8) () (8) () () (8) () (8) (8)

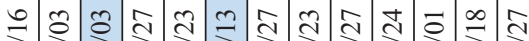

ஓे

它

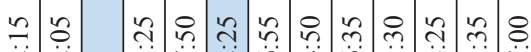

ते

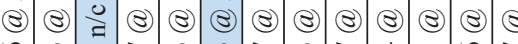

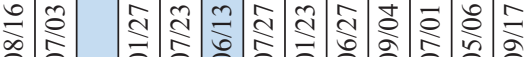

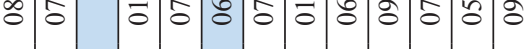

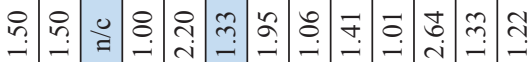

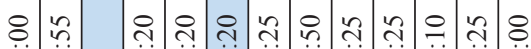

तें

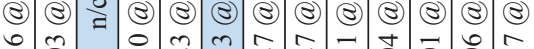

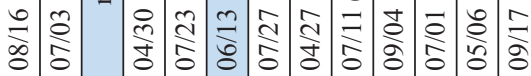

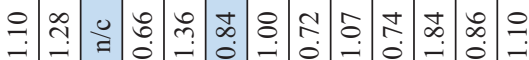

ๆ

ते

(8) (8)

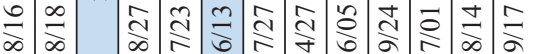

势

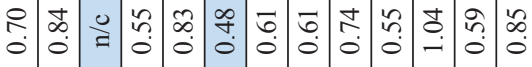

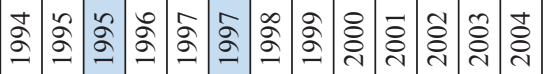




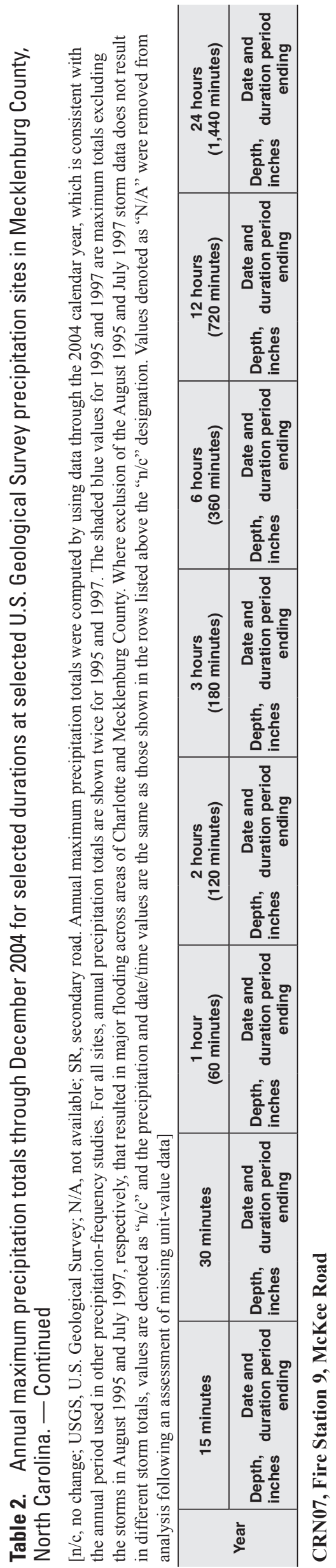

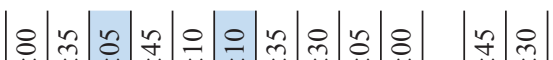

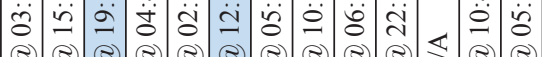

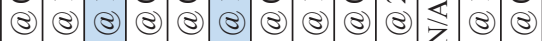

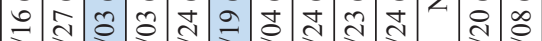
ळ人民

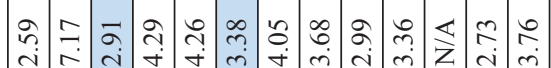

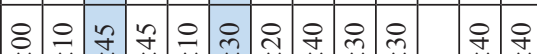

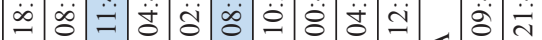
(8) (8) (8) (8) (8) (8) (8) (8) (8) (8) $\frac{4}{z}$ (ब) (8) तิ

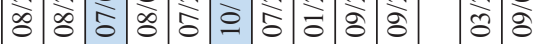

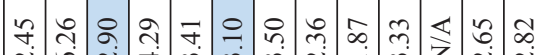

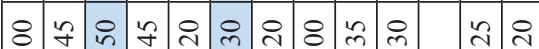

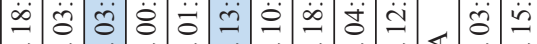

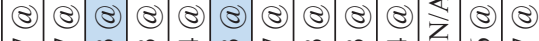

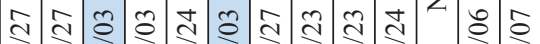

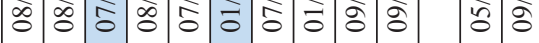

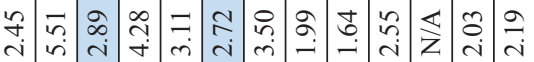

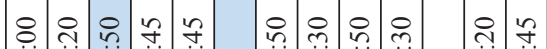

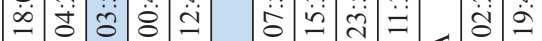

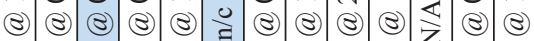
ㄷำ

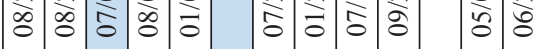

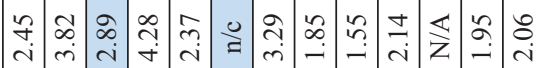

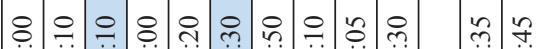

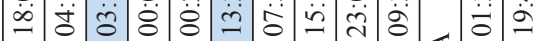

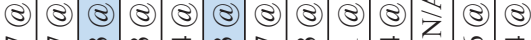
ㄷำ के के

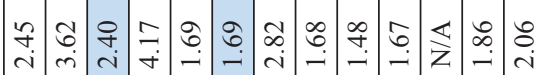

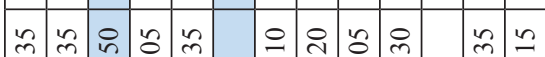

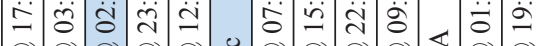
() () () () \&) ปิ ळे

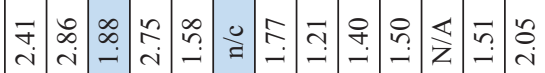

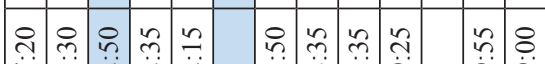

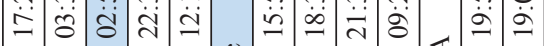
() (열 (8) (8) (8) तิ तิ ळ人

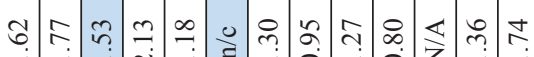
雨年

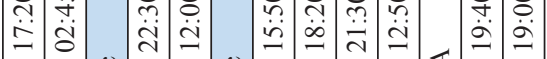

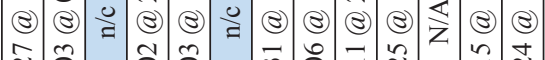

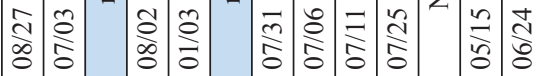

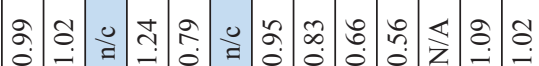

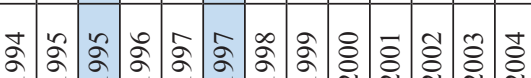

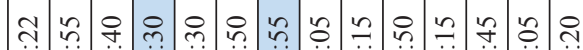

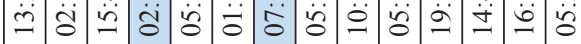

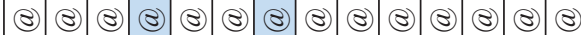

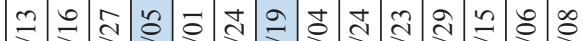

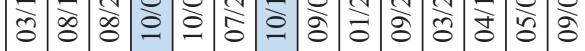

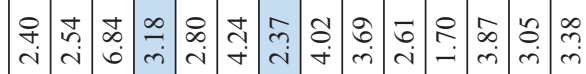

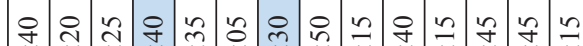

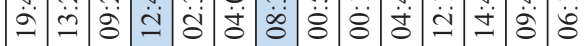

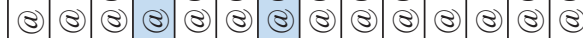

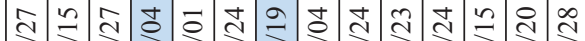

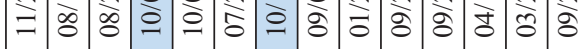

$\infty ⿻$

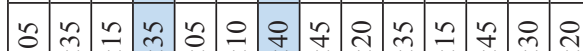

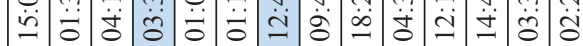

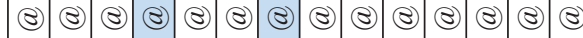

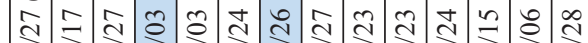
$\exists$ ळे ळै

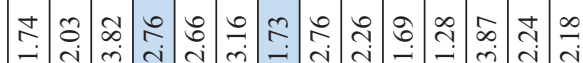

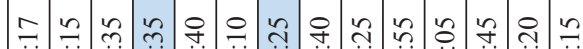

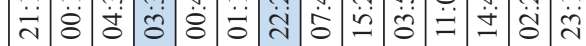

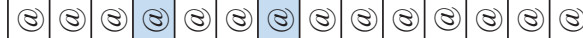

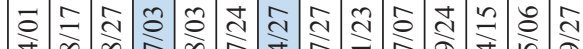

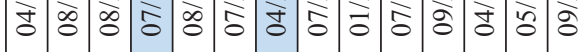

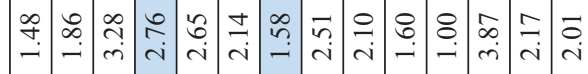

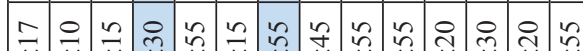

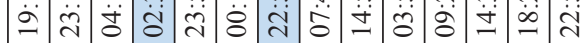

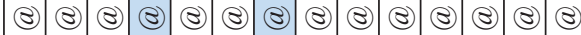

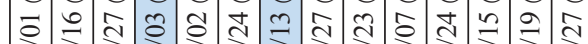

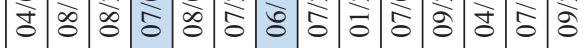

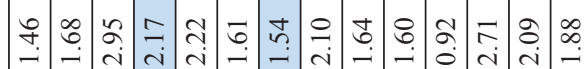

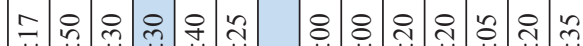

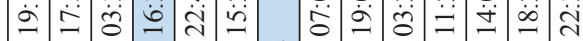

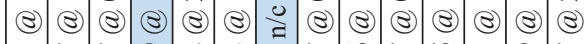
उา

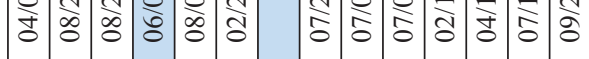

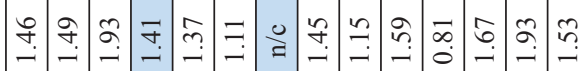

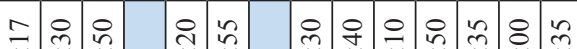

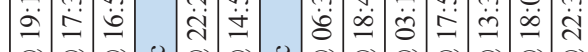

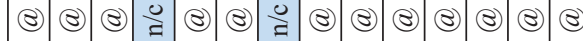

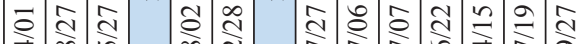

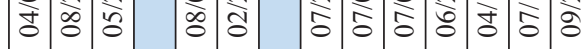

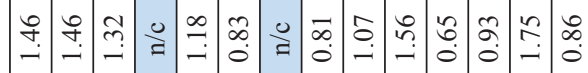

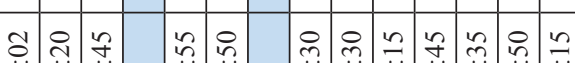

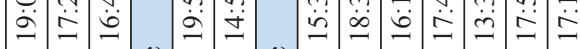

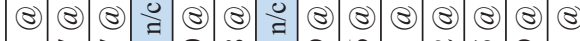

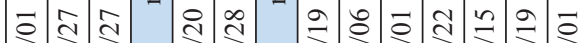

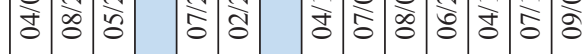

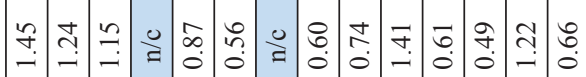

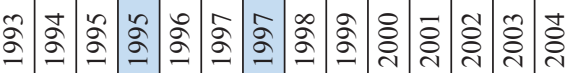




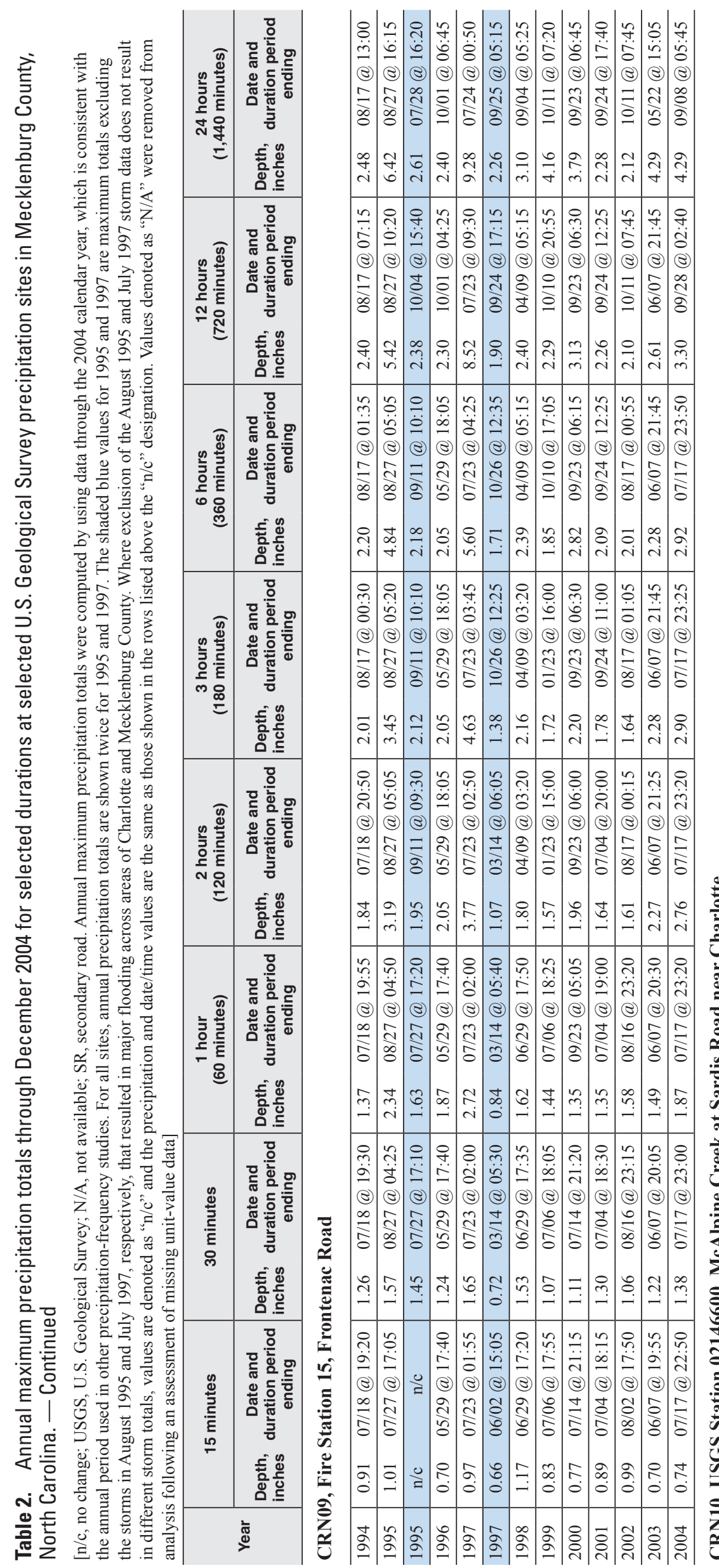

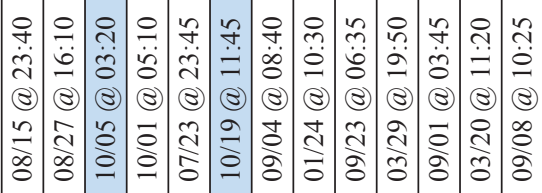

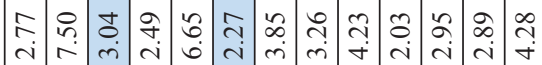

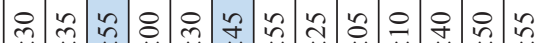

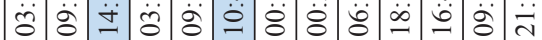
(8) (8) (8) (8) (8) (8) (8) (8) (8) (8) (8) (8) (8) ग)

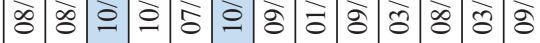

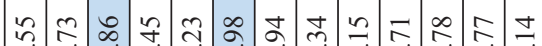

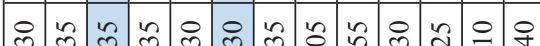

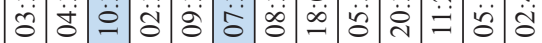

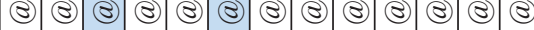
ᄀ) $\infty$ ळ

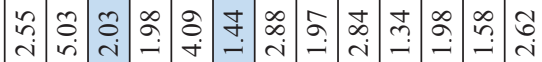
子า

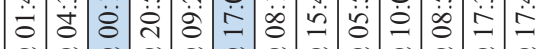

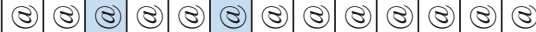

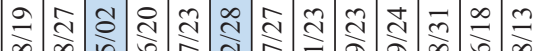
ळे

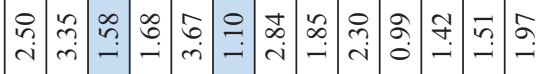
$\because$ กิ

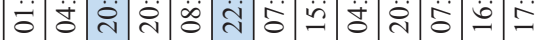

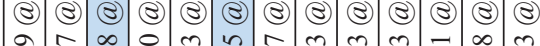
ᄀ)

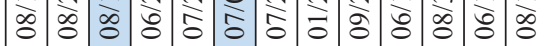

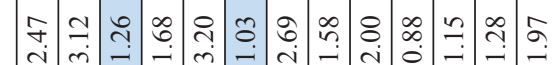

$\curvearrowleft \backsim \backsim$ ก

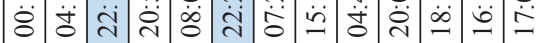
() () () () () () () () () (ㅇ) () () (8) ₹ิ क人

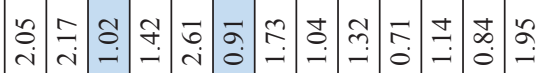

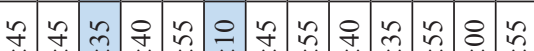

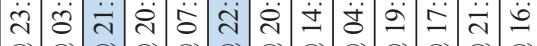
(8) (8) (8) (8) () (8) (8) (8) (8) () () (8) (8)

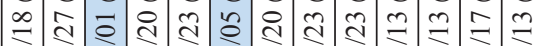
ळ के च ल ๓ $m$ ๓

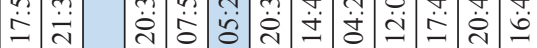
(2) ()

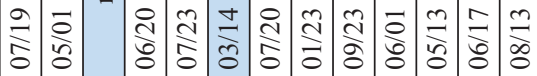

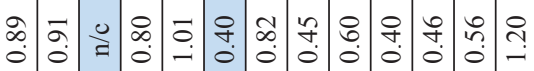

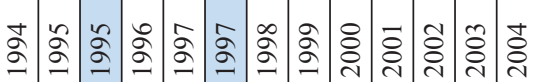




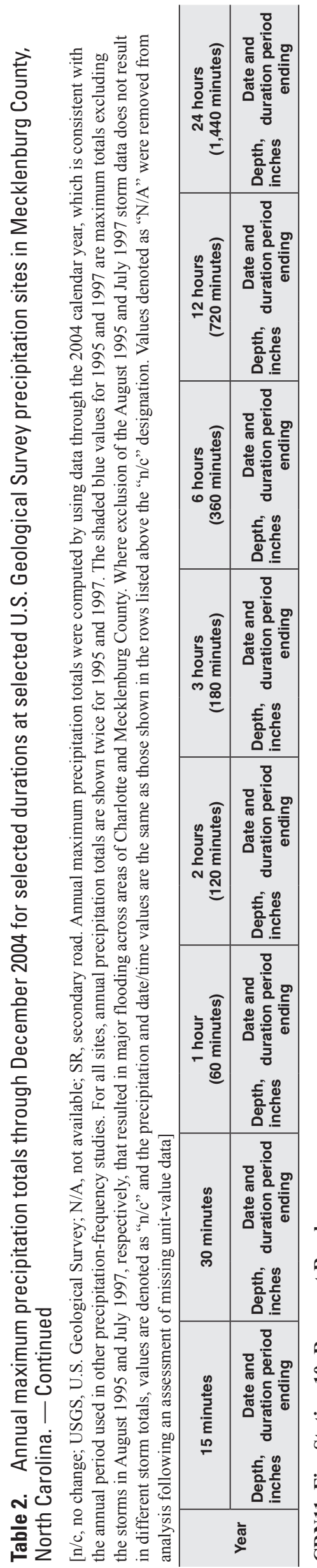

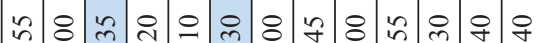
ठ்

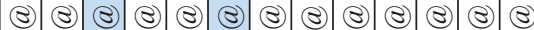
$\pi$ ำ

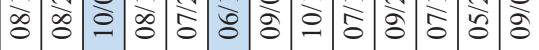

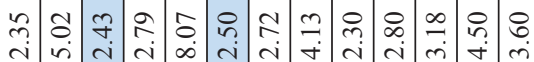

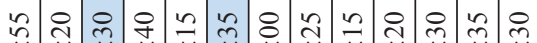

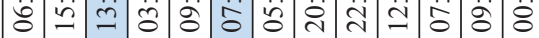

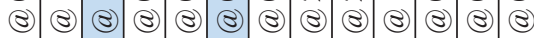

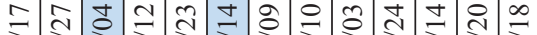
ळ

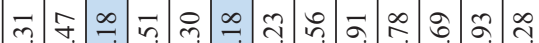
우 $\sim$ m ஸ் (8) (8) (8) (8) (8) (3) (8) (3) (8) (8) (8) (8) (8)

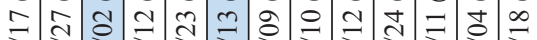

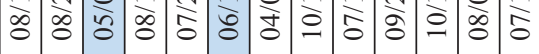

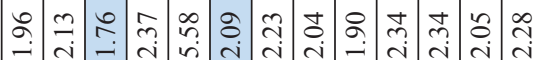

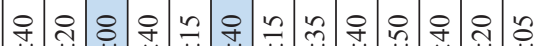

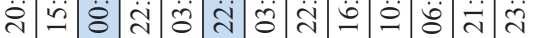
(8) (8) (3) (8) (8) (3) (8) (8) (8) (3) (8) (8) (8)

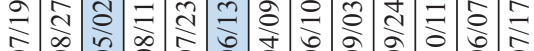
宅

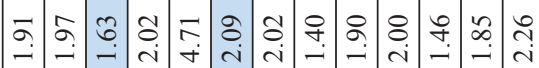
운

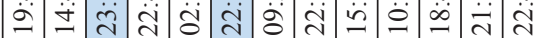

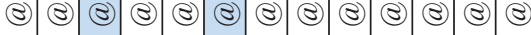

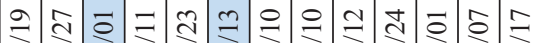
సิ

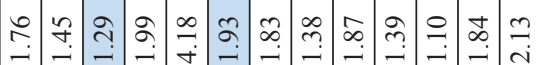
ๆ

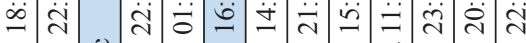

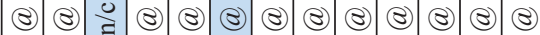

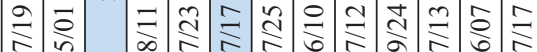
吉施

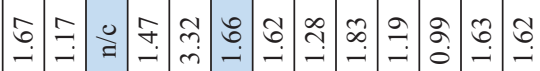
유 웅

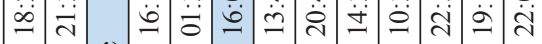
() (8)

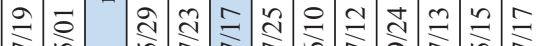
ซี

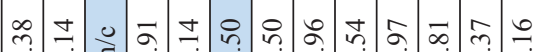

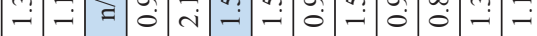
유 능

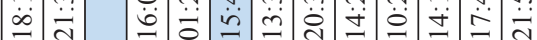
() (8)

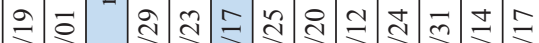
당 है है है

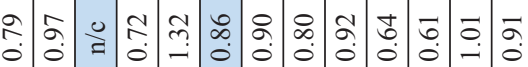

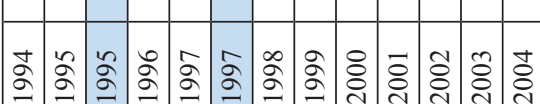

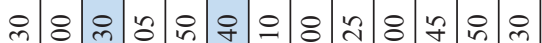
ปิ (8) (8) (8) (8) (8) (8) (8) (8) (8) (8) (8) (8) (8)

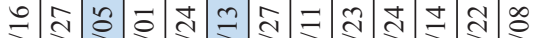
ळ

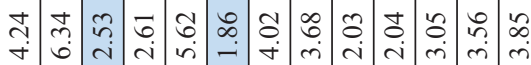

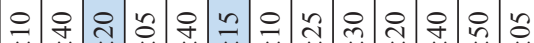

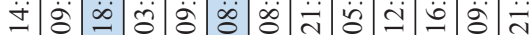

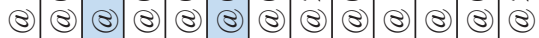

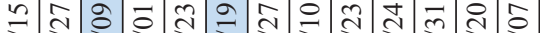
क ळ

そ

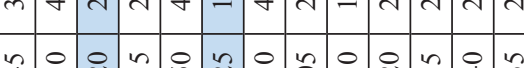

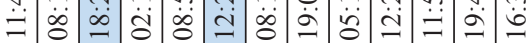
(8) (8) (8) (8) (8) (8) (8) (8) (8) (8) (8) (8) (8)

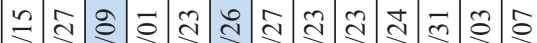
ळ

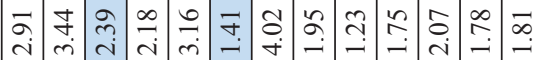

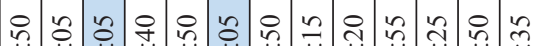

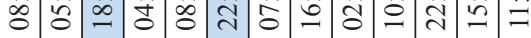
(8) (8) (8) (8) (8) (8) (8) (8) (8) (8) (5) (8) (8)

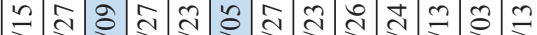
क्ठ

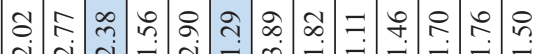

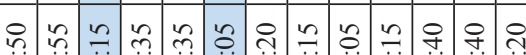

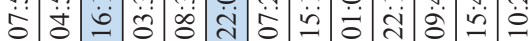
(8) (8) (8) (8) (8) (8) (8) (8) (8) (8) (8) (8) (8)

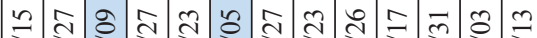
क्ष

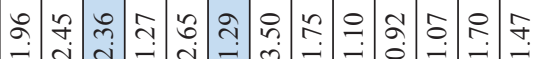
응으의 우의

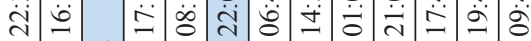
(8) (8)

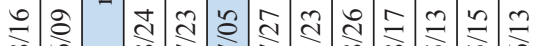
क ठ

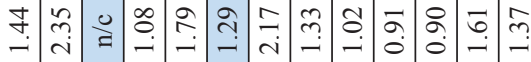
彳

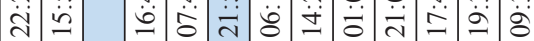

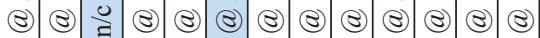
$\because g$ 光

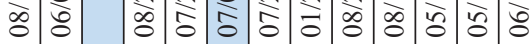

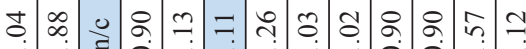

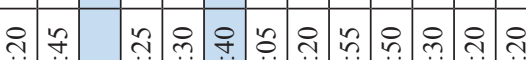

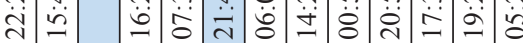
(8) (8) $\because \delta$ ปิ \& \&

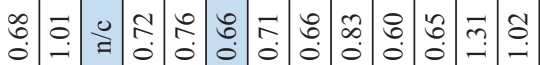

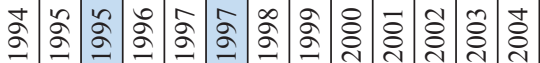




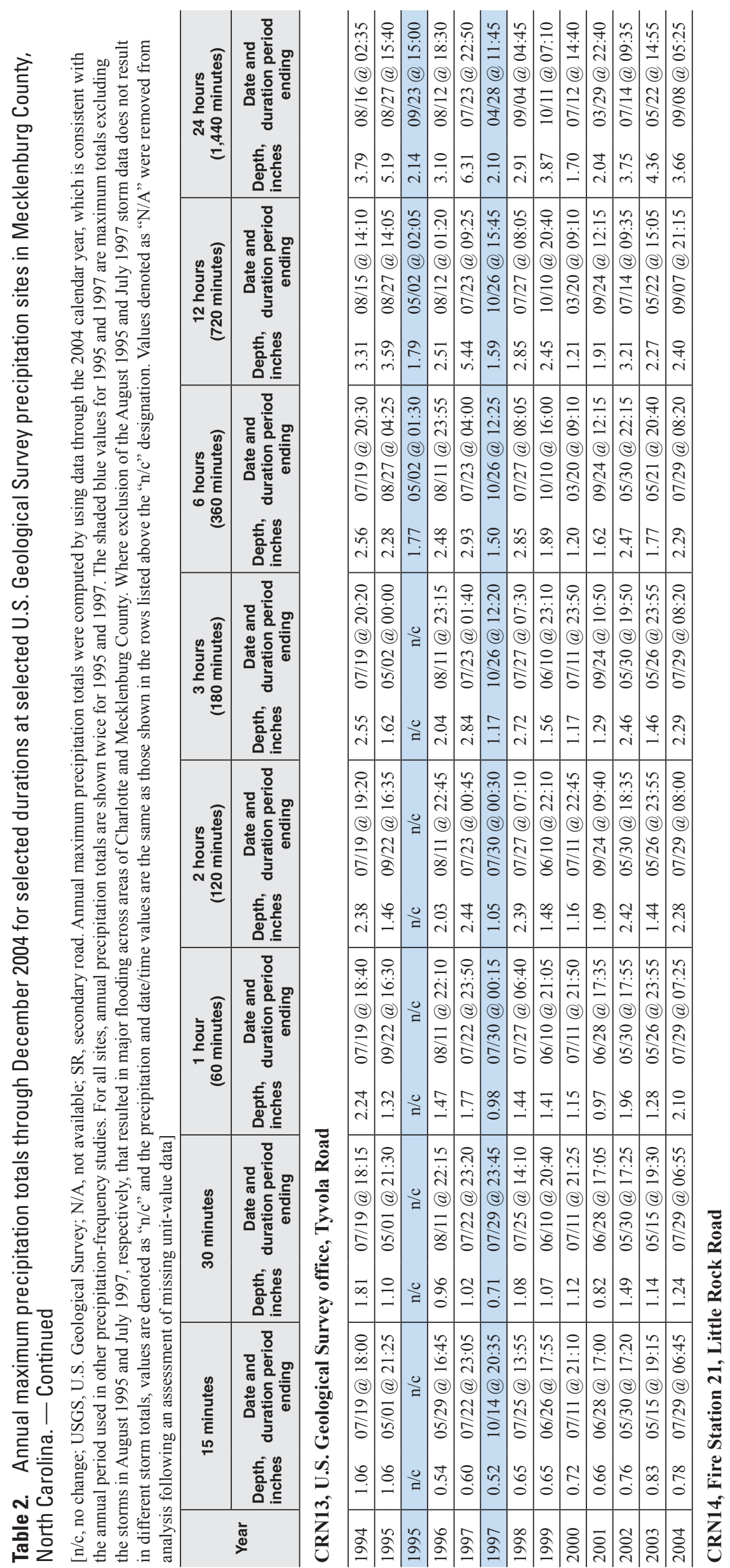

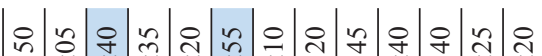

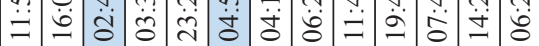
(8) (8) (8) (8) (8) (8) (8) (8) (8) (8) (8) (8) (8) ₹ वे ભำ กิ m \& m

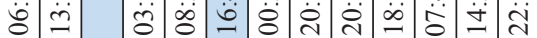

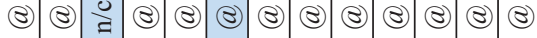

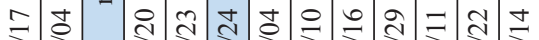

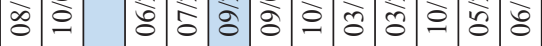

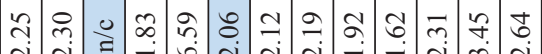
요 뜽 in ரे $\ddot{0}$ की () ()

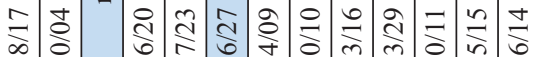

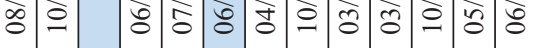
ब.

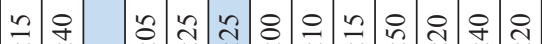

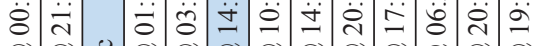

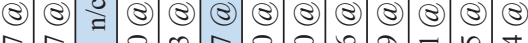
年

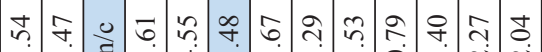

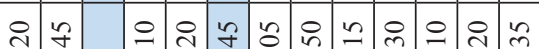

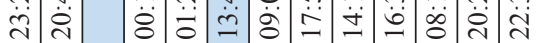

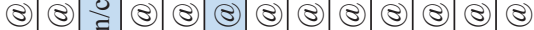

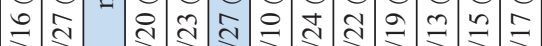
ळ

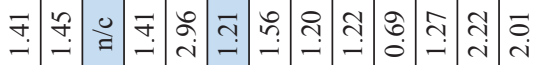
d भ

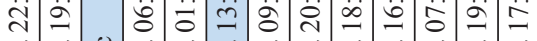

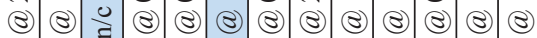

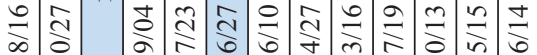
के वे वे

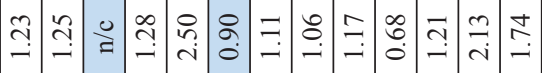
กิ

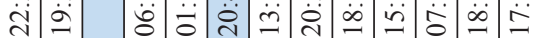
() (8)

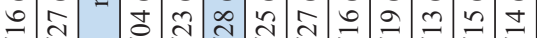
ஃ

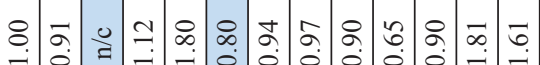
๓ $\sim$ ㅇ

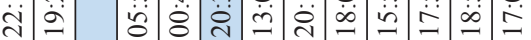
() ()

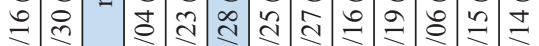
के दे वे है

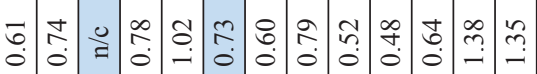
ป 


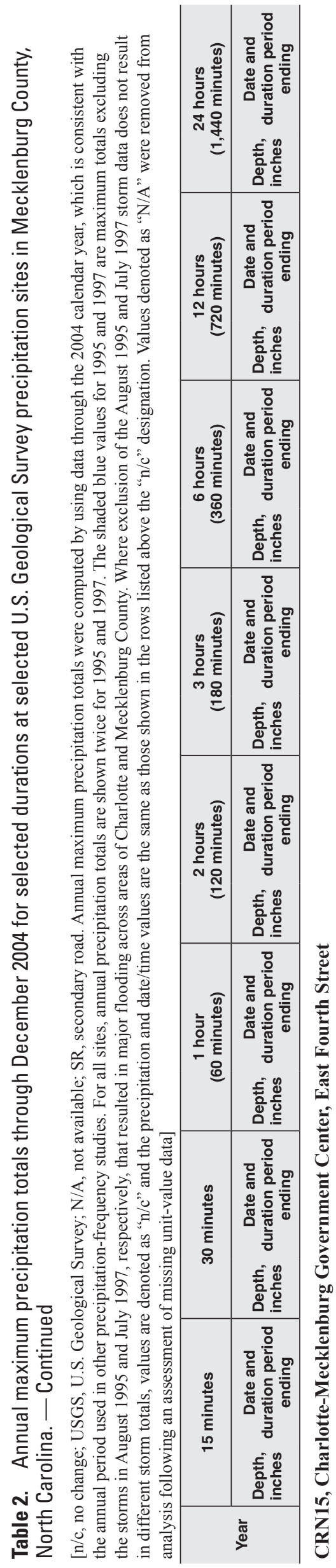

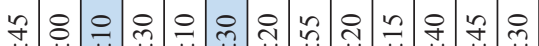

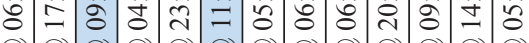

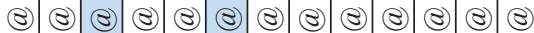

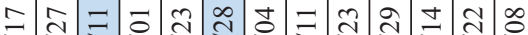
क人

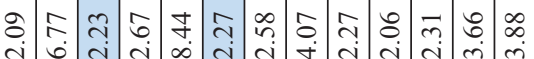

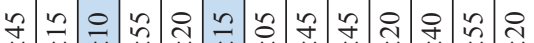

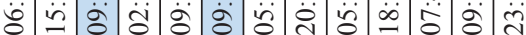

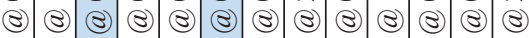

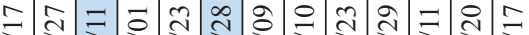
$\infty$ ळ

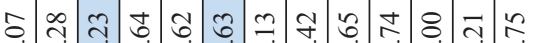

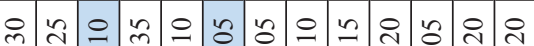

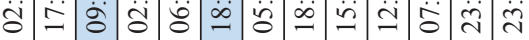
() () (ㅇ () () () () (ㅇ () () () () ()

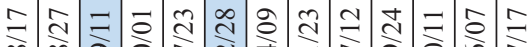
ळ

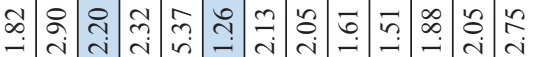

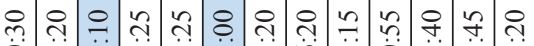

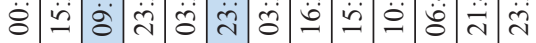
(8) (8) (8) (8) (8) (8) (8) () (8) (8) (8) (8) (8)

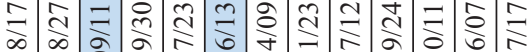

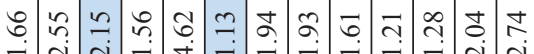

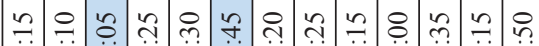

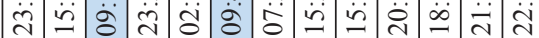

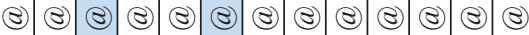

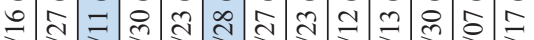
के के

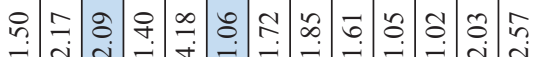

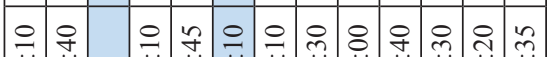

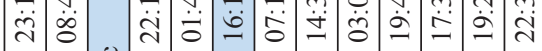
() (8)

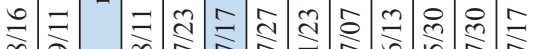

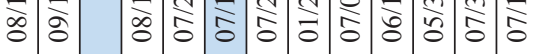

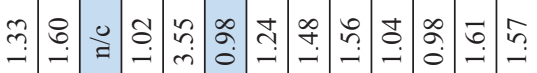
유 ๆ त் () ()

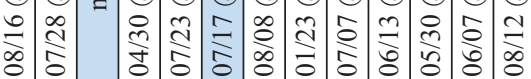
$m \infty$ o $\infty$ a

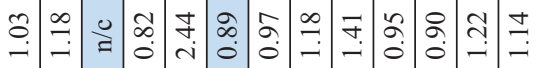
๓

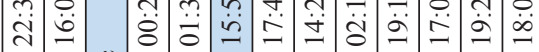

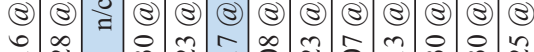

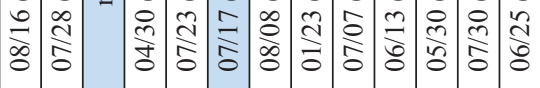

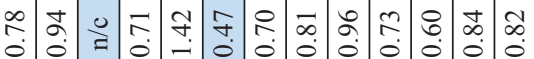

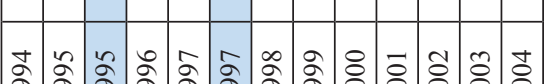

ㅇำ

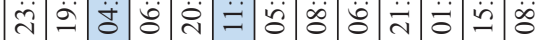

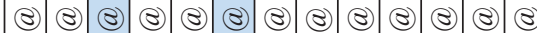

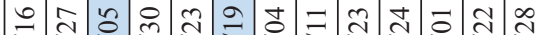
ळ

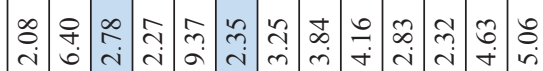
ถน ณ

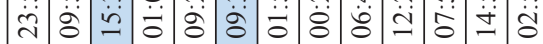
(ㄷ) (8) (8) (8) (8) (8) () (8) (8) (8) (8) (8) (8)

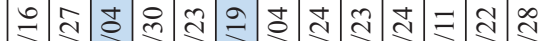
ळ

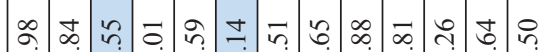

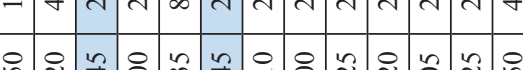

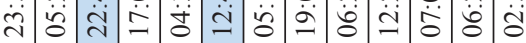

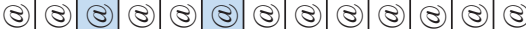

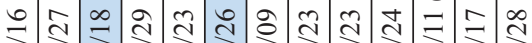
ळ

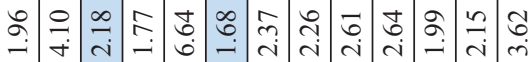

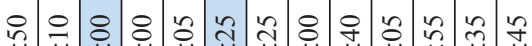
ते

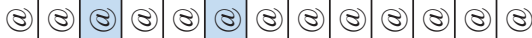

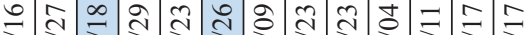

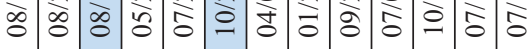

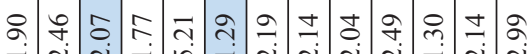
ㄴำ

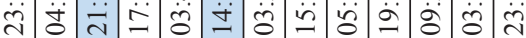
() (8) (8) (8) (8) (8) (8) (8) (8) () (8) (8) (8)

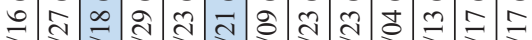
ळे के

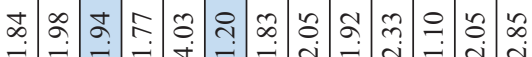
in

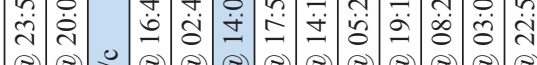
() (8)

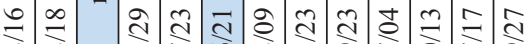
ळ

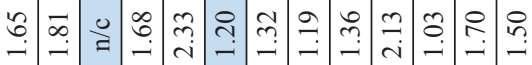

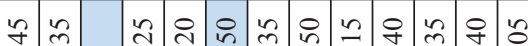

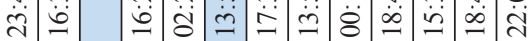
() ()

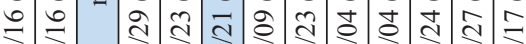

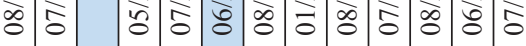

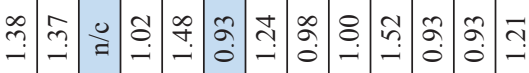

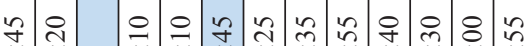

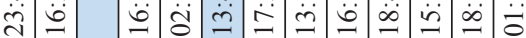

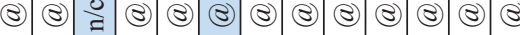
$\therefore=0$ ) ळ

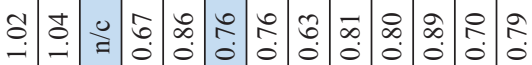

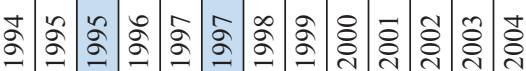




\begin{tabular}{|c|c|c|c|c|c|c|c|c|c|c|c|c|c|c|c|c|c|c|c|c|c|c|c|c|c|c|c|}
\hline 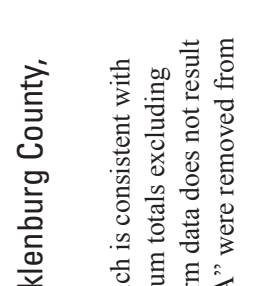 & 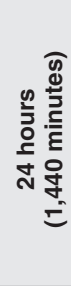 & 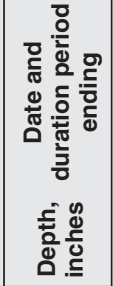 & & & 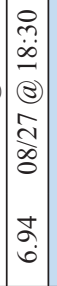 & \begin{tabular}{|c|}
$\dot{j}$ \\
$\tilde{d}$ \\
0 \\
$\tilde{o}$ \\
0 \\
0
\end{tabular} & 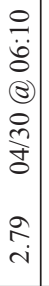 & $=$ & 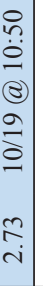 & 市 & 8 & है & $\checkmark$ & ?n & 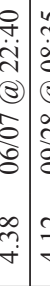 & & & 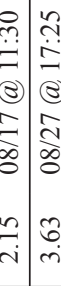 & & 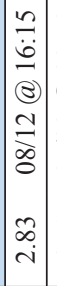 & & 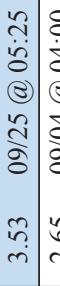 & 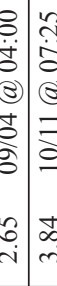 & & & & 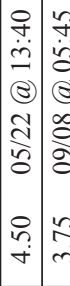 \\
\hline 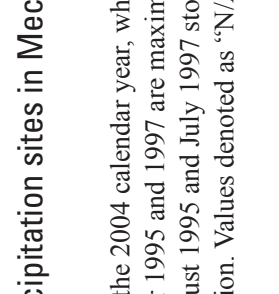 & 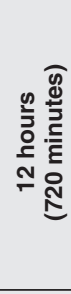 & 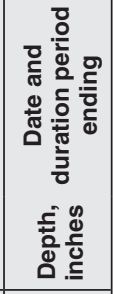 & & & 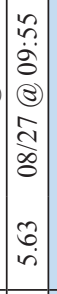 & $\begin{array}{l}n \\
\tilde{n} \\
0 \\
e \\
d \\
0 \\
0\end{array}$ & 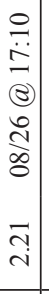 & $\frac{\circ}{\ddot{g}}$ & 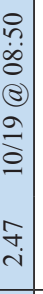 & $\stackrel{n}{\ddot{u}}$ & & n. & تُ & ְֶ) & & & & 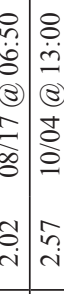 & $\cong$ & 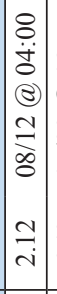 & 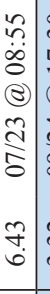 & 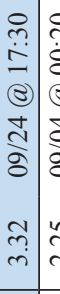 & $\begin{array}{c}8 \\
0 \\
0 \\
0 \\
0 \\
0 \\
0\end{array}$ & & & & $\frac{\sqrt{3}}{\sqrt[n]{y}}$ \\
\hline 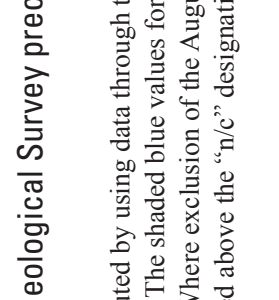 & 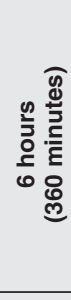 & 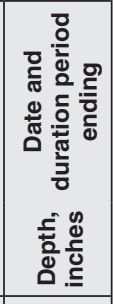 & & $\begin{array}{l}\text { (e) } \\
\frac{n}{80}\end{array}$ & 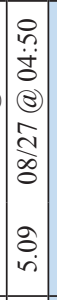 & $\begin{array}{l}n \\
0 \\
\dot{d} \\
e \\
0 \\
\delta \\
\delta \\
\tilde{\delta}\end{array}$ & 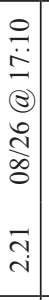 & 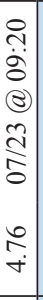 & 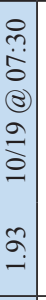 & 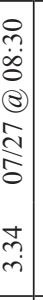 & 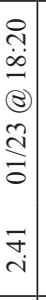 & 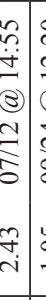 & 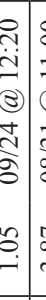 & $\begin{array}{l}\text { s. } \\
\text { ch }\end{array}$ & & & & 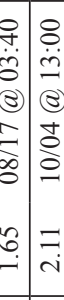 & $\cong$ & 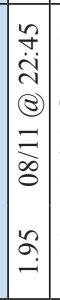 & 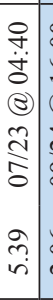 & 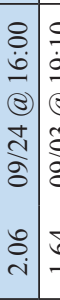 & $\begin{array}{c}\mathbb{U}_{0} \\
-\end{array}$ & है. & $\begin{array}{l}8 \\
0 \\
0 \\
5\end{array}$ & $\left|\begin{array}{l}n \\
i \\
i\end{array}\right|$ & 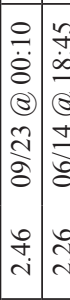 \\
\hline 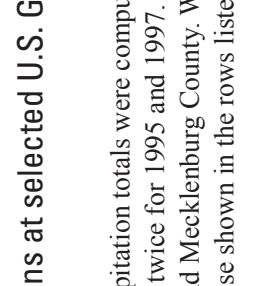 & 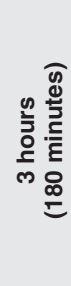 & 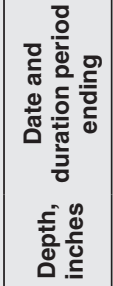 & & $\begin{array}{l}n \\
\ddot{8} \\
\text { en } \\
\text { ते } \\
\text { ठे }\end{array}$ & 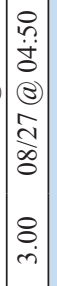 & $\begin{array}{c}n \\
\ddot{8} \\
0 \\
\tilde{\delta} \\
\tilde{\delta} \\
\dot{8}\end{array}$ & 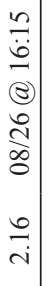 & 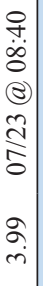 & 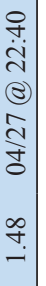 & 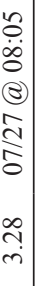 & 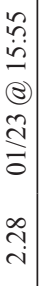 & 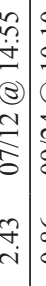 & 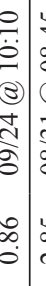 & 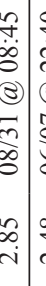 & & & & 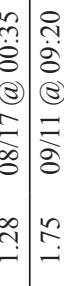 & $\cong$ & 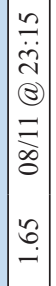 & 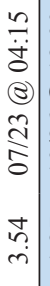 & 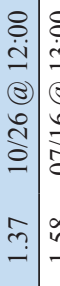 & 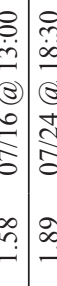 & 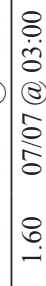 & $\begin{array}{l}\text { (2) } \\
\text { (2) } \\
0 \\
\text { ปे } \\
8\end{array}$ & $\stackrel{\widehat{\infty}}{\rightarrow}$ & 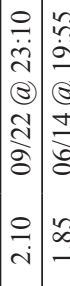 \\
\hline 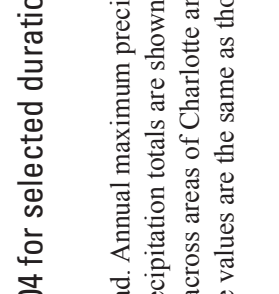 & 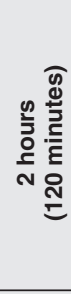 & 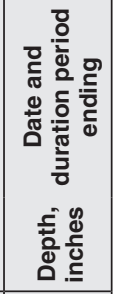 & & & 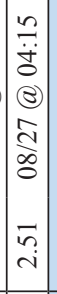 & 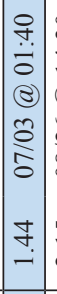 & 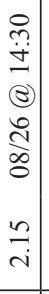 & 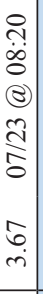 & 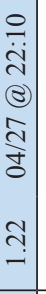 & 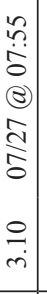 & 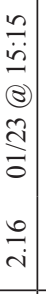 & 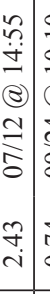 & 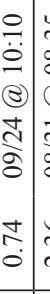 & 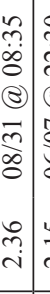 & 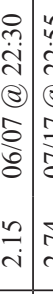 & & & 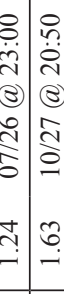 & & 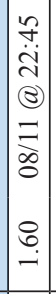 & 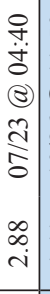 & 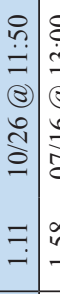 & 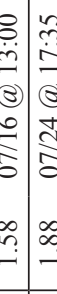 & 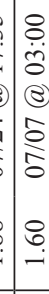 & 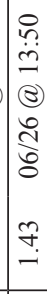 & $\begin{array}{l}8 \\
\dot{0} \\
0 \\
(8) \\
\bar{\Xi} \\
0\end{array}$ & 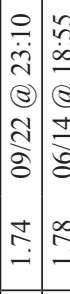 \\
\hline 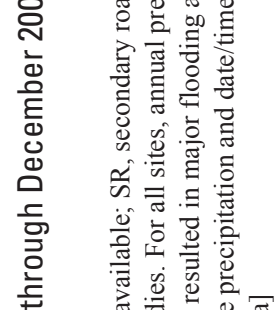 & 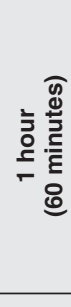 & 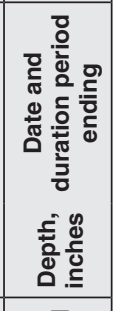 & 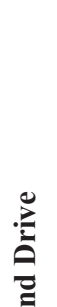 & 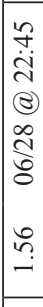 & 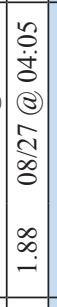 & \begin{tabular}{|c|c}
$n$ \\
$\ddot{0}$ \\
0 \\
$e$ \\
$\tilde{0}$ \\
5 \\
0 \\
\\
\end{tabular} & 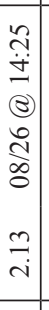 & 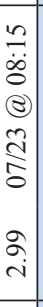 & 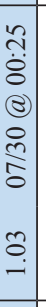 & 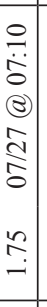 & 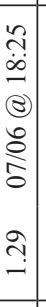 & 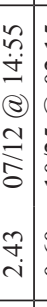 & 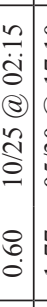 & 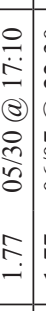 & 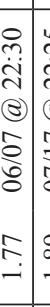 & & & 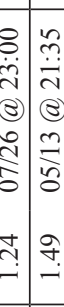 & $\stackrel{3}{\beth}$ & 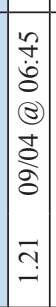 & 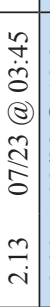 & 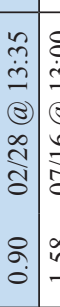 & 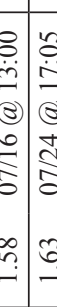 & 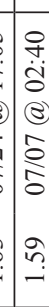 & 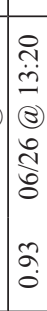 & 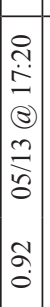 & 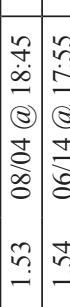 \\
\hline 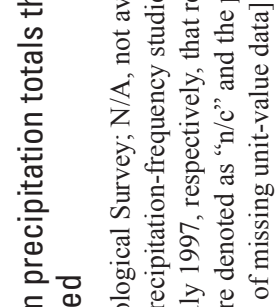 & 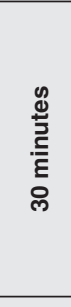 & 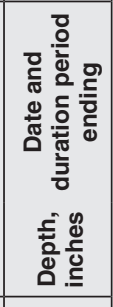 & 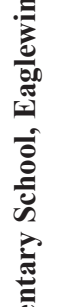 & 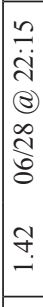 & 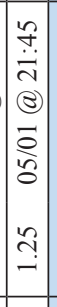 & $\stackrel{0}{\cong}$ & 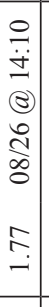 & 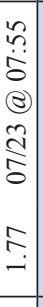 & 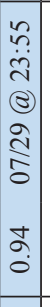 & 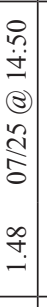 & 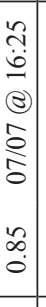 & 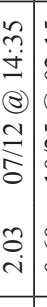 & 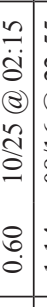 & 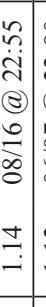 & 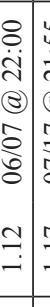 & & & 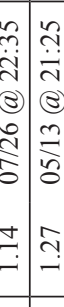 & $\cong$ & 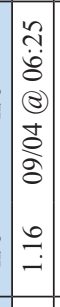 & 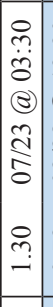 & 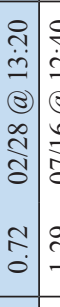 & & 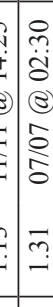 & 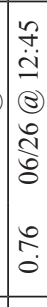 & 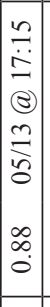 & 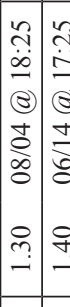 \\
\hline 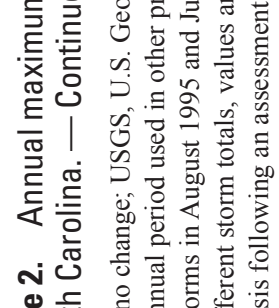 & 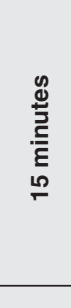 & 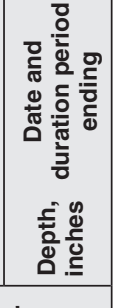 & 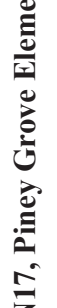 & 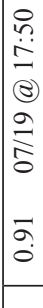 & 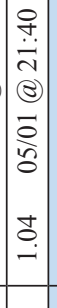 & $\begin{array}{l}0 \\
0 \\
0 \\
0\end{array}$ & 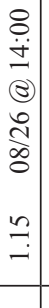 & 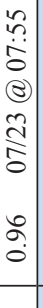 & $\begin{array}{l}0 \\
\tilde{\pi} \\
\tilde{\sim}\end{array} \mid$ & $\begin{array}{l}\stackrel{g}{+} \\
\dot{\Xi}\end{array}$ & 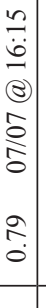 & 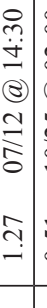 & 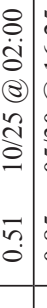 & 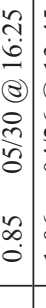 & 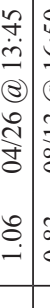 & & & 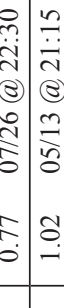 & 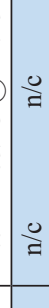 & 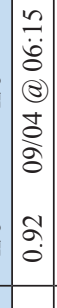 & 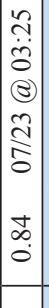 & 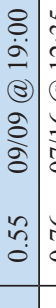 & 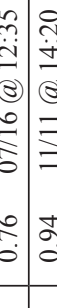 & 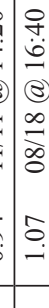 & $\begin{array}{l}\ddot{y} \\
\text { (e) } \\
\text { (e) }\end{array}$ & 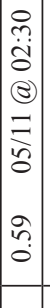 & 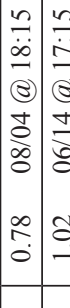 \\
\hline & & & & & 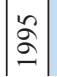 & $\approx$ & ஃু & & & & & & & & & & & & & & & $\sigma_{1}$ & & & & & \\
\hline
\end{tabular}


Table 2

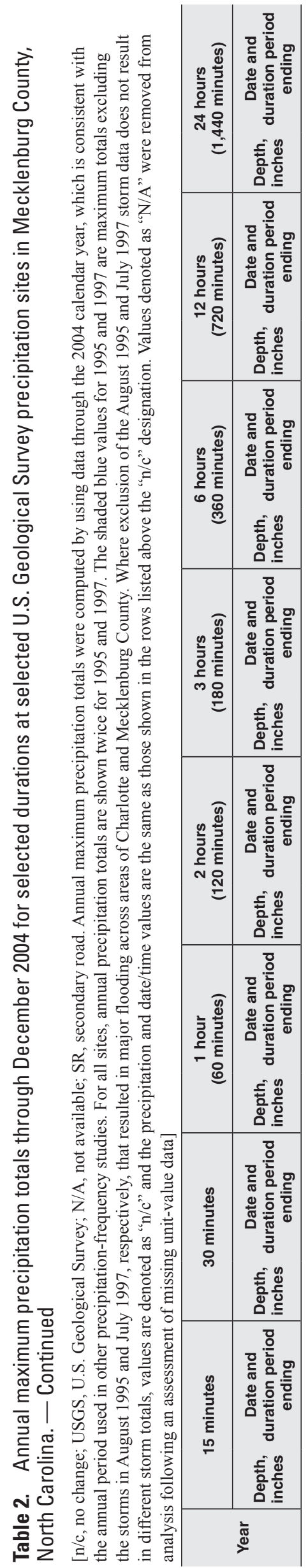

|mln

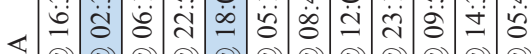

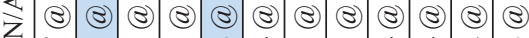

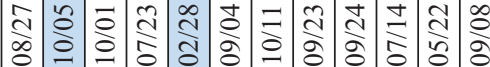

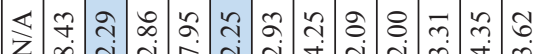

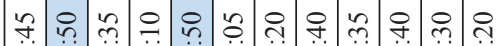

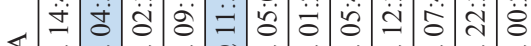
$\bar{z}$ (\&) \& (8) 5)

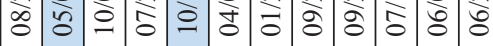

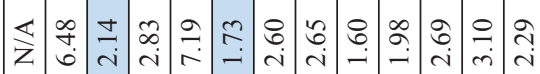

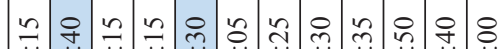
«

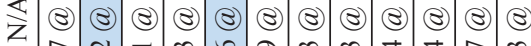
ㄷำㄴำ

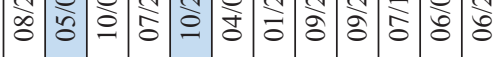

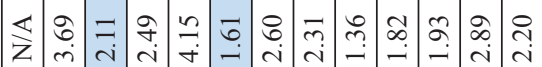

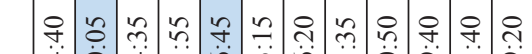

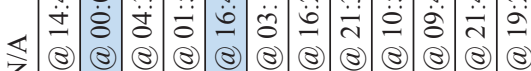

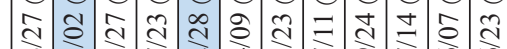

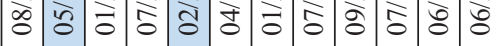

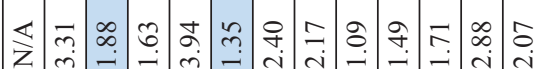

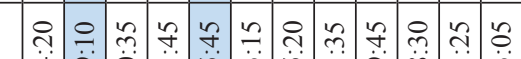

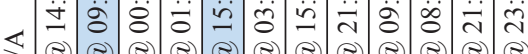

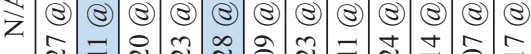
ळ

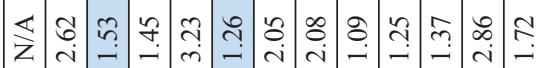

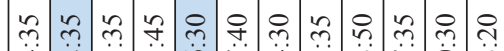

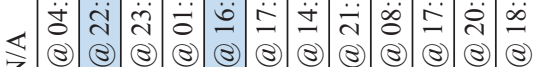
ปิ)

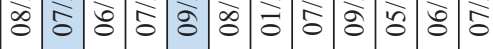

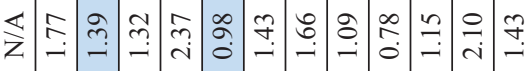

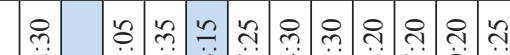
उत्र

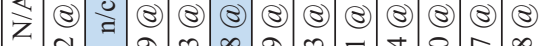

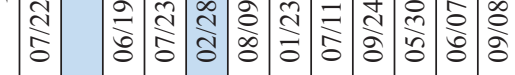

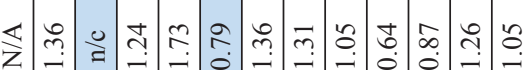
응 4 节。

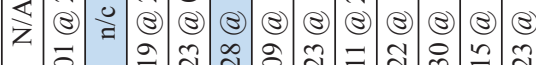

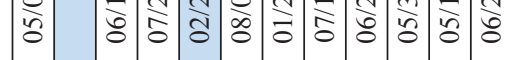

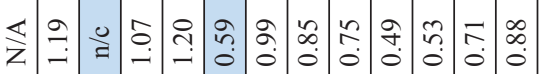

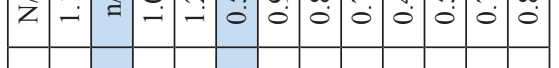

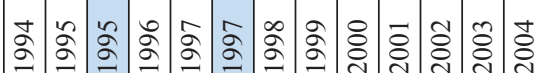

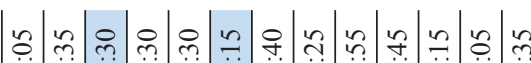
ஷ்

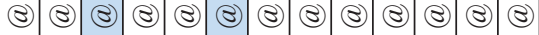

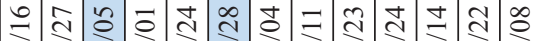
ळ.

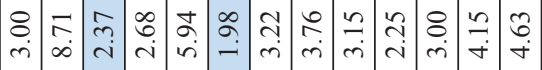

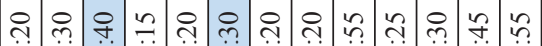

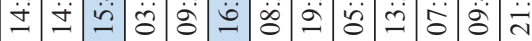

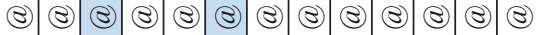
ㄷำ ळ

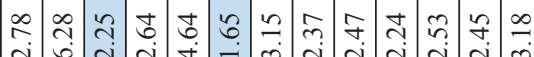

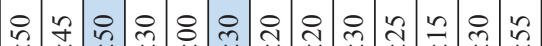

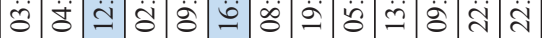

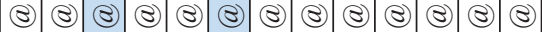

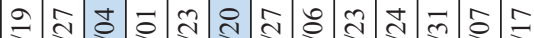
के

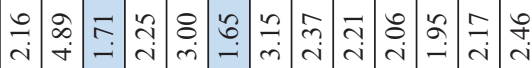

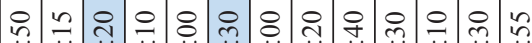

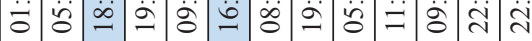

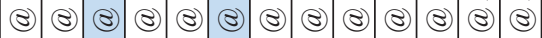
दे तิ ळ人

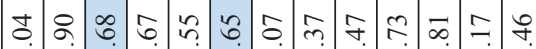

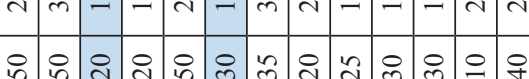

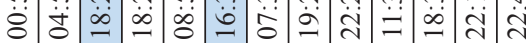

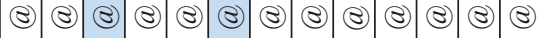

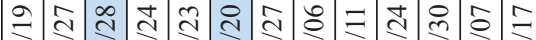
ळ ळ \&

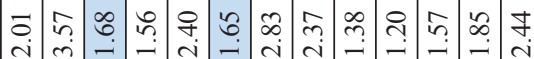

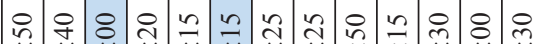

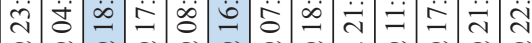

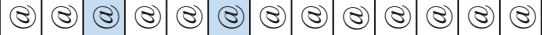

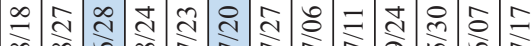

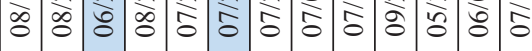

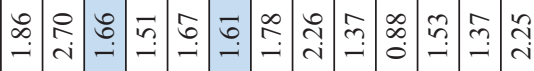

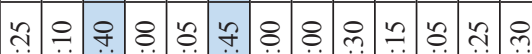

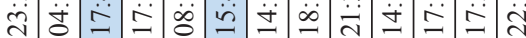

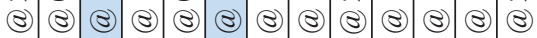

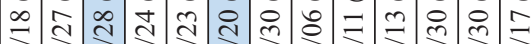
ळे

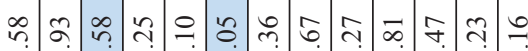

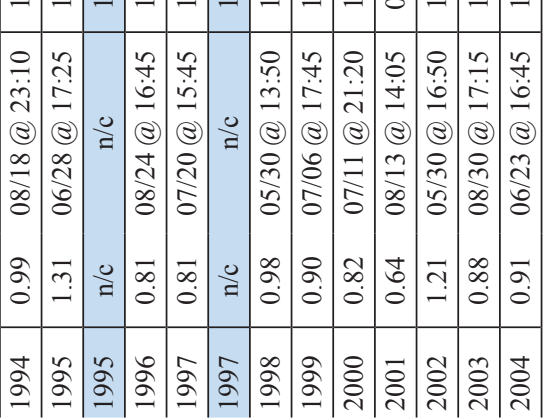



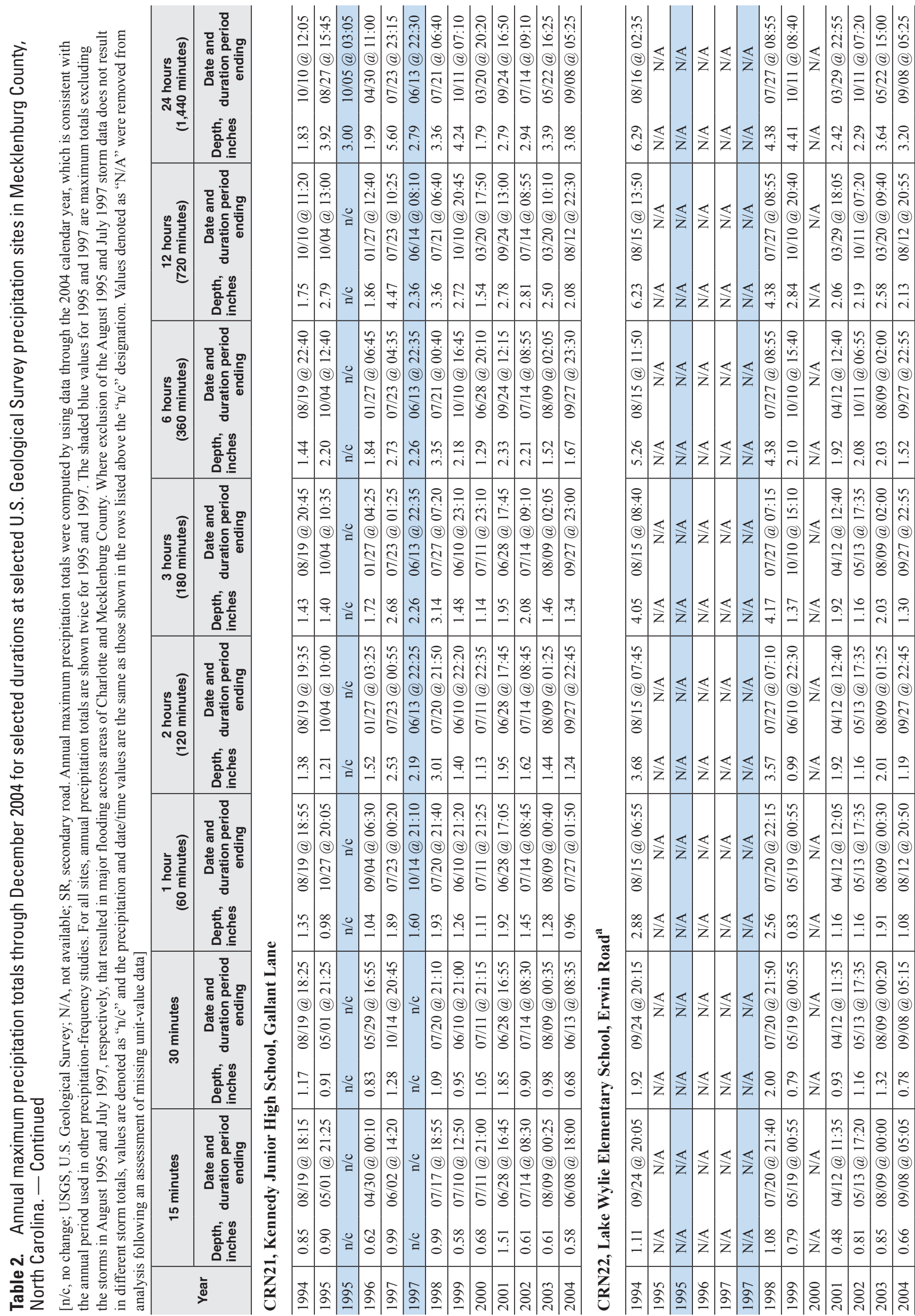

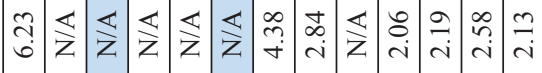
in in o o

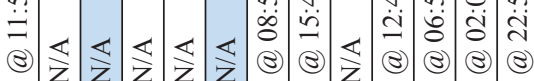

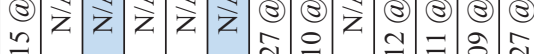

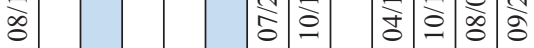

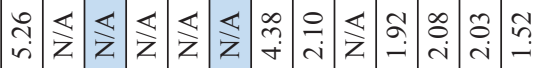

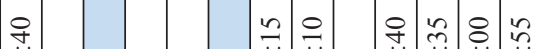

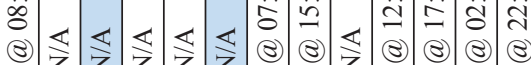

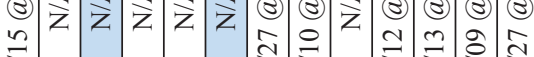
我 $\quad$ 咅

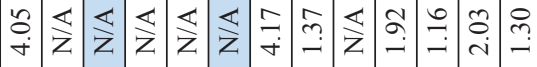
?

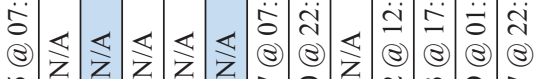

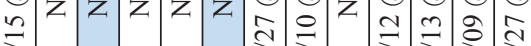
क ।

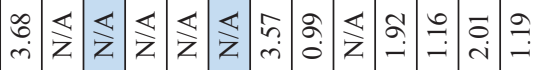
$n$ n

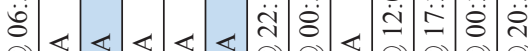

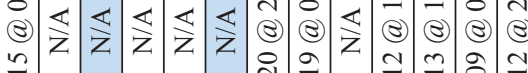

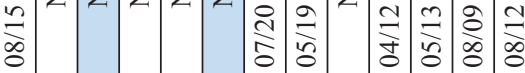

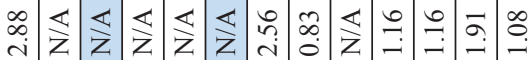
$n$ 只

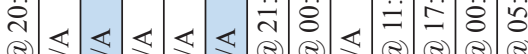

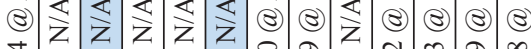

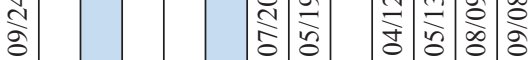

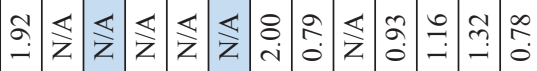

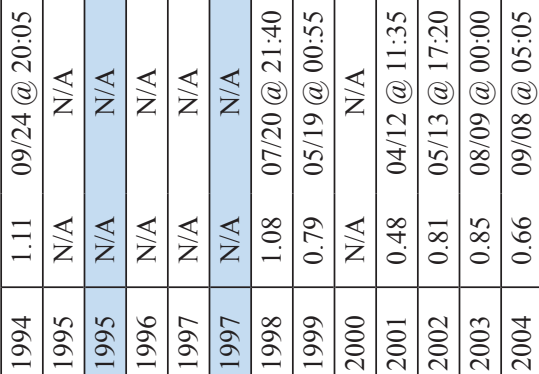


Table 2

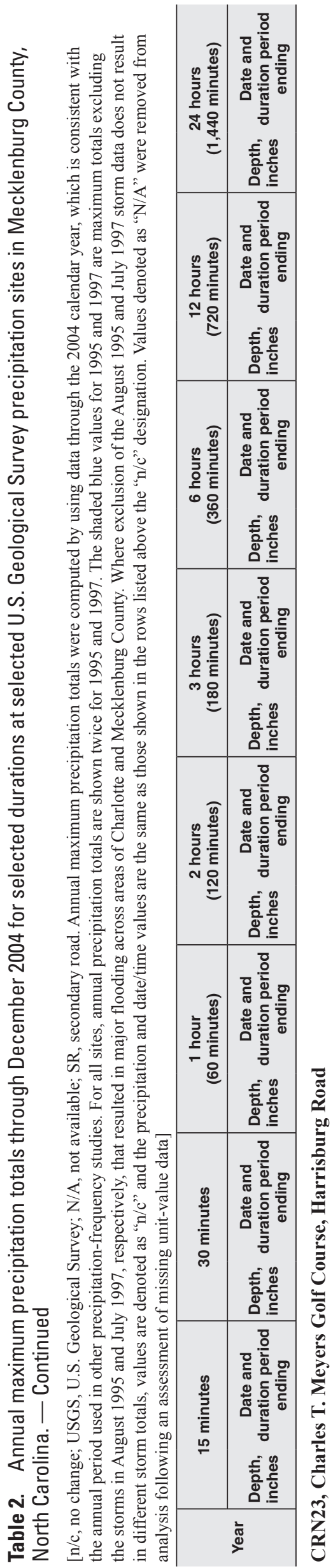

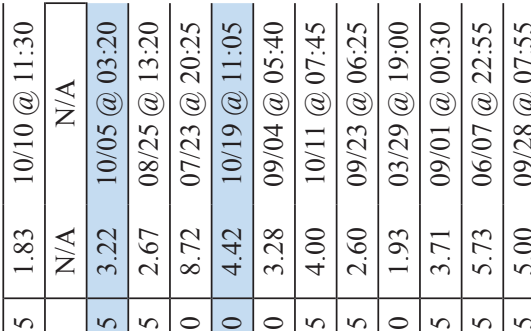

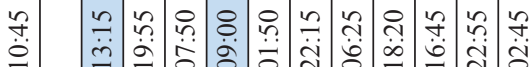

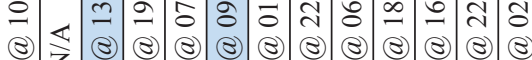
0 z $\begin{aligned} & 0 \\ & 0\end{aligned}$ 으 응ㅎㅇ 응

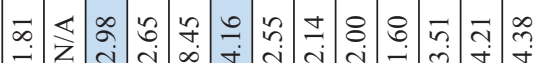

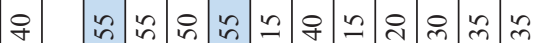

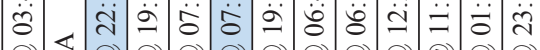

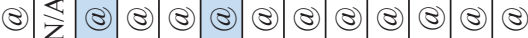

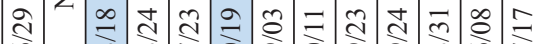
항

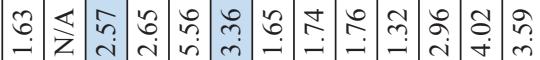

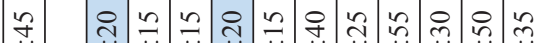

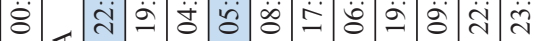

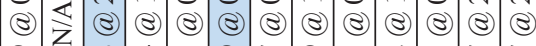

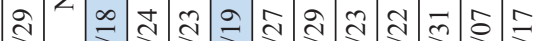
๖ क

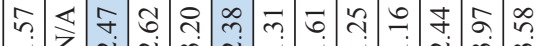

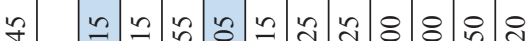

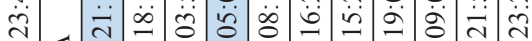

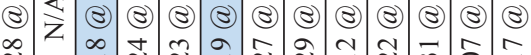

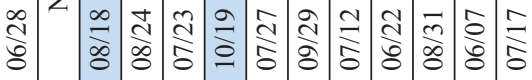

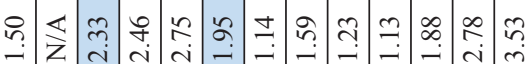
은 ปे

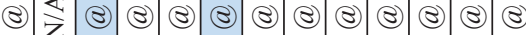

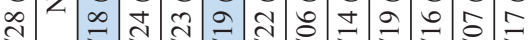
ठ के

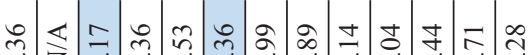

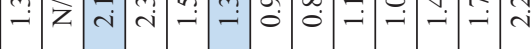
ก

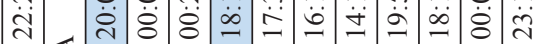

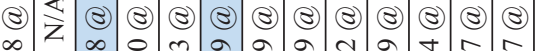

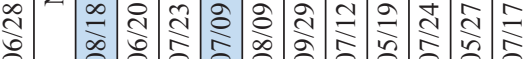

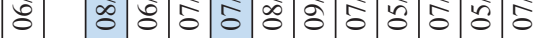

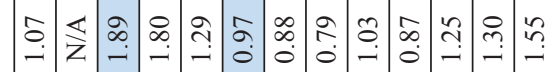

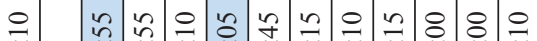

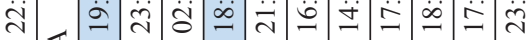

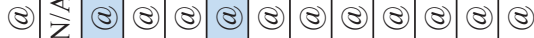

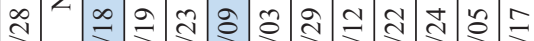
ఫ ஓ

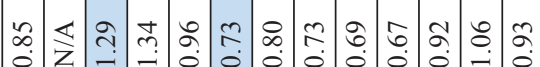

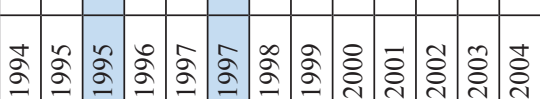

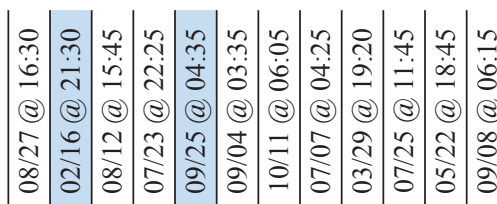
๓ ท

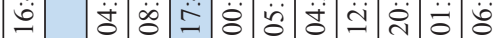

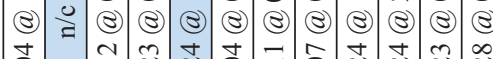

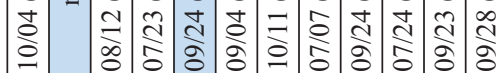
๙ิ $\because$ ๓

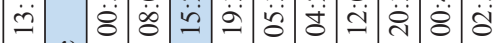

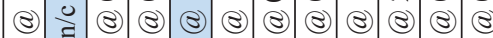

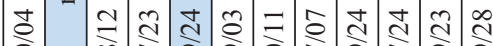
일 華

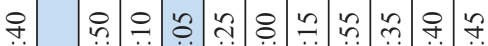

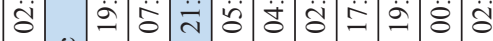
(8)

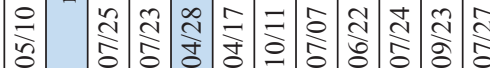
ஜ

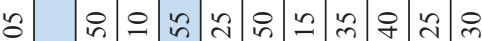

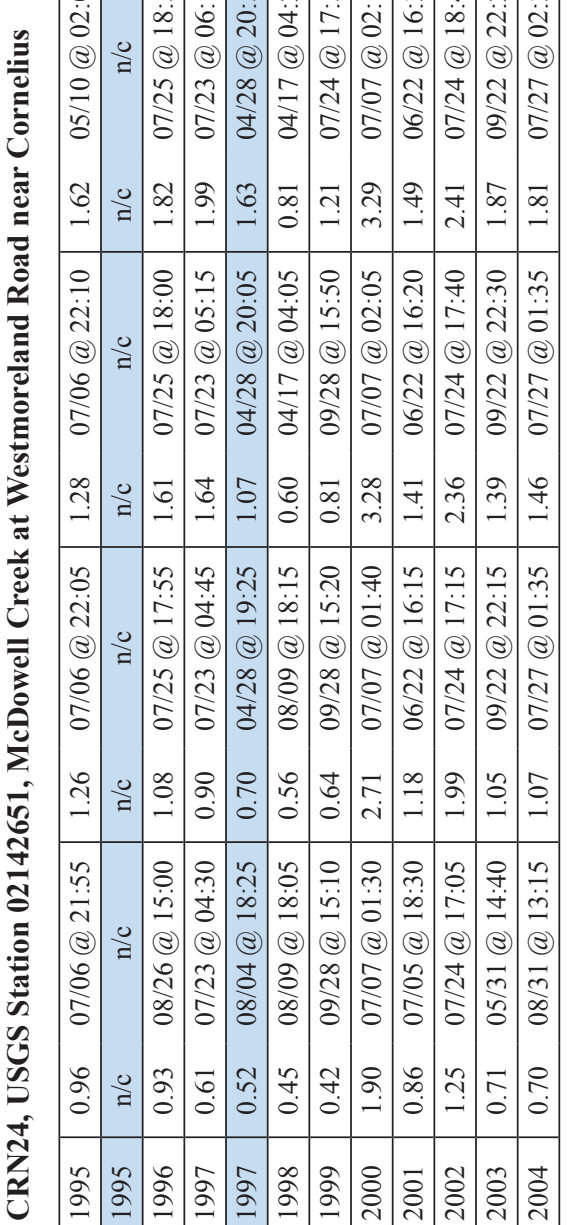




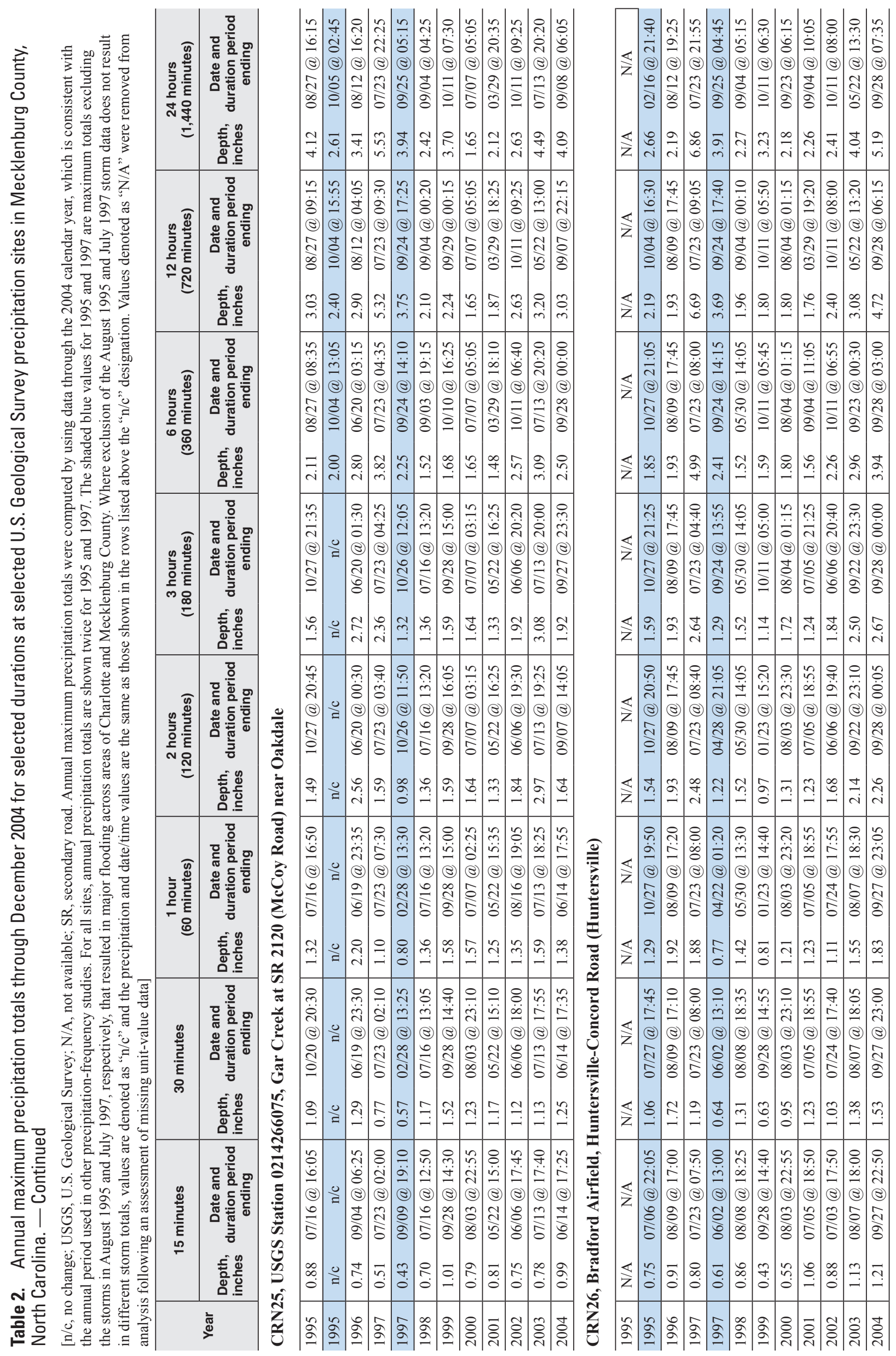




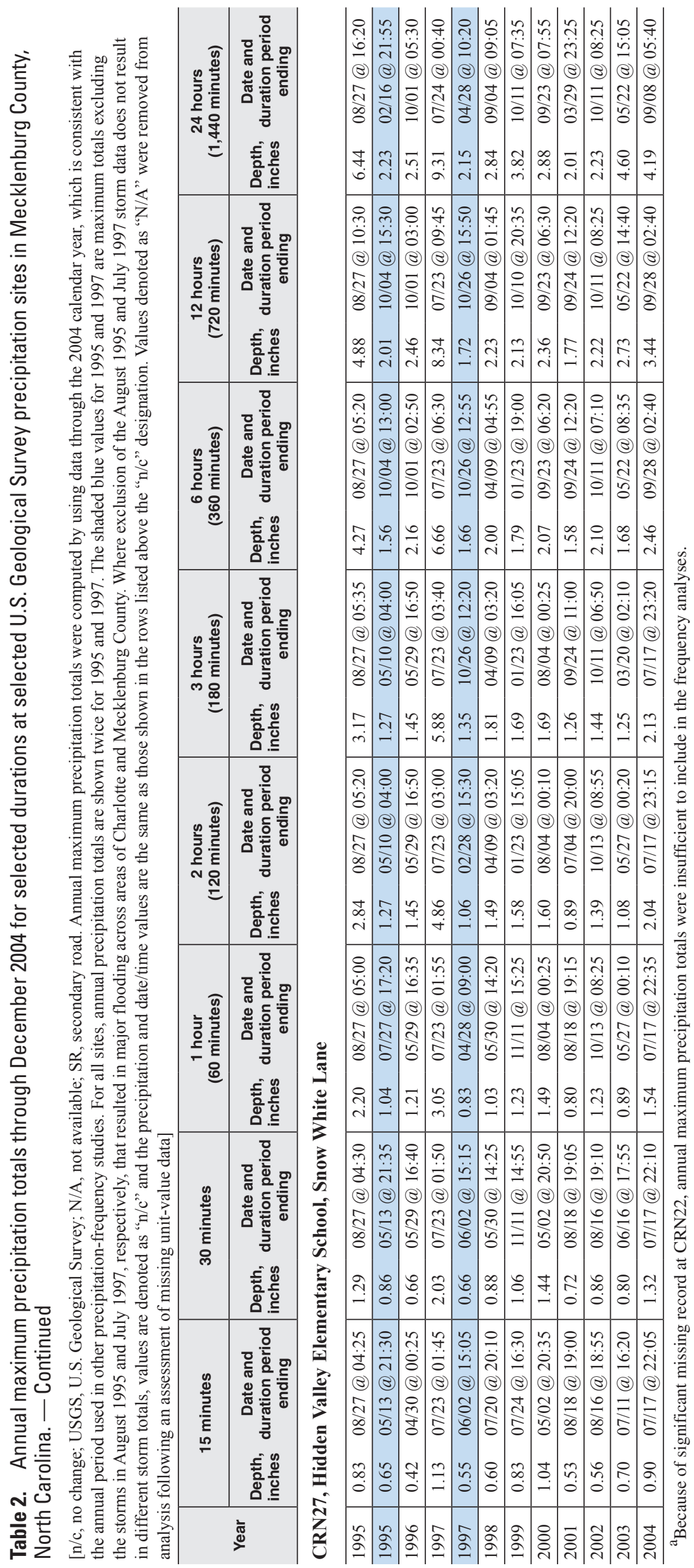





\section{Prepared by:}

U.S. Geological Survey

Enterprise Publishing Network

North Carolina Water Science Center

3916 Sunset Ridge Road

Raleigh, NC 27607

A PDF version of this publication is available online at URL

http://pubs.water.usgs.gov/sir2006-5017/ 


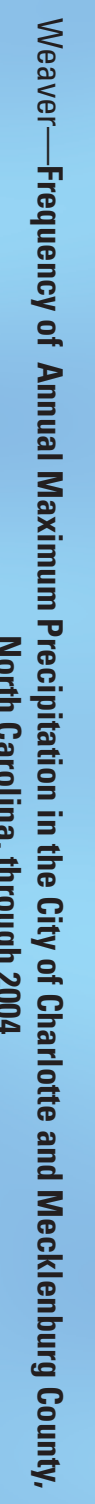

Printed on recycled paper

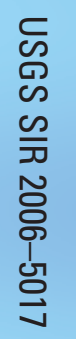

